\title{
Temporal Patterns of Gene Expression in the MNTB During Calyx of Held Development
}

\author{
Douglas Richard Kolson \\ West Virginia University
}

Follow this and additional works at: https://researchrepository.wvu.edu/etd

\section{Recommended Citation}

Kolson, Douglas Richard, "Temporal Patterns of Gene Expression in the MNTB During Calyx of Held Development" (2012). Graduate Theses, Dissertations, and Problem Reports. 4879.

https://researchrepository.wvu.edu/etd/4879

This Dissertation is protected by copyright and/or related rights. It has been brought to you by the The Research Repository @ WVU with permission from the rights-holder(s). You are free to use this Dissertation in any way that is permitted by the copyright and related rights legislation that applies to your use. For other uses you must obtain permission from the rights-holder(s) directly, unless additional rights are indicated by a Creative Commons license in the record and/ or on the work itself. This Dissertation has been accepted for inclusion in WVU Graduate Theses, Dissertations, and Problem Reports collection by an authorized administrator of The Research Repository @ WVU.

For more information, please contact researchrepository@mail.wvu.edu. 
Temporal Patterns of Gene Expression in the MNTB During Calyx of Held Development

Douglas Richard Kolson

Dissertation submitted to the

School of Medicine at West Virginia University

in partial fulfillment of the requirements for the degree of

Doctor of Philosophy

in

Neuroscience

George A. Spirou, Ph.D., Chair

Peter H. Mathers, Ph.D.

Maxim Sokolov, Ph.D.

Rae R. Matsumoto, Ph.D.

Gregory W. Konat, Ph.D.

Neuroscience Graduate Program

Morgantown, West Virginia

2012

Keywords: MNTB, calyx of Held, gene expression, development, synapse, qPCR, microarray 


\begin{abstract}
Temporal Patterns of Gene Expression in the MNTB During Calyx of Held Development
\end{abstract}

\author{
Douglas Richard Kolson
}

Brain development is inextricably linked to changes in gene expression. Providing insight into the mechanisms controlling these complex events is a current challenge in neuroscience. Neurons in the medial nucleus of the trapezoid body (MNTB) receive large specialized glutamatergic nerve terminals, the calyces of Held, which grow very quickly between postnatal day 2 (P2) and P4. Through both quantitative real-time PCR (qPCR) and microarray analysis, we examined the gene expression over time for a select group of voltage-gated potassium channels controlling ion channel function and composition to finely tune their biophysical properties. Low threshold activated potassium channels subunits Kv1.1 (Kcna1) and Kv1.2 (Kcna2) both increase between P0 and P6. However, between P6 and P14, Kcna1 continues to increase while Kcna2 stays more constant. Delayed rectifier potassium channels (Kv3 family), Kv3.1 (Kcnc1) levels increase slowly between P0 and P14 while Kv3.3 (Kcnc3) levels are stable between P0 and P6 followed by a sharp increase between P6 and P14. Hcn2, a member of the hyperpolarization-activated and cyclic nucleotide-gated channel family controlling hyperpolarization-activated current $\left(I_{H}\right)$, also showed stable expression between P0 and P6 followed by an increase between P6 and P14. These data suggest that potassium channel composition changes dynamically during early postnatal development of the MNTB.

We next characterized the genome-wide changes in the MNTB/calyx of Held developmental system utilizing microarrays and dense temporal sampling at ages surrounding growth of the calyceal inputs between P0 and P6. We identified a list of 541 significantly changing genes and clustered them into eight groups based upon their temporal expression profiles. Candidates originating from each of the profile groups were validated by qPCR and showed excellent correlation between both techniques. Many of the changing transcripts are associated with astrocytes and oligodendrocytes in addition to the neuronal contribution. Gene ontology revealed enrichment of genes involved in axon pathfinding and cell adhesion. These results provide a genetic framework for future investigation of mechanisms associated with nerve terminal growth and maturation. 


\section{Acknowledgements}

I would like to thank everyone who helped me in this long and difficult journey that was graduate school. I give my thanks to my mentor, Dr. George Spirou, for funding my research, allowing me to pursue our goals using unfamiliar and complex techniques, and for encouraging me to find my own answers for many questions. Although it did not make for the easiest experience, these skills will serve me well in my future research endeavors. I would not have been able to succeed without the help of Dr. Pete Mathers. Thank you for your patience in the many, many meetings and for sharing your expertise and knowledge in molecular biology. I would like to thank all of my other committee members, both current and past, who helped me to develop and finish my project.

I have shared the company of many people from the lab over the years, both personally and professionally, and would like to thank them all for their contributions even though I can only mention a few. Max and Marycharmain got me started with qPCR, and Chris and Viola helped me learn about and run the microarrays. Brian helped me with my early dissecting, and he also was the captain of my soccer team, which offered great exercise and stress relief. Thanks to Jesse and Lori for grilling almost everything that moves and for the fishing trips to gather more creatures when we ran out. Thanks to the people from the Eye Institute for helping me to hone my ideas. Glen and Marlin helped me keep the mouse colony organized, and Vince was a great study partner for advanced neuroscience.

I would like to thank my friends and family. My mom and dad always supported me, even when they did not understand my decisions. You both helped me to develop a wonderful curiosity to understand how everything works, which is why I am here today....and all of the food didn't hurt either. Thanks to Dusty for sharing the complicated cat with me. Becky and Hansie encouraged me to go back to school, and it definitely changed my life. Kirby generously gave me a place to stay when I was going through some transition, on several occasions. Erica has been one of the best friends I have ever known. Kelli showed me some different aspects of life that I am glad to have not missed. And last, but definitely not least, Natalie has made my last year manageable despite all of the complications. Your company and support has been indispensible, but our journey is just beginning. 


\section{Table of Contents}

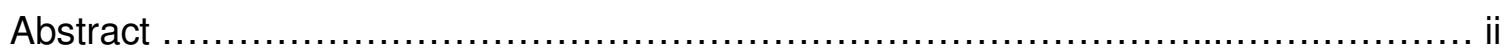

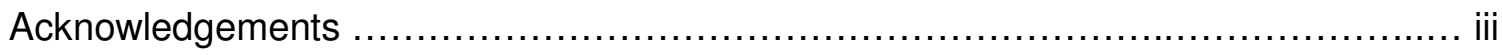

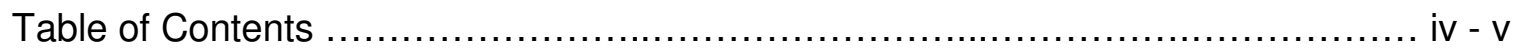

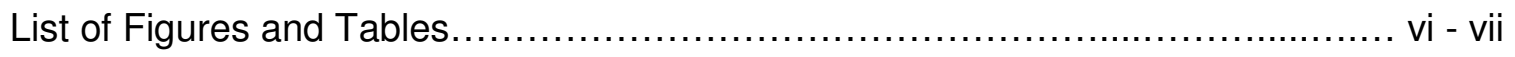

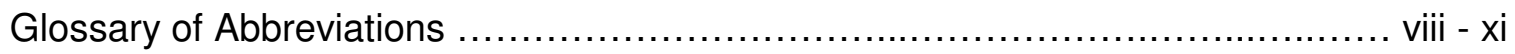

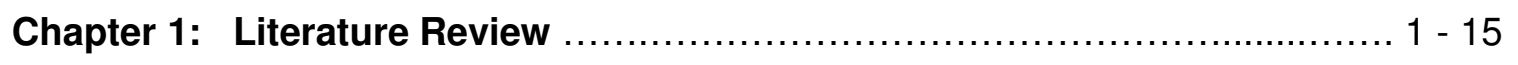

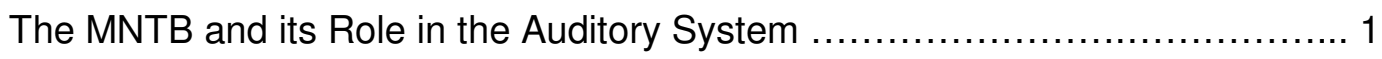

Voltage-gated Potassium Channels in the MNTB $\ldots \ldots \ldots \ldots \ldots \ldots \ldots \ldots \ldots \ldots \ldots$

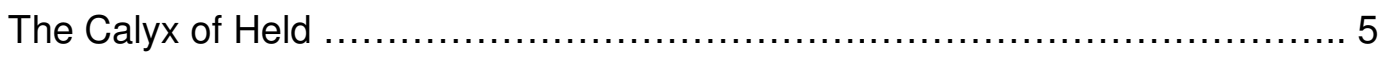

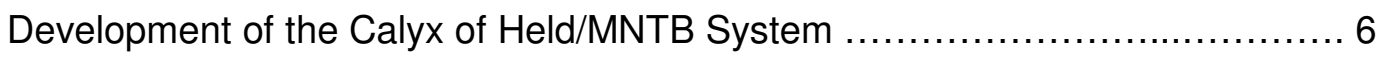

Molecular and Genetic Characterization of the MNTB/Calyx of Held System ..... 8

Microarrays as a Tool to Study Development .............................. 10

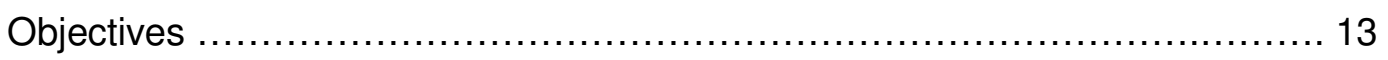

Chapter 2: Changing Expression of Ion Channel Genes in the Developing MNTB

$16-33$

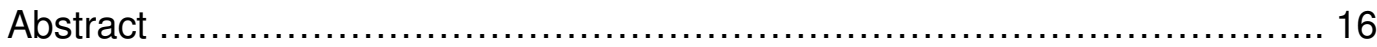




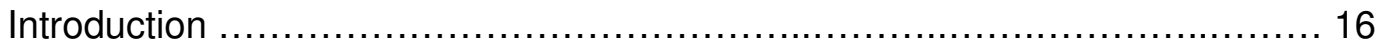

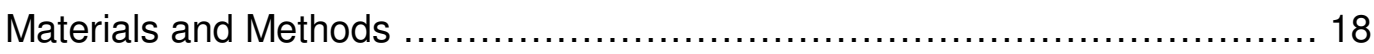

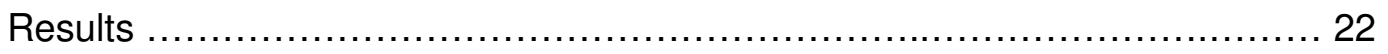

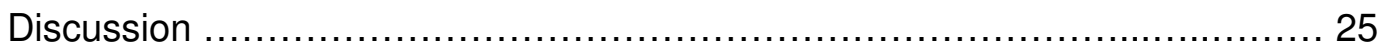

Figures and Tables …...................................................... 30 - 33

\section{Chapter 3: Temporal Patterns of Gene Expression in the MNTB During Calyx of}

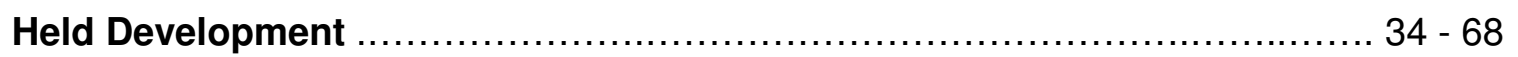

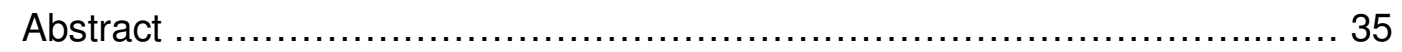

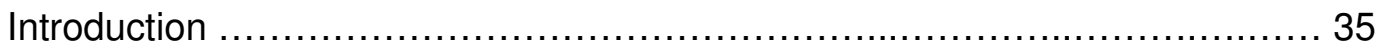

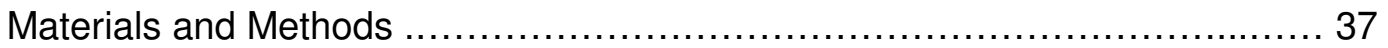

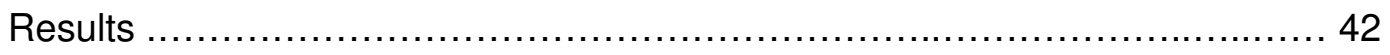

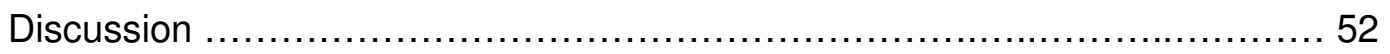

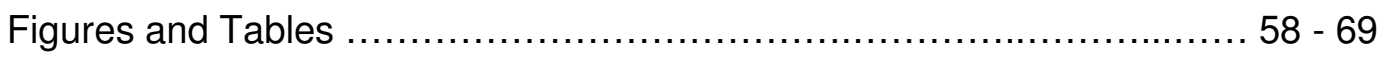

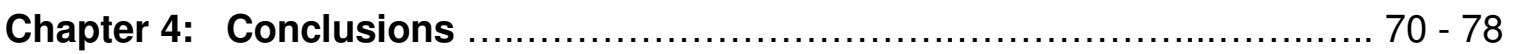

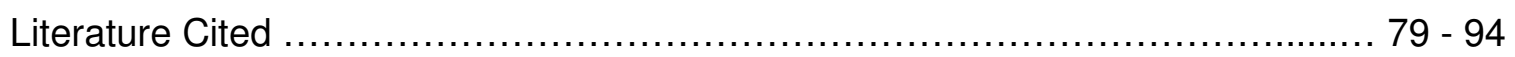

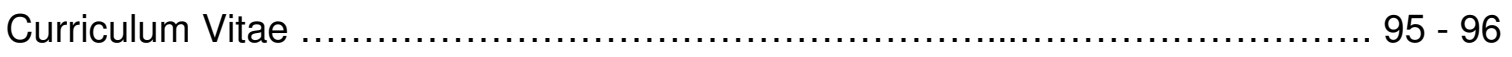




\section{List of Figures and Tables}

\section{Chapter 1: Literature Review}

Figure 1: Superior olivary complex circuitry.

Figure 2: Voltage-gated potassium channel activation and structure.

\section{Chapter 2: Gene Expression Changes for Ion Channels in the Developing MNTB}

Table 1: Primers for real-time PCR experiments

Figure 1: Experimental protocol and rationale.

Figure 2: Gene expression profiles across time for Kv1 channel subunits.

Figure 3: Gene expression profiles across time for Kv3 and Hcn channel subunits.

\section{Chapter 3: Temporal Patterns of Gene Expression in the MNTB During Calyx of Held Development}

Table 1: Primers for real-time PCR experiments.

Table 2: Group distribution and cell-specific expression of $0.1 \%$ FDR gene list.

Table 3: Gene Ontology enrichment analysis

Figure 1: Tissue harvesting and experimental design.

Figure 2: Significantly changing genes grouped into eight temporal expression clusters.

Figure 3: Microarray data were validated by qPCR and confirmed with protein expression measured by immunofluorescence.

Figure 4: Confirmation of microarray results for selected genes showing increasing MNTB expression.

Figure 5: Confirmation of microarray results for selected genes showing complex MNTB expression. 
Figure 6: Confirmation of microarray results for selected genes showing decreasing MNTB expression.

Figure 7: Neurons, astrocytes, and microglia are shown in the MNTB across the ages of P0 to P14.

Figure 8: Oligodendrocyte precursors can be found in the MNTB across the ages of P0 to P14.

Figure 9: Tenascin C (Tnc) expression patterns show changing localization between P0 and $\mathrm{P} 14$. 


\section{Glossary of Abbreviations}

2310046A06Rik

$7 \mathrm{~N}$

$8 \mathrm{~N}$

ACSF

Aldh1L1

Aldoc

AMPA

AP

ATP

ATP5b

Bmp5

Calb1

Cbln1

$\mathrm{Cd} 24 \mathrm{a}$

Cdh

cDNA

CypA

D

Dact1

DCN

Dcx

DEG

DNA

E
Riken cDNA 2310046A06

Seventh cranial nerve

Eighth cranial nerve

Artificial cerebral spinal fluid

Aldehyde dehydrogenase 1 family, member L1

Aldolase C, fructose-biphosphate

2-amino-3-(5-methyl-3-oxo-1,2- oxazol-4-yl) propanoic acid

Action potential

Adenosine triphosphate

ATP synthase, $\mathrm{H}+$ transporting mitochondrial F1 complex, beta subunit

Bone morphogenetic protein 5

Calbindin 1

Cerebellin 1 percursor protein

Cd24a antigen

Cadherin

complementary DNA

Peptidylprolyl isomerase A or cyclophilin A

Dorsal

Dapper homolog 1, antagonist of beta-catenin (Xenopus)

Dorsal cochlear nucleus

Doublecortin

Differentially expressed gene

Deoxyribonucleic acid

Embryonic day 


$\begin{array}{ll}\text { Ednrb } & \text { Endothelin receptor type B } \\ \text { Etf1 } & \text { Eukaryotic translation termination factor 1 } \\ \text { FDR } & \text { False discovery rate } \\ \text { GBC } & \text { Globular bushy cell } \\ \text { GO } & \text { Gene Ontology } \\ \text { Hcn } & \text { Hyperpolarization-activated and cyclic nucleotide-gated } \\ \text { Helz } & \text { Helicase with zinc finger domain } \\ \text { HP } & \text { Hyperpolarization } \\ \text { Hprt } & \text { Hypoxanthine guanine phosphoribosyl transferase } \\ \text { Iba1 } & \text { lonized calcium binding adaptor molecule 1 } \\ \text { IH } & \text { Hyperpolarization-activated current } \\ \text { ILD } & \text { Interaural level difference } \\ \text { ITD } & \text { Interaural time difference } \\ \text { Kv } & \text { Voltage-gated potassium } \\ \text { Kcna1 } & \text { Kv1.1 } \\ \text { Kcna2 } & \text { Kv1.2 } \\ \text { Kcna6 } & \text { Kv1.6 } \\ \text { Kcnc1 } & \text { Kv3.1 } \\ \text { Kcnc3 } & \text { Kv3.3 } \\ \text { L } & \text { Lateral } \\ \text { Lrrtm3 } & \text { Leucine-rich repeat transmembrane neuronal 3 } \\ \text { LSO } & \text { Lateral superior olive } \\ \text { MAP2 } & \text { Microtubule-associated protein 2 } \\ \text { Mitf } & \end{array}$




\begin{tabular}{|c|c|}
\hline mRNA & Messenger RNA \\
\hline MSO & Medial superior olive \\
\hline NG2 & NG2 chondroitin sulfate proteoglycan \\
\hline$P$ & Postnatal day \\
\hline PBS & Phosphate buffered saline \\
\hline PDGFRa & Platelet-derived growth factor receptor alpha \\
\hline PFA & Paraformaldehyde \\
\hline Polr2a & Polymerase (RNA) II (DNA directed) polypeptide A \\
\hline Pvalb & Parvalbumin \\
\hline qPCR & Quantitative real-time PCR \\
\hline Ramp3 & Receptor (calcitonin) activity modifying protein 3 \\
\hline RIN & RNA integrity number \\
\hline RNA & Ribonucleic acid \\
\hline $\mathrm{RP}$ & Resting potential \\
\hline SAGE & Serial analysis of gene expression \\
\hline SAM & Significance Analysis of Microarrays \\
\hline SBC & Spherical bushy cell \\
\hline Sema & Semaphorin \\
\hline Slc17a8 & $\begin{array}{l}\text { Solute carrier family } 17 \text { (sodium-dependent inorganic phosphate } \\
\text { cotransporter), member } 8 \text { or VGlut3 }\end{array}$ \\
\hline SOC & Superior olivary complex \\
\hline Sox10 & SRY-box containing gene 10 \\
\hline SPN & Superior paraolivary nucleus \\
\hline Tnc & Tenascin C \\
\hline V & Ventral \\
\hline VCN & Ventral cochlear nucleus \\
\hline
\end{tabular}


VGlut

Ywhaz
Vesicular glutamate transporter

Tyrosine 3-monooxygenase/tryptophan 5-monooxygenase activation

protein, zeta polypeptide 


\section{Chapter 1: Literature Review}

Mammalian brain development remains one of the least understood topics in neuroscience. Millions of neurons and glia are born and migrate to their precise destinations. Vast numbers of specific connections must form between the neurons, and thousands of different proteins participate in the molecular mechanisms that control these processes. The orchestration of the events is so carefully balanced that alterations in the abundance of a single gene can have dire biological consequences. Gene expression generally leads to protein expression, with several levels of regulation existing between the two. Even after the proteins have been made, there are many additional cellular mechanisms controlling their function, localization, and stability. Untangling this elaborate network of events and gaining insight into what drives these processes offers the potential for great advances in medical treatments for debilitating conditions such as traumatic brain injury, autism, and mental retardation. When attempting to answer such daunting questions, the best approaches make use of an appropriate model system to reduce the complexity of the answers. The medial nucleus of the trapezoid body (MNTB) and its presynaptic input, the calyx of Held, have been characterized thoroughly and offer many advantages for developmental studies. This review chapter begins with a focus on roles and properties of the mature system. Next, the development of the MNTB will be examined along with the potential advantages of this system when compared to existing studies of this kind.

The MNTB and its role in the auditory system

The MNTB is one of several nuclei comprising the superior olivary complex (SOC) in the auditory system of mammals (Fig. 1). The SOC is a bilateral structure comprised primarily of 
three nuclei which are the MNTB, the medial superior olive (MSO), and lateral superior olive (LSO) and several periolivary nuclei. The SOC is involved in sound localization and receives input from both ears. Sound waves cause the deflection of inner hair cell stereocilia in the cochlea, changing the mechanical force into electrical impulses (reviewed by Stover \& Diensthuber, 2011). Dendrites of spiral ganglion neurons receive input from the inner hair cells and transmit the information along their axons, which form the auditory nerve, to globular bushy cells (GBCs) and spherical bushy cells (SBCs), among other cell types, in the ventral cochlear nucleus (VCN; Figure 1). The MNTB receives glutamatergic input from large nerve terminals, known as calyces of Held, originating from the GBCs in the contralateral VCN (Fig. 1)(Tolbert et al., 1982; Spirou et al., 1990; Kuwabara et al., 1991; Smith et al., 1991). The circuitry in the auditory system is arranged in a topographic manner depending upon sound frequency, known as tonotopy. The medial MNTB is more sensitive to high frequency sounds and the lateral MNTB is more sensitive to low frequency sounds (reviewed by Kandler et al., 2009). Each MNTB sends glycinergic inhibitory projections to the ipsilateral MSO and LSO (Spangler et al., 1985; Adams \& Mugnaini, 1990; Smith et al., 2000), the superior paraolivary nucleus (Banks \& Smith, 1992; Sommer et al., 1993), and the ventral nucleus of the lateral lemniscus (Sommer et al., 1993; Smith et al., 1998). The MNTB functions as an inverting relay, changing excitation from the contralateral ear into well-timed ipsilateral inhibition to both the LSO and the MSO. There are two basic cues used by the auditory system for localizing sounds: through comparison of the sound intensities between both ears, also known as interaural level difference (ILD) which is detected in the LSO (reviewed by Tollin, 2003), or through comparison of the timing when the sound arrives at each ear, also known as interaural time difference (ITD) which is detected in the MSO (reviewed by Grothe, 2003). The MNTB, then, plays important roles in sound localization, in addition to other aspects of binaural processing. 
One of the salient features of neurons is their ability to fire action potentials (APs), and the properties of the APs originating in the MNTB neurons must be tightly regulated for them to correctly perform their roles in sound localization. Before discussing how ion channels can modify features of an AP, it is important to review general properties of APs. APs are rapid shifts in the membrane potential of excitable cells such as neurons, and these are driven by rapid changes in ionic conductance and exchange of primarily sodium and potassium ions across the cellular membrane. The concentration of sodium ions is much higher outside of a neuron and the concentration of potassium ions is maintained much higher inside. By selectively controlling the cellular membrane's permeability to sodium, potassium, calcium, and chloride, a membrane potential results from the electrochemical gradients that are produced. When considering an ideal AP, there are several salient features to mention (Fig. 2A). When a stimulus initiates the opening of voltage-gated sodium channels, which occurs when the membrane potential reaches approximately $-55 \mathrm{mV}$ (although this value can vary among neurons), there is an influx of sodium ions driven by the high electrochemical gradient for sodium. This influx causes a rapid depolarization of the membrane which in turn triggers activation of the voltage-gated potassium (Kv) channels, allowing potassium ions to rush out of the neuron. Sodium channels enter an inactivated state after their activation. The potassium current, known as delayed rectifier current, is responsible for repolarizing the neuron (Hodgkin \& Huxley, 1952), returning the cell to its resting membrane potential and slightly overshooting it (known as hyperpolarization) as the potassium channels close. Features affecting APs, such as resting membrane potential and speed of repolarization, can be finely-tuned by the complement of ion channels expressed by a neuron. 
Voltage-gated potassium channels in the MNTB

Kv channels are comprised of four $\alpha$-subunits but can include up to four additional $\beta$-subunits that modify their function (Xu et al., 1998)(Fig. 2B). Most of the Kv channels in mammalian brains contain Kv1 - Kv4 family members, and functional channels can be comprised of four identical or similar subunits. The subunit composition changes the functional, pharmacological, and biophysical properties of the channel (Gutman et al., 2005). Identifying the exact subunit composition of these channels in their native environment is very difficult due to subtle differences between the subtypes and the presence of activity-modifying proteins. Most of the known information comes from study of recombinant homomeric channels in cell lines or by using toxins that bind to certain subunits and prevent their function, such as block of Kv1 channels by dendrotoxins (reviewed by Harvey \& Robertson, 2004). The Kv1 and Kv4 family are low-threshold activated channels, meaning that their open probability increases with a small depolarization from the resting membrane potential. Kv1 channels can influence resting membrane potential and the numbers of action potentials fired by a neuron (Brew et al., 2003; Brew et al., 2007; Oertel et al., 2008). Kv4 channels generate a transient potassium current that requires prior hyperpolarization before it can be activated (reviewed by Maffie \& Rudy, 2008). Kv2 and Kv3 channels have high activation thresholds, requiring significant depolarization of the cell membrane that is typically induced during an action potential. Kv3 channels have rapid kinetics and contribute to fast neuronal firing rates (Brew \& Forsythe, 1995; Wang et al., 1998). Kv2 channels also have a high-threshold of activation, and although their kinetics are much slower, they also appear to contribute to high frequency firing (Johnston et al., 2008b). These channel types comprise the delayed rectifier class of potassium channels.

There have been multiple studies examining the localization of particular channel subunits to the MNTB and their contributions to AP characteristics. The Kv1 family members that have been 
identified in the MNTB are Kv1.1, Kv1.2, and Kv1.6 (Dodson et al., 2002). In the Kv2 family, high levels of Kv2.2 mRNA have been found in the MNTB (Johnston et al., 2008b). Kv3 family channels have long been associated with rapidly firing neurons, and the subunits Kv3.1 and Kv3.3 have been localized to the MNTB (Brew \& Forsythe, 1995; Wang et al., 1998; Li et al., 2001). From the Kv4 family, only Kv4.3 subunits are found in the MNTB (Johnston et al., 2008a).

Another related family of channels are the hyperpolarization-activated cyclic nucleotide-gated (Hcn) channels, and these channels control the hyperpolarization-activated current $\left(I_{H}\right)$. This current plays a role in many different cellular functions including pacemaker activity and resting membrane potentials (reviewed by Robinson \& Siegelbaum, 2003). There are four different genes in mammals, Hcn1-4, that encode the subunits comprising the homo- or heterotetrameric channels (Ludwig et al., 1998; Seifert et al., 1999). In auditory neurons, $I_{H}$ is known to be involved in crucial processes such as coincidence detection in MSO neurons (Khurana et al., 2012) and control of neuronal excitability in MNTB neurons (Hassfurth et al., 2009). Two different members of the Hcn channel family, Hcn2 and Hcn4, have been localized within the MNTB. (Koch et al., 2004; Leao et al., 2006).

The calyx of Held

The calyx of Held is one of the largest nerve terminals in the mammalian nervous system with each calyx covering large portions of the postsynaptic cell and containing hundreds of synaptic contacts and active zones along with very large readily releasable pools of synaptic vesicles (Rowland et al., 2000; Satzler et al., 2002; Taschenberger et al., 2002). Due to the size of this nerve terminal, studies have been possible investigating synaptic transmission by performing electrophysiological recording from both the presynaptic and postsynaptic sites simultaneously 
(Borst et al., 1995; Schneggenburger \& Forsythe, 2006). Importantly, this system has been used to quantify localized presynaptic intracellular calcium over a large range of concentrations and how particular calcium levels influence the dynamics of synaptic vesicle release (reviewed by Kochubey et al., 2011).

Development of the calyx of Held/MNTB system

Observational studies characterizing many aspects of the developing calyx of Held have been performed in detail, giving a well-established timeline of events. Axons originating from the contralateral VCN reach the region of the MNTB by embryonic day (E) 13.5 (Howell et al., 2007), and functional synapses form by E17 (Hoffpauir et al., 2010). Morest (1968) used Golgistained tissue from an opossum to describe development of the calyx of Held as consisting of four stages of growth (Morest, 1968). During the first stage, growth cones from globular bushy cells enter the MNTB. The second stage consists of small flattened terminals, known as protocalyces, forming from growth cones. Stage three involves the protocalyces developing into larger cup-shaped terminals known as young calyces. Finally, in stage four, the calyces fenestrate and take on the classical claw-like appearance for which they are named. A series of experiments using the tracers $\mathrm{Dil}$ and biocytin characterized efferent projections from the cochlear nucleus (Kandler \& Friauf, 1993). The observations recorded by Kandler and Friauf (1993) confirmed the timing and stages of development for the calyx of Held originally put forth by Morest (1968). More recent work shows that stage one begins embryonically and continues through postntatal day $(P)$, stage two takes place at P2-P3, and stage three begins by $\mathrm{P} 4$ in mice (Hoffpauir et al., 2006). Calyx of Held maturation is considered to be mostly complete by P14 (Taschenberger et al., 2002). 
One of the prominent features of the calyx of Held/MNTB synapse has been the innervations ratio of one calyx of Held per MNTB neuron in the mature system (Zook \& DiCaprio, 1988; Banks \& Smith, 1992; Kandler \& Friauf, 1993; Berrebi \& Spirou, 1998; Hoffpauir et al., 2006; Rodriguez-Contreras et al., 2008). There is indication, though, that multiple inputs can innervate MNTB cells at early postnatal ages (Bergsman et al., 2004; Hoffpauir et al., 2006; RodriguezContreras et al., 2008; Hoffpauir et al., 2010), although the prevalence of this process has not been established. Since there is only one large calyx per cell in the mature system then there must be a compressed period of competition for some cells that leads to the growth of one of the inputs, which occurs prior to the onset of hearing after P8 (Mikaelian et al., 1965). This kind of transition from multiple to single innervations is prevalent in the Purkinje cell/climbing fiber system (reviewed by Miyazaki \& Watanabe, 2011 and Watanabe \& Kano, 2011) and at the neuromuscular junction (reviewed by Buffelli et al., 2004). Because the MNTB offers a more homogenous system than the cerebellum and would complete competition much more quickly than the several week process in the neuromuscular junction, the MNTB may offer an advantageous model to study this developmental process.

There is a series of developmental events that take place in the MNTB. The MNTB first becomes discernible at E17 (Hoffpauir et al., 2010) and the cells grow larger within the first few postnatal days (Taschenberger et al., 2002; Hoffpauir et al., 2010). The biophysical properties of the MNTB cells change dramatically as well. There is a large increase in the size of the synaptically-evoked postsynaptic currents (Hoffpauir et al., 2006) along with a transition from a tonic to phasic firing pattern due to the presence of potassium channels containing Kv1.1 and Kv1.2 subunits (Brew \& Forsythe, 1995; Dodson et al., 2002; Hoffpauir et al., 2010), a decrease in the input resistance due in part to Hcn channels involved in the regulation of neuronal excitability (Hassfurth et al., 2009), and a narrowing of the action potentials conferred by the rapid kinetics of Kv3 channels (Brew \& Forsythe, 1995; Wang et al., 1998; Hoffpauir et al., 2010; 
Rusu \& Borst, 2011). The MNTB also seems to promote growth of the calyx through an unknown mechanism. GBCs in the VCN form calyces when forming synapses onto MNTB neurons, but they also form normal bouton-like synapses on other types of neurons, such as in the ventral nucleus of the lateral lemniscus (Spirou et al., 1990; Smith et al., 1991). In hippocampal slices, it was also found that synaptic properties can vary based upon the postsynaptic target (Maccaferri et al., 1998). This suggests that some form of interaction or signaling can take place between a synaptic input and postsynaptic neuron, and this idea has also been set forth regarding calyx formation (Rubel \& Fritzsch, 2002). Together, the precise timing, accelerated rates, and specificity of these processes make the MNTB/calyx of Held an excellent system for correlating gene expression with known developmental events.

Molecular and genetic characterization of the MNTB/calyx of Held system

Only a limited number of studies have utilized the MNTB as a model system, and they are just beginning to elucidate some of the mechanisms and properties attributed to this interesting system. A noteworthy feature of the system is the exclusive connectivity between the VCN and the contralateral MNTB, even though the same axons first pass through the ipsilateral MNTB. In mutant mice lacking Robo3 in cells from rhombomeres 3 and 5, the connectivity is completely disturbed with all of the calyces of Held forming between the VCN and the ipsilateral MNTB neurons (Renier et al., 2010). This may be due to the removal of Robo3's established role in preventing Slit/Robo repulsion at the midline (Sabatier et al., 2004), which could result in premature repulsion of the VCN axons away from the midline. In other studies, removal of the cochlear input from one ear in neonatal mice was shown to lead to both ipsilateral and contralateral MNTB connections forming from the intact VCN (Hsieh et al., 2007). It was discovered that mutant mice lacking EphB2 and EphB3 exhibit more connections between the VCN and the ipsilateral MNTB than wild-type mice in addition to the normal connectivity with the 
contralateral MNTB (Hsieh et al., 2010). This led to the identification of one mechanism contributing to this contralateral specificity, which is signaling within MNTB neurons initiated through ephrin-B2 ligands interacting with EphB2 and EphB3 receptors on VCN axons (Hsieh et al., 2010). In unilaterally deafferented mice, induced ipsilateral MNTB projections from the VCN were repelled through ephrin-B reverse signaling (Nakamura et al., 2012). Factors contributing to the formation of the calyx of Held have also been sought previously. Mice that lack the cell adhesion protein NB-2/contactin 5 have MNTB neurons lacking calyces $8 \%$ of the time and exhibiting increased apoptosis (Toyoshima et al., 2009). However, since $90 \%$ of the MNTB neurons retain normal calyces of Held, there are likely multiple other factors involved in these processes.

Virus-mediated delivery of mutant proteins has been utilized in the calyx of Held as a method of targeted genetic manipulation. Through in vivo over-expression of a dominant negative mutant using this technique, the function of a protein complex known as the exocyst was determined to be membrane addition during presynaptic maturation affecting the volume and complexity of the calyces of Held (Schwenger \& Kuner, 2010). This helped to clarify the role of the exocyst, as it had been associated with vesicle trafficking in several other organisms (He \& Guo, 2009). In mammals, however, the exocyst does not appear to affect local recycling of synaptic vesicles (Schwenger \& Kuner, 2010). MNTB neurons have also been studied in vitro using organotypic slice cultures and were shown to maintain similar membrane properties to acute slices (Lohrke et al., 1998), but the calyces of Held do not survive in these preparations (Tong et al., 2010). Using this preparation with high and low potassium culture medium, the effects of membrane depolarization in the absence of evoked action potentials could be assessed by measuring the expression of several voltage-gated potassium channels. It was found that increased membrane depolarization in the high potassium condition resulted in higher levels of intracellular calcium which led to increased mRNA levels for Kv1.1 and Kv3.3 channel subunits (Tong et al., 2010). 
These results suggest the presence of homeostatic mechanisms for tuning neuronal excitability, allowing the postsynaptic neuron to mature in coordination with the growing calyx of Held.

A set of previous studies attempted to identify molecular factors crucial to the function of the SOC through the study of its transcriptome using serial analysis of gene expression (SAGE) (Koehl et al., 2004; Nothwang et al., 2006). In the first study, SAGE analysis of the SOC from 60-day-old rats yielded more than ten thousand different transcripts encoding proteins with functions including energy supply and myelination (Koehl et al., 2004). In a follow-up study, genes enriched in the transcriptome of the SOC were identified by comparison to transcriptomes from hippocampus and striatum. This analysis yielded thirty-three genes with higher expression in the SOC representing functional classes such as action potential propagation, myelination, exocytosis, and energy metabolism (Nothwang et al., 2006). Although these studies begin to probe aspects of the MNTB and calyx of Held, numerous questions remain, especially regarding how the calyx forms and matures. When faced with so many questions about complex developmental processes, using a global approach examining the entire transcriptome can offer a good starting point, regardless of the specific aspects being examined. Microarrays have been used extensively for just this purpose.

\section{Microarrays as a Tool to Study Development}

Many previous studies examining developmental processes have used the cerebellum as a model, partially because of its relatively simple and repetitive organization (Goldowitz \& Hamre, 1998). The development of this brain region has been characterized extensively (Altman, 1972; Kagami \& Furuichi, 2001; Watanabe \& Kano, 2011) and will be summarized briefly here. Just after birth, granule cell progenitors in the external granular layer begin to proliferate profusely, eventually accounting for nearly half of the neurons in the mammalian brain. Also at around P0, 
Purkinje cells start to form a single layer, known as the Purkinje cell layer, beneath the external granular layer. Starting at about P0 in the 'creeper' stage of climbing fiber innervation, the climbing fibers originating in the inferior olive synapse onto temporary dendrites and soma of Purkinje cells. By P3, the granule cells are differentiating and extending their axons bilaterally, which become known as parallel fibers. At about P5, the 'pericellular nest' phase entails the climbing fibers surrounding and forming many synapses with the somata of Purkinje cells. Around P7, granule cells start to migrate along Bergmann glial fibers to a location beneath the Purkinje cell layer and form the inner granular layer. Between P7 and P21, the molecular layer forms as dendritic trees of the Purkinje cells grow and arborize extensively while synapses form between the parallel fibers and Purkinje cell dendritic spines. Beginning at about P9 in the 'capuchon phase', a single climbing fiber on each Purkinje cell translocates to the apical portion of the soma and finally into the dendritic tree, forming synapses during the 'dendritic phase' around P12. This is followed by the non-specific elimination of all of the somatic synapses between climbing fibers and Purkinje cells. Around P10, mossy fibers originating from many sources, such as the cerebral cortex, innervate the granule cell dendrites and form glomeruli. By $\mathrm{P} 21$, the architecture of the cerebellum is established and almost identical to that of the adult animal.

One of the earliest microarray studies correlating development of the cerebellum to changes in gene expression examined five different developmental ages between E18 and P56 (Kagami \& Furuichi, 2001). This study showed that over $80 \%$ of the more than twelve thousand genes represented on the microarray were expressed in the developing cerebellum with 897 genes being differentially expressed, and functional clusters of genes were related to the developmental stages of their peak expression. Another microarray study used cDNA arrays to analyze expression patterns for 3459 genes at seven different time points ranging from P2 to P42 (Lim et al., 2004), and these results were clustered into four groups that correlated with 
expected gene functions based upon the known developmental events. In an attempt to narrow the scope of the results in these high-throughput studies, a different study limited their search to 172 genes involved in synapse formation and function on a custom DNA microarray (Takahashi et al., 2005), and from this approach it was determined that synapse-related genes peaked at P7 with the largest transcriptional turning point being P10, marking the end of the initial phases of cerebellar growth. Along the same lines, another study focusing entirely on transcription factors during development of the cerebellum discovered more than 200 genes present in the developing cerebellum, with 24 showing cell- or stage-specific patterns of expression (Schuller et al., 2006). Overall, the results from gene expression studies examining the developing cerebellum have proven so complex that a database, called the Cerebellar Development Transcriptome Database, has been established to organize and share some of this information (Sato et al., 2008; Furuichi et al., 2011).

The transcriptomes of many other systems during periods of development or change have been characterized through the use of microarray studies. The hippocampus is a popular model, and its development has been studied between E16 and P30 (Mody et al., 2001). Attempts to isolate genes involved in memory formation within the hippocampus using microarrays are quite numerous (Cavallaro et al., 2001; Luo et al., 2001; Leil et al., 2002; Leil et al., 2003; O'Sullivan et al., 2007; reviewed by Benoit et al., 2011). The concept of using sensory systems to probe the genome surrounding periods of development or sensory stimulation has been attempted many times. The transcriptome of the cochlear nucleus has been examined before and after hearing onset with the intent of characterizing global differences (Harris et al., 2005). The ability for the neurons to survive deafferentation increases after hearing onset, and this study detected a corresponding increase in pro-survival genes and a decrease in pro-apoptotic genes (Harris et al., 2005). The barrel cortex has been used to discover gene expression changes involved in experience-dependant plasticity (Valles et al., 2011). The retina has been used to study 
changes associated with eye development and the onset of vision (Dorrell et al., 2004). Transcripts involved in the formation of the olfactory bulb have been characterized (Cho et al., 2009). However, one common theme in these studies is an extremely complex network of changes that is challenging to unravel.

\section{Objectives}

Based upon this information, we designed several experiments to extend previous work and increase our understanding of developmental processes in the brain. Since the MNTB/calyx of Held system offers the many advantages mentioned previously, it is predicted that some of the complications encountered in earlier developmental studies can be minimized, clarifying the results of the experiments. The changing biophysical properties of the developing neurons within the MNTB can be linked to changes in the ion channels. In the first study, we created temporal expression profiles for genes controlling Kv and Hon channels in the MNTB. This was accomplished utilizing unamplified qPCR, amplified qPCR, and microarray analysis. In the second study, we expanded the scope of the experiments by using microarrays to characterize the transcriptome of the developing MNTB/calyx of Held system between P0 and P6. Through the analysis of temporal profiles of gene expression and correlation to discreet developmental events, we hope to identify potential pathways, gene categories and mechanisms controlling synaptic growth and maturation. Extensive qPCR of separate unamplified samples is used to confirm the microarray results and ensure accuracy of the findings. We expect that this information will also extrapolate to more generalized synapse growth and maturation in all brain regions. 


\section{Figure 1}

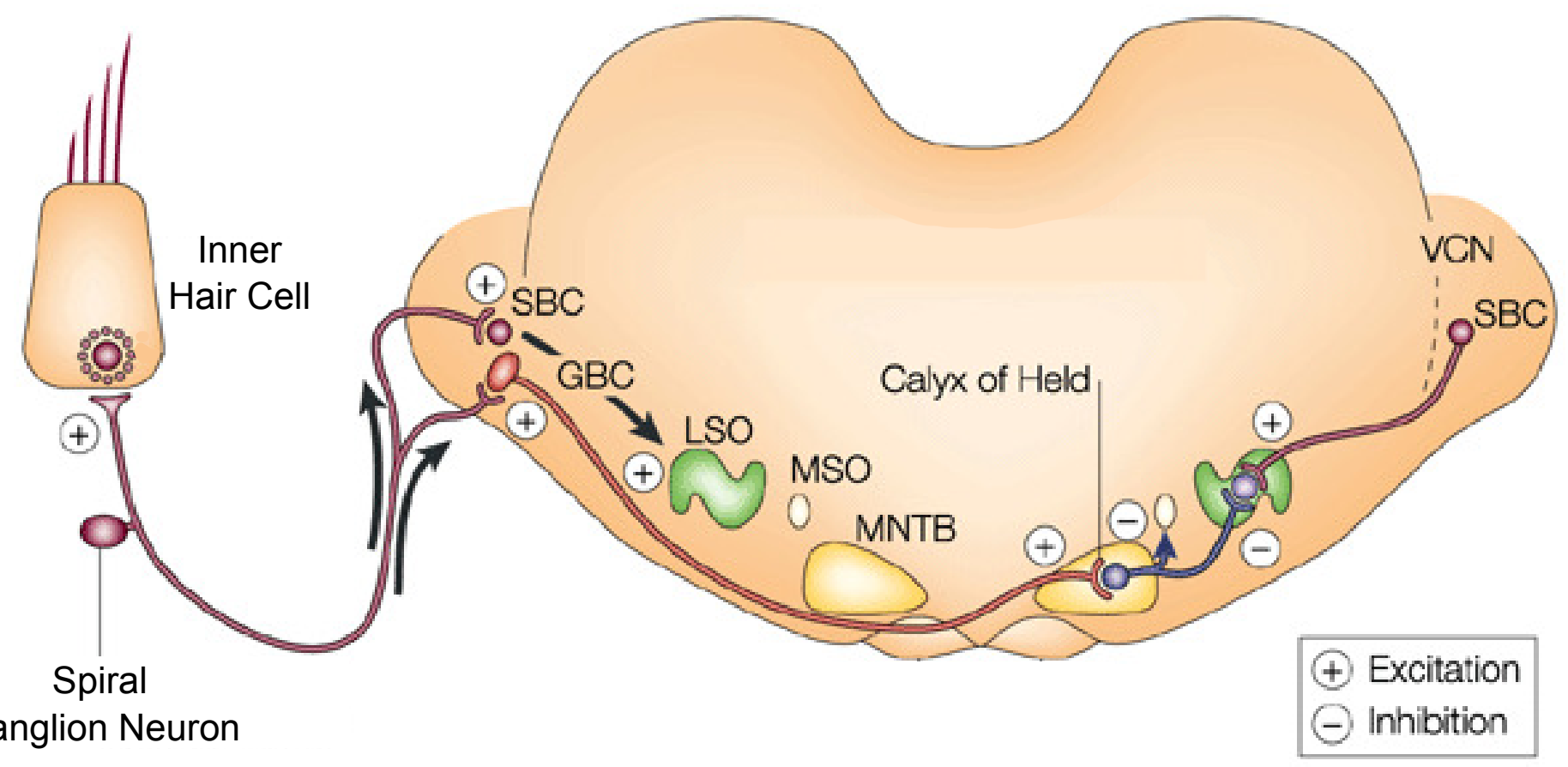

Figure 1: Superior olivary complex circuitry. Sound information is transmitted from inner hair cells to the dendrites of spiral ganglion neurons, down the auditory nerve, and onto globular bushy cells (GBCs) and spherical bushy cells (SBCs) in cochlear nucleus. A GBC in the ventral cochlear nucleus (VCN) sends an excitatory projection (red line, + ) to the contralateral medial nucleus of the trapezoid body (MNTB) forming a nerve terminal known as the calyx of Held. The MNTB sends inhibitory output (blue lines, -) to both the ipsilateral medial superior olive (MSO) and lateral superior olive (LSO). These three nuclei and several periolivary nuclei form the superior olivary complex, which is involved in sound localization. Adapted from (von Gersdorff \& Borst, 2002). 


\section{Figure 2}
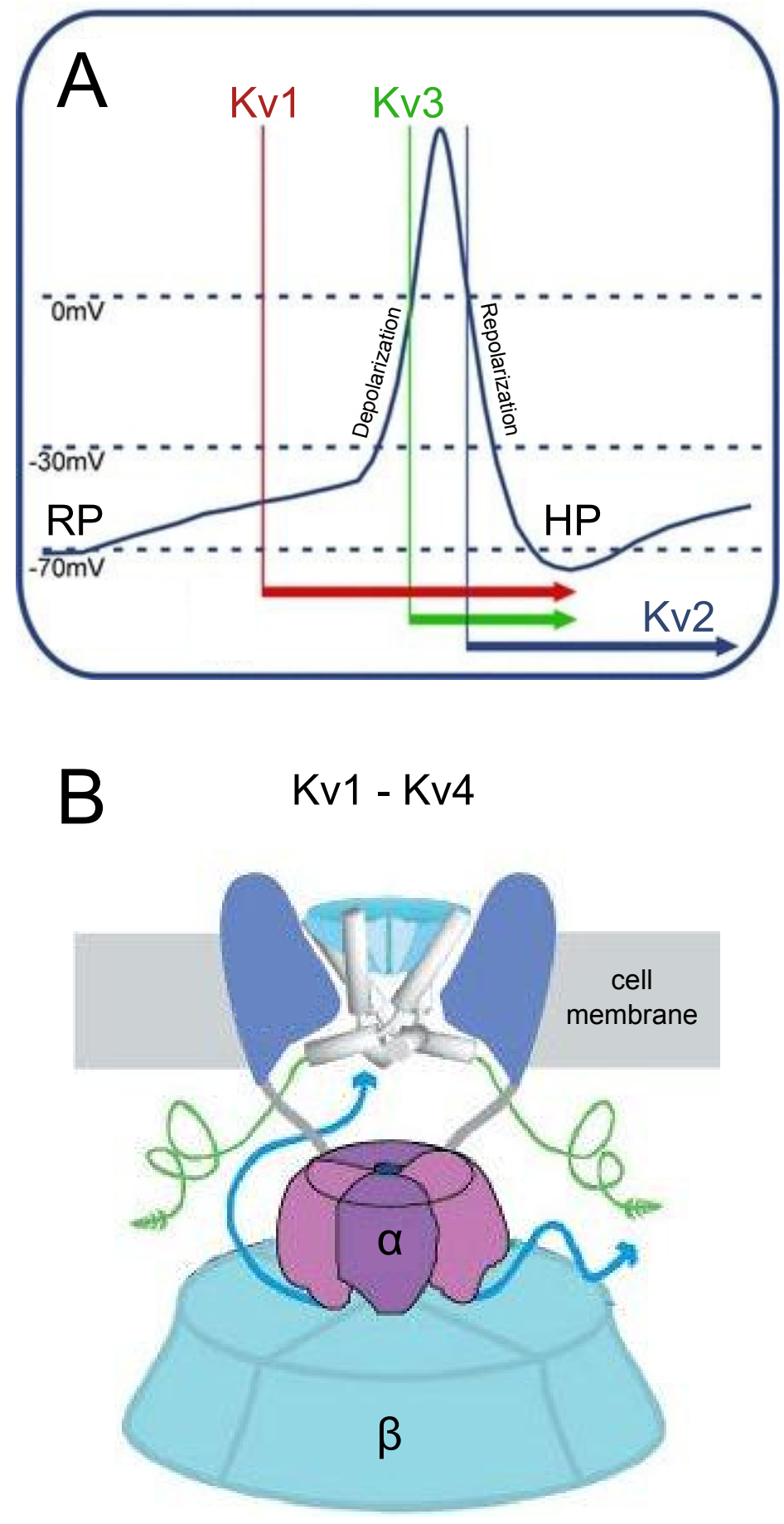

Figure 2: Voltage-gated potassium channel activation and structure. A. An ideal action potential showing the general phases and thresholds of activation for Kv1, Kv2, and Kv3 channels. The resting potential (RP), depolarization phase, repolarization phase, and hyperpolarization (HP) are marked. Adapted from (Johnston et al., 2010). B. The general structure of a voltage-gated potassium (Kv) channel from Kv1 Kv4 families. The tetrameric channel formed from $\alpha$-subunits (purple) and the accessory $\beta$-subunits (light blue) are shown. Adapted from (Yellen, 2002). 


\section{Chapter 2: Changing Expression of Ion Channel Genes in the Developing MNTB}

\section{Abstract}

Maturing neurons utilize a host of mechanisms controlling ion channel function and composition to finely tune their biophysical properties. Utilizing both quantitative real-time PCR (qPCR) and microarray analysis, we examined the gene expression profiles for a select group of voltagegated potassium channels between embryonic day 18.5 (E18.5) and postnatal day 14.5 (P14.5) in the developing MNTB. Among low threshold activated potassium channels (Kv1 family), Kv1.1 (Kcna1) and Kv1.2 (Kcna2) both increase between P0 and P6. However, between P6 and P14, Kv1.1 continues to increase while Kv1.2 stays more constant. Kv1.6 (Kcna6) levels did not vary much during this time frame. Among delayed rectifier potassium channels (Kv3 family), Kv3.1 (Kcnc1) levels increase slowly between P0 and P14 while Kv3.3 (Kcnc3) levels are stable between P0 and P6 followed by a sharp increase between P6 and P14. Hcn2, a member of the hyperpolarization-activated and cyclic nucleotide-gated channel family controlling hyperpolarization-activated current $\left(\mathrm{I}_{H}\right)$, also showed stable expression between P0 and P6 followed by an increase between P6 and P14. These data suggest that potassium channel composition changes dynamically during early postnatal development of the MNTB.

\section{Introduction}

Each type of neuron has action potential characteristics and biophysical properties that are specialized to optimize its function within the nervous system. The biophysical properties of neurons are largely determined by the quantities, types, density, and cellular distribution of ion channels that they express. The role of the MNTB, a prominent cell group in the auditory 
brainstem, in sound localization requires specific firing properties that are facilitated by the complement of its voltage-gated ion channels (Trussell, 1999). Mature MNTB neurons typically fire only one action potential for each depolarization due to the presence of potassium channels containing Kv1.1 and Kv1.2 subunits (Brew \& Forsythe, 1995; Dodson et al., 2002). The MNTB is capable of very high firing rates because of its extremely brief action potentials conferred by the rapid kinetics of Kv3 channels ((Brew \& Forsythe, 1995; Wang et al., 1998). Another family of channels, the hyperpolarization-activated and cyclic nucleotide-gated mixed cation (Hcn) channels control the hyperpolarization-activated current $\left(\mathrm{I}_{H}\right)$ and are involved in the regulation of neuronal excitability in the MNTB (Hassfurth et al., 2009). These channels and others shape the specialized action potentials characteristic of the MNTB principal neurons.

In an effort to understand and distinguish the roles and functions of specialized areas of the brain, the many different phenotypes of adult neurons and their underlying arrays of ion channels have been the focus of numerous studies in nearly all neuronal systems. However, understanding how these phenotypes change during development, and the associated gene expression profiles, is not well understood. Potassium currents in neurons change during the course of development (Harris et al., 1988; Gurantz et al., 2000), but most systems are comprised of multiple neuronal subtypes with varying functions which make the results of these maturational studies extremely complex. The developing calyx of Held/MNTB system overcomes several complications for this type of study. In the MNTB, the population of neurons is homogeneous (Hoffpauir et al., 2006) and changes in several biophysical properties of the neurons during early development have been characterized (Hoffpauir et al., 2010). Furthermore, growth of the calyx of Held occurs over a compressed time frame of P2 to P4 (Hoffpauir et al., 2006) which precedes the onset of sensitivity to airborne sounds between P8 and P12 (Mikaelian et al., 1965). These advantages and focused maturational events make the calyx of Held/MNTB an ideal system for gene expression studies. 
In this study, we characterized some of the changes in ion channel gene expression associated with hallmark physiological events in the developing MNTB. We utilized several techniques including qPCR and microarray analysis to measure developmental changes in transcript levels for several well-studied ion channels including members of the Kv1 and Kv3 family of voltagegated potassium channels and members of the Hcn family. We found that many of these genes increase during the developmental time frame between P0 and P14, but there are differences in the shapes of the profiles for individual subunits. These data suggest transcriptional regulation and developmental shifts in the subunit compositions for these ion channels throughout this period encompassing growth of the calyx of Held and the onset of hearing. The dynamic expression patterns of these channels in the MNTB provide an initial framework for identifying how functional properties can be acquired and modified through transcriptional regulation in an individual population of neurons.

\section{Materials \& Methods}

All procedures involving animals were approved by the West Virginia University Institutional Animal Care and Use Committee.

Tissue Collection and RNA Extraction

Brains from FVB mice (NIH/NCI/DCT production facility in Frederick, MD and Jackson Labs in Bar Harbor, ME) were dissected in ice-cold low $\mathrm{Ca}^{2+}$ artificial cerebral spinal fluid (ACSF) at ages ranging from embryonic day 18.5 (E18.5) to postnatal day 14.5 (P14.5). For the unamplified qPCR experiments, tissue from 3-5 littermates was collected and pooled together. 
For the amplified qPCR and microarray experiments, one littermate was collected at each of 7 time points (P0, P1, P2, P3, P4, P6, and P14) from 5 different litters. When using animals from a single litter on multiple days, the first dissection was done on P0 and then on subsequent days at the same time of day (+/- 2 hours). The low $\mathrm{Ca}^{2+}$ ACSF contained the following: $125 \mathrm{mM}$ $\mathrm{NaCl}, 2.5 \mathrm{mM} \mathrm{KCl}, 3 \mathrm{mM} \mathrm{MgCl} 2,0.1 \mathrm{mM} \mathrm{CaCl}_{2}, 25 \mathrm{mM}$ glucose, $25 \mathrm{mM} \mathrm{NaHCO}$, $1.25 \mathrm{mM}$ $\mathrm{NaH}_{2} \mathrm{PO}_{4}, 0.4 \mathrm{mM}$ ascorbic acid, $3 \mathrm{mM}$ myo-inositol, and $2 \mathrm{mM}$ Na-pyruvate. Reagents were obtained from Sigma (St. Louis, MO). The ACSF solution was saturated with $95 \% \mathrm{O}_{2} / 5 \% \mathrm{CO}_{2}$ before being used.

Coronal tissue slices of approximately $200 \mu \mathrm{m}$ thick were made from the dissected brains using a VF-200 tissue slicer (Precisionary Instruments Inc., Greenville, NC) and immediately placed into ice-cold low $\mathrm{Ca}^{2+}$ ACSF. Only slices with discernible MNTB on both faces of the tissue were used for the experiments (Fig. 1). The MNTB regions within the brain slice were carefully removed using a 26-gauge needle under a dissecting scope and transferred directly into lysis solution (Stratagene, La Jolla, CA) and frozen at $-80^{\circ} \mathrm{C}$. The RNA extraction and DNase treatment were later performed in groups using the Absolutely RNA Nanoprep kit (Stratagene). An Agilent 2100 Bioanalyzer (Santa Clara, CA) was used to measure the concentration and assess the quality of the RNA.

Quantitative Real-time PCR (qPCR) Analysis

For unamplified samples, the pooled RNA extracted from 3-5 littermates was reverse transcribed into cDNA using oligo(dT) primers and the StrataScript or Accuscript qPCR cDNA Synthesis Kits (Stratagene) according to the manufacturer's directions. For amplified samples, cDNA was generated using the WT-Ovation ${ }^{\text {TM }}$ Pico RNA Amplification System (NuGEN Technologies, San Carlos, CA) as described below. Primers specific for each gene (Table 1) 
were designed using Primer 3 software (Rozen \& Skaletsky, 2000) with mouse mRNA sequences from GenBank (http://www.ncbi.nlm.nih.gov/genbank/) and Ensembl (http://www.ensembl.org). When possible, PCR products were chosen so that they would detect all known transcript variants and cross exon boundaries to avoid amplification of genomic DNA. The primers were synthesized and purified using standard desalting by Integrated DNA Technologies (Coralville, IA). Each set of primers was confirmed to amplify a single product by obtaining a single band on a $2 \%$ agarose gel. The PCR amplification efficiencies for each primer set were confirmed to be between $90 \%$ and $110 \%$. The qPCR reactions were prepared using the Brilliant SYBR Green qPCR Master Mix (Stratagene), a reference dye, $150 \mathrm{nM}$ of each primer, and cDNA from the reverse transcription. Reactions were incubated at $95^{\circ} \mathrm{C}$ for $10 \mathrm{~min}$, and then cycled $30 \mathrm{X}$ to $40 \mathrm{X}$ at $95^{\circ} \mathrm{C}$ for 30 seconds, $55-58^{\circ} \mathrm{C}$ for 60 seconds, and $72^{\circ} \mathrm{C}$ for 60 seconds using a Stratagene Mx3000P real-time PCR system. Fluorescence was recorded during every cycle at both the annealing step $\left(55-58^{\circ} \mathrm{C}\right)$ and the extension step $\left(72^{\circ} \mathrm{C}\right)$. In order to further verify amplification of a single product from each reaction, a melting curve analysis was added at the end of the run. Each sample was run in triplicate and averaged to produce a single data point, and the results were normalized to the levels of the reference genes (hypoxanthine guanine phosphoribosyl transferase (Hprt) for 11/39 unamplified samples; Hprt and peptidylprolyl isomerase A (cyclophilin A or CypA) for 28/39 unamplified samples; Hprt, CypA, and polymerase (RNA) II (DNA directed) polypeptide A (Polr2a) for all amplified samples).

Two similar methods were used to quantify the mRNA levels in these experiments that are both based on the standard $\Delta \Delta^{\mathrm{Ct}}$ calculation. For the unamplified qPCR, a normalization factor was calculated by taking the geometric mean of the available reference genes (Vandesompele et al., 2002)(See Results). This factor is used to correct for sample input amount and allows for relative comparisons between the quantification cycles for each gene. For the amplified qPCR, 
a very similar method was used with the inclusion of the primer efficiencies for the genes of interest and reference genes, known as the Pfaffl method (Pfaffl, 2001). The resulting values for each gene were then converted to fold-change values relative to a chosen age and shown as a temporal profile across time.

RNA Amplification and Microarray Analysis

In order to follow a single litter across developmental ages and still obtain sufficient quantities of cDNA from a single mouse pup for hybridization to the microarrays, RNA obtained in the previous steps was amplified using the WT-Ovation ${ }^{\mathrm{TM}}$ Pico RNA Amplification System (NuGEN Technologies, San Carlos, CA). Only samples with an RNA integrity number (RIN) (Schroeder et al., 2006) of 5.0 or higher as measured on the Agilent 2100 Bioanalyzer were considered acceptable for amplification. We used $5 \mu \mathrm{g}$ of the resulting cDNA as a template to create sense strand cDNA with the WT-Ovation Exon Module (NuGEN) followed by fragmentation, biotinlabeling using the FL-Ovation cDNA Biotin Module V2 (NuGEN) and hybridization to mouse GeneChip 1.0 ST Exon Arrays (Affymetrix, Santa Clara, CA). The microarrays were scanned with a GeneChip Scanner $30007 \mathrm{G}$ (Affymetrix, Santa Clara, CA).

The microarray data were normalized using Genomics Suite software version 6.3 (Partek Inc., St. Louis, MO) along with Affymetrix annotation files. We chose to use RMA (Robust Multichip Average) with quantile normalization and GC pre-background adjustment, and the analysis was limited to the core-level genes supported by RefSeq transcripts or full-length mRNAs. 


\section{Results}

In order to characterize gene expression for selected ion channels in the developing MNTB, we utilized the techniques of $\mathrm{PPCR}$ and microarray analysis. Biophysical properties of MNTB neurons have been studied after the nucleus becomes identifiable at about E17 in mice (Hoffpauir et al., 2010). These studies reveal a maturational profile in which neurons transition from tonic to phasic firing patterns and exhibit a rapid decrease in action potential half-width (Hoffpauir et al., 2010). These features of cell physiology are known to be influenced by the abundance of certain potassium channels, specifically Kv1 and Kv3 family members (Forsythe \& Barnes-Davies, 1993; Rothman \& Manis, 2003). We performed dense temporal sampling of gene expression during these events by extracting RNA from micro-dissected MNTB tissue (Fig. $1 \mathrm{~A})$ at multiple ages: $\mathrm{E} 18.5, \mathrm{P} 0.5, \mathrm{P} 1.5, \mathrm{P} 2.5, \mathrm{P} 3.5, \mathrm{P} 4.5, \mathrm{P} 5.5, \mathrm{P} 8.5$, and $\mathrm{P} 14.5$ for the unamplified qPCR and P0, P1, P2, P3, P4, P6 and P14 for the amplified qPCR and microarray experiments. These time points surround significant developmental events in the MNTB including the formation of the calyx of Held between P2 and P4 and the onset of hearing around P8-P10 (Figure 1B)(Mikaelian et al., 1965; Hoffpauir et al., 2006; Hoffpauir et al., 2010).

At early ages (E17-P1), MNTB neurons generate multiple action potentials (AP) in response to a depolarizing current step (Hoffpauir et al., 2010). By P2, the number of APs generated at the onset of the current step begins to decrease, and by P5 the neurons exhibit a more mature phenotype only firing one AP (phasic firing)(Figure 1C). This phasic firing pattern continues through adulthood and has been associated with increased expression of Kv1 channels (Banks \& Smith, 1992; Forsythe \& Barnes-Davies, 1993; Wang et al., 1998; Dodson et al., 2002; Rothman \& Manis, 2003). There is also a rapid decrease in the AP half-widths between P0 and P14 (Figure 1D). This biophysical property is affected by the expression of Kv3 channels as 
these channels play a role in high-frequency firing (Brew \& Forsythe, 1995; Wang et al., 1998; Rothman \& Manis, 2003).

Kv1 Channel Expression Parallels Firing Pattern Shift

To explore the transcriptional changes concurrent with the observed modifications in firing properties, we first examined the temporal gene expression profiles of the Kv1 channel subunits that have been shown to be expressed by the MNTB neurons, specifically Kv1.1, Kv1.2, and Kv1.6 (Dodson et al., 2002). To measure mRNA transcript levels, we utilized qPCR of unamplified cDNA, qPCR of amplified cDNA, and microarray analysis and compare the results in Figure 2. Kv1.1 (Kcna1) transcript levels exhibit an increasing profile between P0 and P14 as exhibited by each of the three approaches. Both types of qPCR experiments show an increase of more than 2.5-fold between P0 and P6. In the case of Kv1.2 (Kcna2), each of the three approaches shows an early increase between P0 and P6 followed by a leveling out of the transcript levels between P6 and P14. The qPCR experiments show an increase in transcript levels of more than 2.5-fold between P0 and P6. However, transcript levels for Kv1.6 (Kcna6) change very little in our study between P0 and P14. This overall increase in Kv1 mRNA correlates rather well with the observed transition from tonic to phasic firing pattern in these maturing neurons (Hoffpauir et al., 2010).

\section{Kv3 Channel Expression Parallels Action Potential Narrowing}

Next, we examined the developmental gene profiles for Kv3.1 and Kv3.3 channel subunits that are expressed by MNTB neurons and responsible for their narrowing action potentials (Wang et al., 1998; Li et al., 2001). The transcript levels for Kv3.3 (Kcnc3) show steady to slowly increasing expression levels between P0 and P5 with neither qPCR experiment reaching a 2- 
fold change. This temporal sequence is followed by a strong increase in expression after P6 in all of the profiles for Kv3.3. Kv3.1 poses additional challenges for expression studies due to alternative splicing. Primers for the qPCR experiments were chosen to capture both splice variants $(a+b)$, but microarray probes reported the combination of both splice variants together and Kcnc1b separately. Kv3.1 (Kcnc1a+b) levels in the amplified qPCR experiments display an increasing profile through P14, showing a more than 2-fold increase by P6 and a slowed rate of growth between P6 and P14. The strong increase of Kcnc3 expression and the slow increase detected for Kcnc1 by amplified qPCR agree with the known transition towards extremely brief action potentials and decreasing action potential half-widths characteristic of MNTB neurons (Brew \& Forsythe, 1995; Rudy \& McBain, 2001; Hoffpauir et al., 2010).

Hcn2 Channel Expression Increases After Calyx Growth

To further characterize expression profiles of ion channels that contribute to neuronal excitability and synaptic responsiveness, we also examined the expression levels for family member 2 of the hyperpolarization-activated cyclic nucleotide-gated mixed cation channel (Hcn2). This family controls $\mathrm{I}_{\mathrm{H}}$, which is a mixed inward current consisting of both $\mathrm{Na}+$ and $\mathrm{K}+$ ions that has been shown to affect neuronal membrane excitability and resting membrane potential (Chen, 1997; Shaikh \& Finlayson, 2003). The expression levels from all three plots for Hcn2 fluctuate only slightly between P0 and P6 with a steep increase between P6 and P14. Hcn1 was detected in the microarray data and showed mostly stable expression that begins to decrease by P14. These results suggest an increasing contribution of $H c n 2$ subunits in controlling $I_{H}$ in the maturing MNTB beginning after growth of the calyx of Held. 


\section{Discussion}

Intrinsic biophysical properties of neurons are controlled by the complement of ion channels which they express, but the density of ion channels within neurons does not remain constant during maturation. In this study, we examined the temporal gene expression profiles for some of the well-studied voltage-gated potassium channels in MNTB principal neurons during the time frame surrounding growth of the calyx of Held. Many of these ion channels exhibit an increasing expression profile, which is not surprising during this dynamic period of maturation and growth. However, the shapes of these profiles for each channel subunit and how they correlate to the known developmental events may provide additional insight into channel composition and regulation in the maturing system.

\section{Kv1 Channel Subunits Ratio Changes with Time}

Previous studies propose that there is an increase in the functional protein for Kv1 channels in the MNTB during formation of the calyx of Held and the onset of hearing (Hoffpauir et al., 2010). Evidence supporting the roles of these channels comes from several sources including observed changes in electrophysiology combined with toxin studies (Brew \& Forsythe, 1995; Dodson et al., 2002; Hoffpauir et al., 2010) and from the phenotypes of mutant mice lacking specific Kv1 channel subunits (Brew et al., 2003; Brew et al., 2007). It has been proposed that most Kv1 channels in MNTB principal neurons contain both Kv1.1 and Kv1.2 subunits (Dodson et al., 2002) and the balance between these subunits in the tetrameric channels may be a way for the neurons to modulate their excitability (Brew et al., 2007). Unamplified qPCR results for Kv1.1 and Kv1.2 were published in Hoffpauir et al. (2010), but additional experiments presented here confirm and strengthen earlier findings. By evaluating unamplified qPCR, amplified qPCR, and microarray data on the same channel subunits, a higher level of confidence in the accuracy 
of the gene expression can be obtained. These data show that of the Kv1 channel genes, Kv1.1 mRNA in the MNTB increases the largest amount between P0 and P14. Kv1.2 mRNA increases between $\mathrm{P} 0$ and P6 but then the expression stabilizes, and Kv1.6 mRNA remains relatively constant throughout the ages examined.

Although changes in mRNA levels do not always correlate directly with changes in protein levels, gene transcription is the most common mechanism for controlling protein levels. Therefore, we would expect levels of many proteins to exhibit an expression profile similar to their mRNAs, making it likely that the subunit composition of Kv1 channels in the MNTB is changing during this time frame. Kv1.6 subunits would be more prominent at the earliest ages before increasing amounts of Kv1.1 and Kv1.2 decrease their relative abundance. Between P0 and P6 as Kv1.1 and Kv1.2 channel transcript numbers increase, more of the channels would contain both of these subunits, assuming most channels are heteromeric as suggested by Dodson et al. (2002). After P6, however, Kv1.1 continues to increase sharply while Kv1.2 levels off implying an increasing ratio of $\mathrm{Kv} 1.1$ to $\mathrm{Kv} 1.2$ through the onset of hearing. These predictions are similar to those made by Brew et al. (2007) who also quantified transcript levels

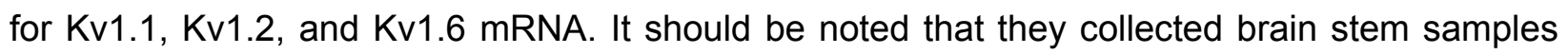
containing potentially dozens of neuronal subtypes as opposed to our tissue collection that contains predominantly one neuronal subtype. Although glial cells have been shown to express various voltage-gated potassium channels (Attali et al., 1997; Bordey \& Sontheimer, 2000), there appears to be minimal contribution to glial potassium currents from members of the $\mathrm{Kv} 1$ and Kv3 family members examined here (Bekar et al., 2005). Therefore, our study should more accurately reflect the expression changes occurring in the MNTB principal neurons. 


\section{Kv3.3 Contributes to Changing Action Potential Width}

The Kv3 channel subunits play an important role in the adult MNTB by shortening the duration of action potentials to support high frequencies of activity (Brew \& Forsythe, 1995; Wang et al., 1998; Rudy \& McBain, 2001). These data showed that Kv3.3 mRNA exhibits the largest increase among the genes examined. The sharpest increase in message occurred after P6. Kv3.1 mRNA levels are more difficult to interpret because there are two known splice variants (Kv3.1a and Kv3.1b) present throughout the brain (Ribera \& Spitzer, 1992). The qPCR and microarray results for levels of both Kv3.1 splice variants combined show a slight increase across the entire age range, but the contribution of each splice variant individually is not known. We were unable to accurately measure Kcnc1 transcript levels in our unamplified qPCR experiments due to an expected bias against the Kcnc1b isoform inadvertently created through the use of oligo(dT) priming in the reverse transcription. The microarray data reveal that the two splice variants seem to exhibit different expression patterns. Although it is not possible to assess the relative abundance of each splice variant from these experiments, Kcnc1a is probably increasing since Kcnc1b is decreasing and the combined profiles are increasing. Kv3.3 appears to be the most abundant Kv3 family member in the auditory brainstem (Li et al., 2001), so these combined results imply that its increasing transcript levels lead to larger Kv3 currents and are the primary channel subunit that affects action potential duration.

Hon1 is Detected in the Developing MNTB

Although MNTB neurons have been shown to express both Hcn2 and Hcn4 subunits (Koch et al., 2004; Leao et al., 2006), we were unable to obtain consistent results when examining Hcn4 transcript levels with qPCR (data not shown). Hcn4 did not appear above background levels in the microarray data either, suggesting that very little mRNA for Hcn4 was present in our 
samples. This could possibly be due to an amplification bias against the Hcn4 transcript. Hen1 was reported to not be expressed in the MNTB of young rats (P20 to P30) (Koch et al., 2004), yet this gene was detected by our microarray study. The profile for Hcn1 from our data appears to be decreasing by $\mathrm{P} 14$, so the transcript levels may be dropping and become undetectable at later ages. These differences in Hcn family genes may also be representative of divergence in the gene expression of the MNTB between mice and rats.

\section{Alternative Splicing Affects Kv3.1 Profiles}

In addition to adjusting the transcript levels for each channel subunit, there are many other mechanisms available to a neuron for fine tuning the function of ion channels (Coetzee et al., 1999). Some of these channel subunits have multiple splice variants with each having specific properties when incorporated into a functional channel. One instance of this can be seen with Kv3.1 where the two splice variants can be regulated through different mechanisms (Liu \& Kaczmarek, 1998a). Kv3.1b activity is modified by its phosphorylation state, showing rapid dephosphorylation upon high-frequency stimulation which promotes faster firing (Song et al., 2005). Kv1.2 channel subunits are also affected by phosphorylation with both the activity and trafficking patterns being affected (Huang et al., 1994; Connors et al., 2008). Although these post-translational modifications cannot be identified in gene expression studies, there is still much to be learned through careful study of transcript levels relative to maturational events. In this study, we focused on the overall expression profiles of channel subunits and not their individual splice variants or absolute expression levels. The alternative splicing issue only affects our interpretation of Kv3 channel expression because Kv1 channel subunits and Hcn2 do not have multiple splice variants. 
Increased Intracellular Calcium May Influence Kv Channel Expression

The mRNA levels for many of the Kv1 and Kv3 channel subunits measured in this study are increasing during the time frame encompassing growth of the calyx of Held and the onset of hearing. Neuronal activity leads to an increase in the intracellular calcium levels which can then lead to changes in gene expression (Ghosh \& Greenberg, 1995; West et al., 2001). Previous studies have shown that activity can affect the expression of Kv1 channels in the hippocampus (Raab-Graham et al., 2006) and Kv3 channels in the inferior colliculus (Liu \& Kaczmarek, 1998b). Incubation of organotypic slice cultures of MNTB in medium containing increased levels of potassium, which leads to higher levels of intracellular calcium, displayed an increase in transcript levels for Kv1.1 and Kv3.3 (Tong et al., 2010). It is likely that increased intracellular calcium levels, in addition to other activity-based mechanisms, contribute to the increasing gene expression reported here. Further studies, including characterizing the effects of removing activity from the in vivo system, would help to clarify the specific role of activity on ion channel expression in the developing MNTB.

The data from these experiments agree with previous findings and extend our knowledge of individual channel subunit expression in the developing MNTB. Changes in gene expression provided here clarify one aspect of neuronal control and set the groundwork for additional studies examining how splicing and channel composition contribute to neuronal maturation. These findings provide a framework that can be expanded to provide further insight into mechanisms of acquisition for biophysical properties in maturing neurons. 
Table 2-1: $\quad$ Primers for real-time PCR experiments

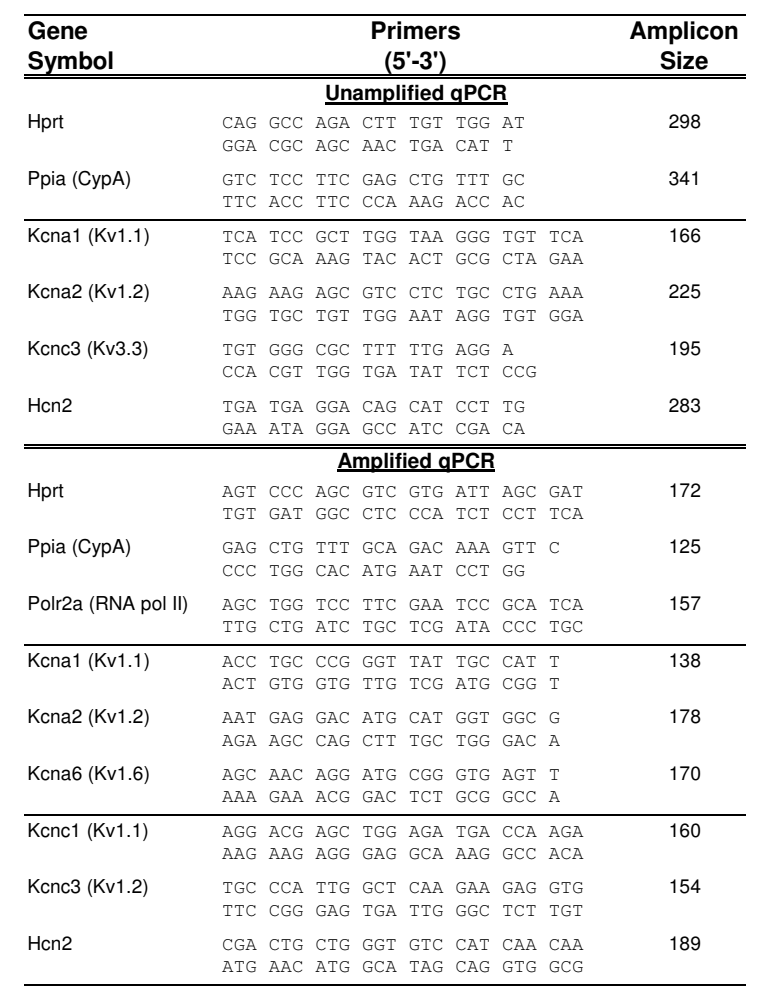




\section{Figure 2-1}
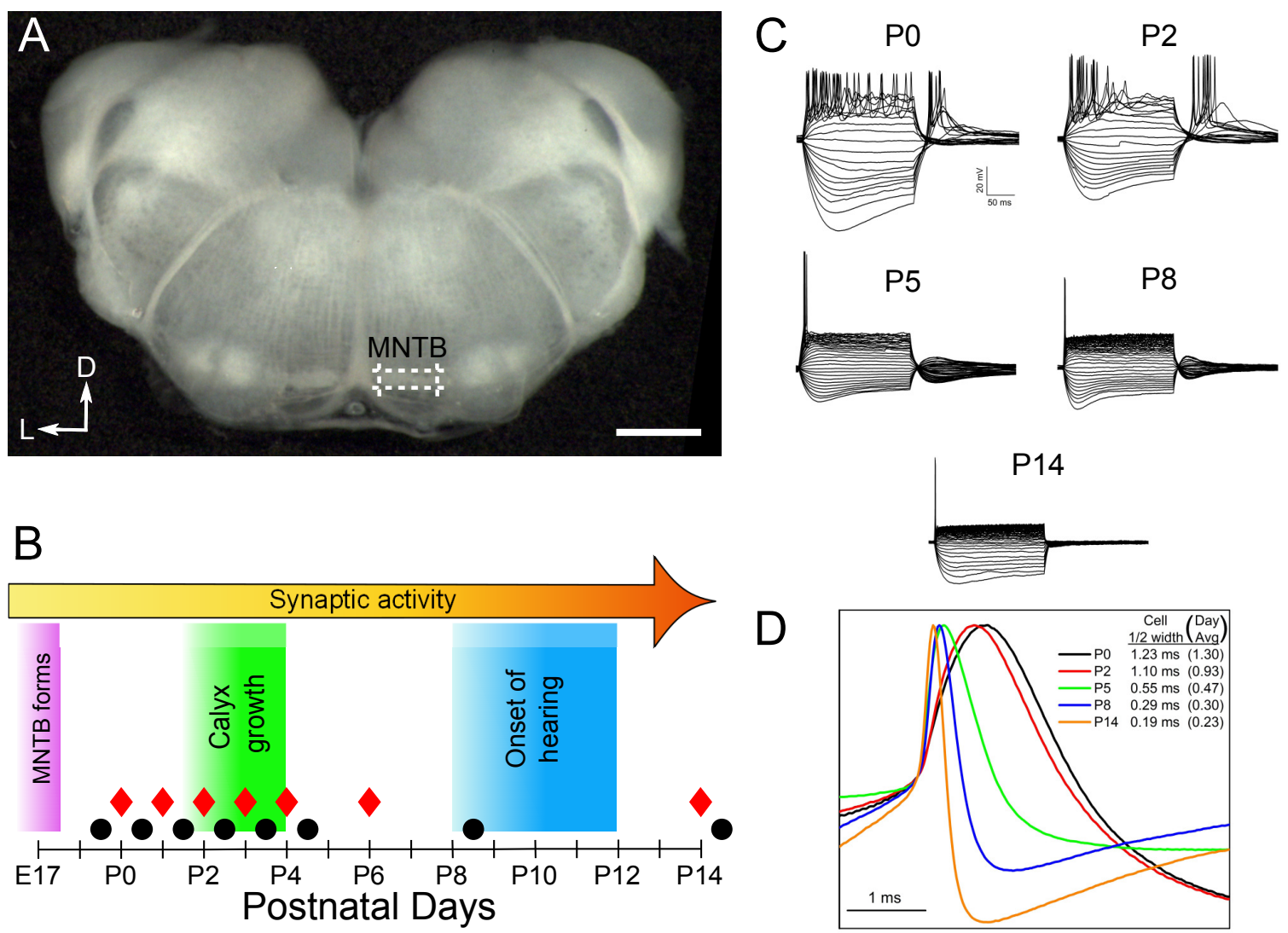

Figure 1. Experimental protocol and rationale. A, Example of a freshly prepared brain slice of $\sim 200 \mu \mathrm{m}$ thickness at $\mathrm{P3}$ showing MNTB. Dashed lines show cuts made to extract MNTB tissue for RNA collection. Scale bar is $500 \mu m$. MNTB, medial nucleus of the trapezoid body; V, ventral; L, lateral. B, Timeline illustrating some major events in early MNTB development, designated by colored blocks. Sample collection time points are shown for unamplified qPCR (black circles) and amplified qPCR or microarray experiments (red diamonds). C, Current clamp recordings of representative MNTB neurons at P0, P2, P5, P8, and P14 in response to 200 ms current steps injected in 5 pA increments, ranging from -100 pA to 500 pA. MNTB neurons generate multiple action potentials during single depolarizing current steps early in development (P0 and P2) and then transition to the "adult-like" phenotype as early as P5, when the majority of cells generate only 1-2 spikes at the onset of the current pulse. D, Electrophysiology results showing action potential half-widths decreasing more than 5-fold between $\mathrm{P} 0$ and $\mathrm{P} 14$. The first action potentials from the cells shown at each age are aligned at the inflection points and their amplitudes are normalized. Individual half-widths for each cell are indicated, along with the average for each developmental day shown in parentheses. Data shown in C and D were published in Hoffpauir et al., 2010. 


\section{qPCR}
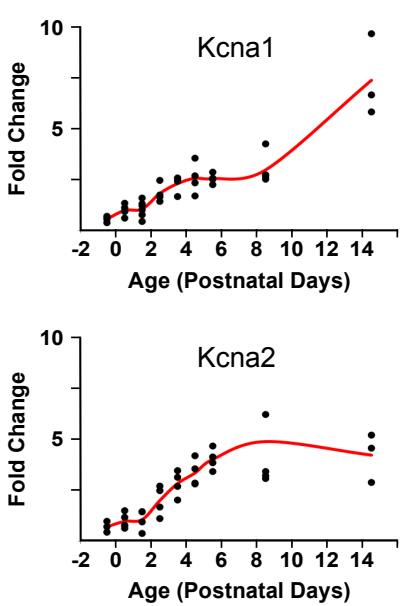

\section{Microarray}
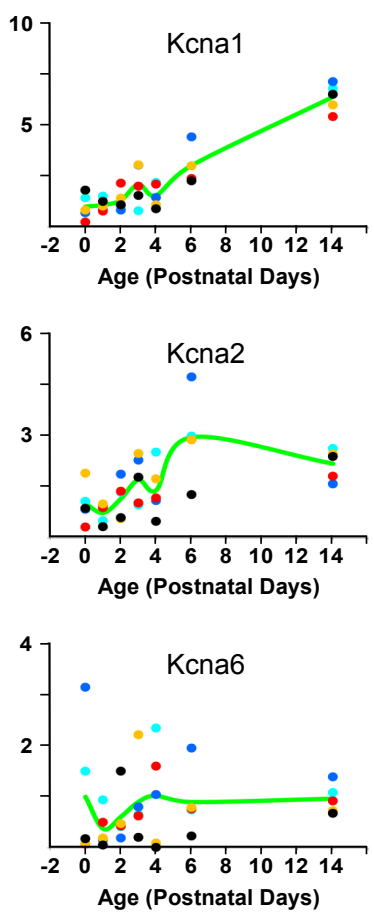
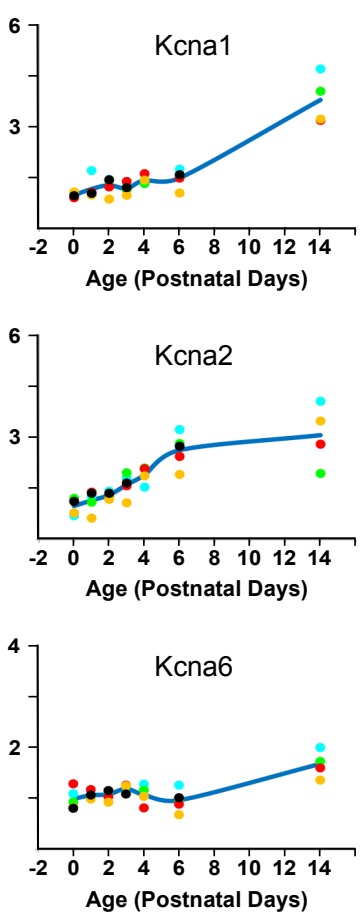

Figure 2. Gene expression profiles across time for Kv1 channel subunits. Kcna1, Kcna2, and Kcna6 unamplified qPCR results, amplified qPCR results, and microarray results are shown. The profiles for each gene are similar regardless of the technique used. Data were normalized to the reference genes (see methods) and shown relative to values at P0. Unamplified qPCR data points were generated from pooled animal samples (3-5 littermates); each symbol represents a different litter. Amplified qPCR and microarray data points represent individual animals with each color representing one litter across ages. Kcna1 - Kv1.1; Kcna2 - Kv1.2; Kcna6 - Kv1.6. 


\section{Figure 2-3}

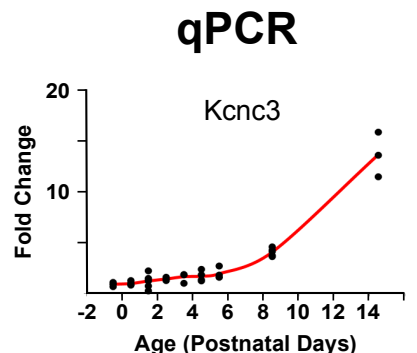

qPCR - Amplified

\section{Microarray}
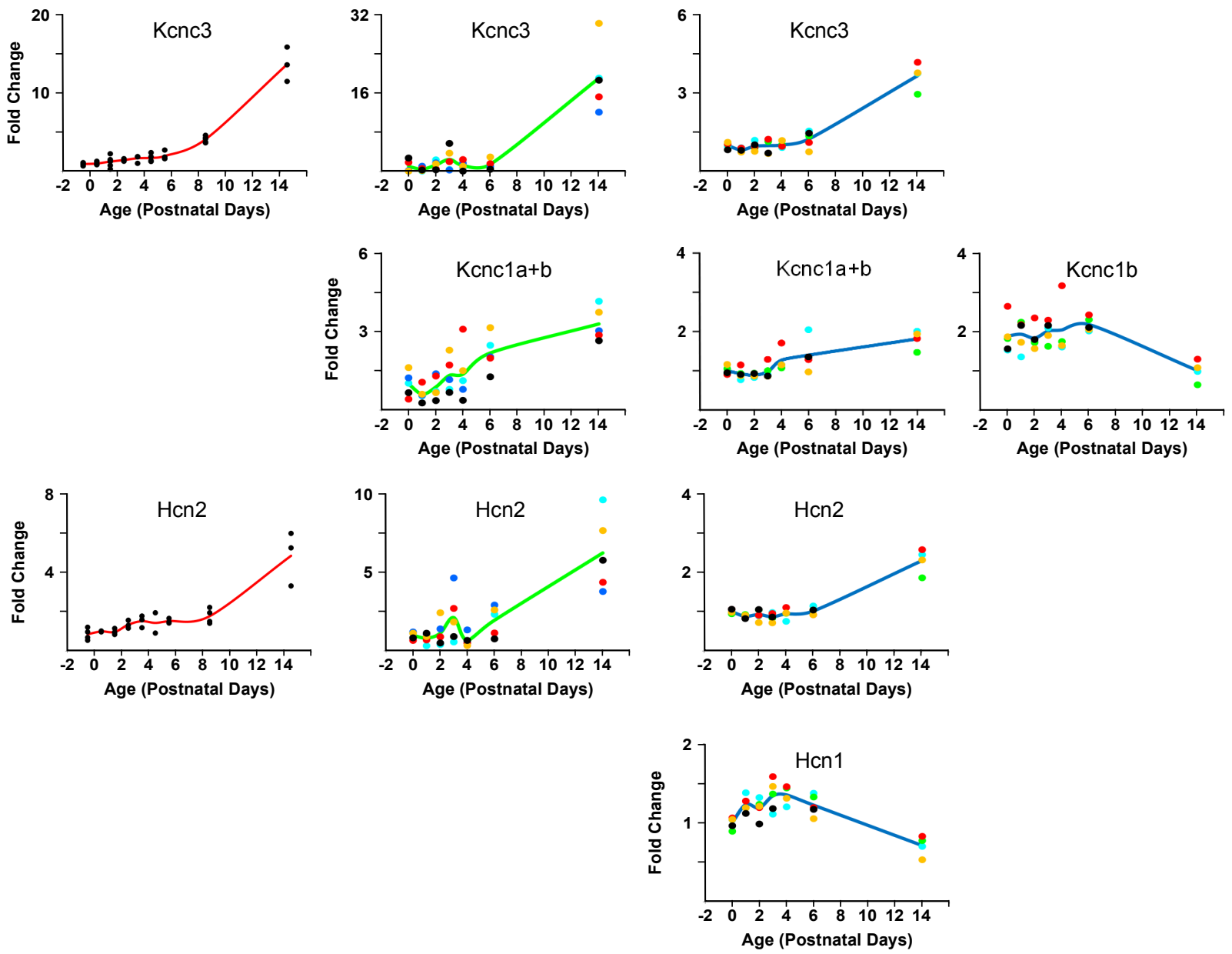

Figure 3. Gene expression profiles across time for Kv3 and Hon channel subunits. Unamplified qPCR results, amplified qPCR results, and microarray results are shown. Data were normalized to the reference genes (see methods) and shown relative to values at P0. Plot format is identical to that used in Figure 2. In the case of Kcnc1, primers for the amplified qPCR detected both splice variants $(a+b)$ while microarray results show the two splice variants together and then Kcnc1b separately (see results). Kcnc1 - Kv3.1; Kcnc3 - Kv3.3; Hcn2 - hyperpolarizationactivated cyclic nucleotide-gated channel, family member 2 . 
Title:

Temporal Patterns of Gene Expression in the MNTB During Calyx of Held Development

Abbreviated title:

MNTB Gene Expression During Calyx Growth

Author names and affiliations:

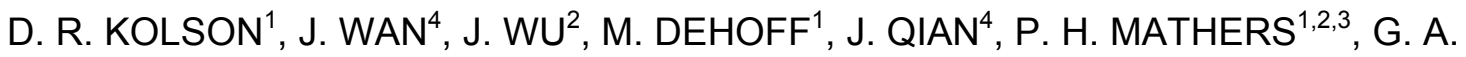
SPIROU ${ }^{1,2}$

${ }^{1}$ Sensory Neuroscience Research Center, ${ }^{2}$ Otolaryngology, HNS, ${ }^{3}$ Biochemistry, West Virginia University School of Medicine, Morgantown, WV; ${ }^{4}$ Wilmer Eye Institute, Johns Hopkins University School of Medicine, Baltimore, MD

Corresponding author:

George A. Spirou

West Virginia University School of Medicine

PO Box 9303 Health Sciences Center

One Medical Center Drive

Morgantown, WV 26506-9303

gspirou@hsc.wvu.edu

Number of pages: 35

Number of figures: 9 , tables: 3

Number of words for abstract: 164, introduction: 441, discussion: 1785

No conflict of interest

Acknowledgements:

This work was supported by NIH/NIDCD grant (DC007695) and NIH/NIDCD grant (DC007695S1) to GS, and a NIH/NIGMS grant (GM103105) to the Center for Neuroscience. We acknowledge $\mathrm{CN}$ colleagues for critical discussions and Chris Daugherty for assistance with the microarray experiments. 


\section{Chapter 3: Temporal Patterns of Gene Expression in the MNTB During Calyx of Held Development}

\section{Abstract}

Understanding how global gene expression changes are linked to discreet developmental events remains an elusive challenge in neuroscience. Neurons in the medial nucleus of the trapezoid body (MNTB) receive large specialized glutamatergic nerve terminals, the calyces of Held, which grow very quickly between postnatal day 2 (P2) and P4. We characterized the genome-wide changes in this developmental system utilizing microarrays and dense temporal sampling at ages surrounding growth of the calyceal inputs between P0 and P6. We identified a list of 541 significantly changing genes and clustered them into eight groups based upon their temporal expression profiles. Candidates originating from each of the profile groups were validated by $\mathrm{qPCR}$ and showed excellent correlation between both techniques. Many of the changing transcripts are associated with astrocytes and oligodendrocytes in addition to the neuronal contribution. Gene ontology revealed enrichment of genes involved in axon pathfinding and cell adhesion. These results provide a genetic framework for future investigation of mechanisms associated with nerve terminal growth and maturation.

\section{Introduction}

Understanding cellular mechanisms controlling neuronal development and maturation remains one of the more elusive challenges in neuroscience. Synaptic growth and refinement are controlled by precise genetic programs being executed by neurons, astrocytes, and oligodendrocytes, and these cell types all interact dynamically adding additional layers of 
complexity to the finely-tuned and coordinated events. These processes are best unraveled with a genome-wide approach, and previous studies have taken this angle. Some of the early developmental studies have explored gene expression during formation of cerebellar cortical circuitry (Kagami \& Furuichi, 2001; Lim et al., 2004; Takahashi et al., 2005). Studies have been done before and after significant maturational events affecting groups of cells, such as the onset of hearing in the developing cochlear nucleus (Harris et al., 2005) and the onset of vision in the developing retina (Dorrell et al., 2004). A more recent and extensive study used microarrays and in situ hybridization to characterize and localize the genes expressed during neurogenesis and development of the hypothalamus (Shimogori et al., 2010). Although these are only a few examples of the previous work, all of these studies reveal extremely complex patterns of gene expression that require significant numbers of additional experiments to unravel.

To gain a better understanding of the most complex events, it is advantageous to remove as many confounding issues as possible which can be done through the use of an appropriate experimental system. The MNTB/calyx of Held is an ideal system for studies of developmental gene expression because it offers multiple advantages over other brain regions. The MNTB is comprised of predominantly one neuronal subtype that undergoes focused maturational events including rapid growth of the calyx of Held in just a few days between postnatal day 2 (P2) and P4 (Hoffpauir et al., 2006), significant alterations to the biophysical properties of the neurons (Hoffpauir et al., 2010), and the presence of evoked activity resulting from the onset of hearing between P8 and P12 (Mikaelian et al., 1965). These discrete events allow for some direct correlation between in vivo gene expression in one type of neuron and known factors that can affect levels of expression.

To characterize the transcriptome of the MNTB neurons during calyx of Held growth, we performed a detailed microarray study encompassing this developmental time period. 
Expression patterns for 541 differentially expressed genes identified between P0 and P6 were clustered into eight groups based upon their temporal profiles, and more than 20 candidates covering every profile group were validated with qPCR. Established roles for groups of genes identified include cell adhesion and axon guidance, and a significant portion of the genes were found to be associated with astrocytes and oligodendrocytes.

\section{Materials \& Methods}

All procedures involving animals were approved by the West Virginia University Institutional Animal Care and Use Committee.

Tissue Collection and RNA Extraction

FVB mice (NIH/NCl/DCT production facility in Frederick, MD and Jackson Labs in Bar Harbor, $\mathrm{ME}$ ) were used in all experiments. Brains were quickly dissected in ice-cold low $\mathrm{Ca}^{2+}$ artificial cerebral spinal fluid (ACSF) at postnatal day 0 (P0), P1, P2, P3, P4, P6, and P14. P0 was defined as being between 6 and 12 hours after birth. When using littermates at multiple time points, the first dissection was done on PO and then on subsequent days at the same time of day (+/- 2 hours). The low $\mathrm{Ca}^{2+}$ ACSF contained the following: $125 \mathrm{mM} \mathrm{NaCl}, 2.5 \mathrm{mM} \mathrm{KCl}, 3$ $\mathrm{mM} \mathrm{MgCl} 2,0.1 \mathrm{mM} \mathrm{CaCl}_{2}, 25 \mathrm{mM}$ glucose, $25 \mathrm{mM} \mathrm{NaHCO}$, $1.25 \mathrm{mM} \mathrm{NaH} \mathrm{PO}_{4}, 0.4 \mathrm{mM}$ ascorbic acid, $3 \mathrm{mM}$ myo-inositol, and $2 \mathrm{mM}$ Na-pyruvate. Each of the reagents was obtained from Sigma (St. Louis, MO). The ACSF solution was saturated with $95 \% \mathrm{O}_{2} / 5 \% \mathrm{CO}_{2}$ prior to use. 
Coronal tissue slices were cut from the dissected brains using a VF-200 tissue slicer (Precisionary Instruments Inc., Greenville, NC) at a thickness of approximately $200 \mu \mathrm{m}$ and immediately placed into ice-cold low $\mathrm{Ca}^{2+}$ ACSF. Only slices with discernible MNTB on both faces of the tissue were used for the experiments (Fig. 1A). The MNTB regions within the brain slice were carefully removed using a 26-gauge needle under a dissecting scope to obtain an enriched population of MNTB cells (Fig. 1A'). The dissected tissue was transferred directly into either Iysis solution (microarrays; Stratagene, La Jolla, CA) or TRIzol reagent (qPCR) (Invitrogen, Carlsbad, CA) and frozen at $-80^{\circ} \mathrm{C}$. The RNA extraction and DNase treatment were later performed in groups using either the Absolutely RNA Nanoprep kit (microarrays; Stratagene) or the RNeasy Micro Kit (qPCR; Qiagen, Valencia, CA). An Agilent 2100 Bioanalyzer (Santa Clara, CA) was used to measure the concentration and assess the quality of the RNA.

RNA Amplification and Microarray Analysis

In order to follow a single litter across developmental ages and still obtain sufficient quantities of cDNA from a single mouse pup for hybridization to the microarrays, RNA obtained in the previous steps was amplified using the WT-Ovation ${ }^{\mathrm{TM}}$ Pico RNA Amplification System (NuGEN Technologies, San Carlos, CA). Only samples with an RNA integrity number (RIN) (Schroeder et al., 2006) of 5.0 or higher as measured on the Agilent 2100 Bioanalyzer were considered acceptable for amplification. We used $5 \mu \mathrm{g}$ of the resulting cDNA as a template to create sense strand cDNA with the WT-Ovation Exon Module (NuGEN). This was followed by fragmentation and biotin-labeling using the FL-Ovation cDNA Biotin Module V2 (NuGEN) and hybridization to mouse GeneChip 1.0 ST Exon Arrays (Affymetrix, Santa Clara, CA). The microarrays were scanned with a GeneChip Scanner 3000 7G (Affymetrix, Santa Clara, CA). 
The microarray data were normalized using Genomics Suite software version 6.3 (Partek Inc., St. Louis, MO). We used GC pre-background adjustment, RMA background normalization, and quantile normalization between samples. Our analysis was limited to the core-level probes/genes supported by RefSeq transcripts or full-length mRNAs. Before continuing with our analyses, we removed some genes from further analysis whose expression levels from all samples were within the lowest $25 \%$, because such intensities are very close to background levels. We then used Significance Analysis of Microarrays (SAM) (http://wwwstat.stanford.edu/ tibs/SAM/) (Tusher et al., 2001) to identify the genes showing differential expression at any stage(s) from P0 to P6. P14 data was only used for clustering and profile analysis. With a one-way analysis of variance and a false discovery rate (FDR) of $0.1 \%$, we achieved a list of 541 differentially expressed genes (DEGs) between the ages from P0 to P6. These significantly changing genes were then clustered using $k$-means with pairwise correlation metrics and $k=8$. In order to increase weighting for the later ages, which have unsampled intervals of 2 days (P4-6) and 8 days (P6-14), only the time points of P0, P2, P4, P6, and P14 were used in the $k$-means clustering analysis. An additional $k$-means clustering analysis was performed using 15 points, which included extrapolated time points for every age between P0 and $\mathrm{P} 14$; this analysis yielded very similar results to the 5 point $k$-means clustering (data not shown). As a final filter, all 541 genes were graphed and compared within group to ensure accurate profile clustering by our algorithm. Based upon these graphs, 3 of the genes were moved into different groups that captured their profiles more accurately (Calb1 from group 4 to 3, Cd24a from group 1 to 6 , Hmgcr from group 1 to 6$)$. Gene Ontology (GO) analysis was performed using DAVID Bioinformatics Resources (http://david.abcc.ncifcrf.gov/)(Huang et al., 2007) and a hypergeometric model with a p-value cutoff of $<0.05$ to identify the most highly enriched GO categories in our 541 gene list. The resulting list was manually filtered to yield a final list containing the most informative and least redundant categories (Table 3). 
Quantitative Real-time PCR Analysis

The pooled RNA extracted from 4-6 littermates as described above was reverse-transcribed into cDNA using SuperScript III Reverse Transcriptase (Invitrogen) and random priming. We emphasize that different animals were used for validation than were used for microarray studies. Primers (Table 1) were designed using NCBI Primer-Blast (http://www.ncbi.nlm.nih.gov/tools/primer-blast/) to cross introns and detect all known splice variants, when possible, and were synthesized by Integrated DNA Technologies (Coralville, IA). The PCR amplification efficiencies for each primer set were confirmed to be between $90 \%$ and $110 \%$, and each set of primers was confirmed to amplify a single product by obtaining a single band on a $2 \%$ agarose gel. Quantitative real-time PCR was performed using Brilliant II SYBR Green qPCR Master Mix (Stratagene) with $250 \mathrm{nM}$ of each primer and $0.2 \mathrm{ng}$ of cDNA in each reaction. Samples were analyzed in triplicate using a Stratagene MX3005P instrument (Santa Clara, CA) with cycling conditions of $95^{\circ} \mathrm{C}$ for 10 minutes followed by 40 cycles of $95^{\circ} \mathrm{C}$ for 30 seconds, $60^{\circ} \mathrm{C}$ for 1 minute, and $72^{\circ} \mathrm{C}$ for 1 minute. A melting analysis was performed at the conclusion of the run to further verify the amplification of a single product.

To identify reference gene candidates for use in the qPCR studies, we first examined the microarray data to find the most stably expressed genes between P0 and P14 followed by validation of the four top candidates (see Results). The stability of each reference gene was assessed by comparing its expression to the geometric mean of all four candidates. The relative expression levels of the genes chosen for validation were quantified by first calculating a normalization factor for each sample. The normalization factor is calculated by taking the geometric mean of the four reference genes (Vandesompele et al., 2002). This factor is then used to correct for sample input amount and allows for relative comparisons between the quantification cycles for each gene. In order to quantify the mRNA levels in these experiments, 
a method based on the standard $\Delta \Delta^{\mathrm{Ct}}$ calculation was used with the inclusion of the primer efficiencies for the genes of interest and reference genes. This set of calculations is known as the Pfaffl method (Pfaffl, 2001). The resulting values for each gene were then converted to foldchange values relative to a chosen age and shown as a temporal profile across time.

Immunofluorescence

FVB mice at P0, P3, P6 and P14 were anesthetized with ketamine/xylazine $(100 / 10 \mathrm{mg} / \mathrm{kg})$ in addition to hypothermia at P0, P3, and P6. Animals were perfused transcardially with phosphate buffered saline (PBS) followed by a solution of $4 \%$ paraformaldehyde (PFA) in PBS. The brain was removed from the skull and postfixed overnight at $4^{\circ} \mathrm{C}$ in $4 \%$ PFA in PBS. The brain was transferred to cryoprotectant $(30 \%$ sucrose in $0.075 \mathrm{M}$ sodium phosphate buffer $\mathrm{pH}$ 7.4 ) at $4^{\circ} \mathrm{C}$ for $1-2$ days prior to freezing and sectioning. Coronal sections of the brainstem were cut at $40 \mu \mathrm{m}$ thickness using a freezing microtome (model HM 450, Microm, Waltham, MA).

The sections were placed in blocking solution (3\% goat serum in PBS containing $0.1 \%$ Triton X100) for 1 hour. Next, the sections were incubated overnight at $4^{\circ} \mathrm{C}$ with agitation using combinations of the following primary antibodies diluted in blocking solution: chicken polyclonal anti-MAP2 (EnCor Biotechnology, Gainesville, FL at 1:5,000); guinea pig polyclonal anti-VGLUT 1\&2 (Chemicon, Billerica, MA at 1:2500 each); rabbit polyclonal anti-parvalbumin (Swant, Marly, Switzerland at 1:250); rat monoclonal anti-tenascin C (clone MTn-12 from Abcam, Cambridge, MA at 1:200); mouse monoclonal anti-Aldh1L1 (clone N103/39, Antibodies Inc., Davis, CA at 1:250); rabbit anti-Iba1 (Wako Chemicals USA, Richmond, VA at 1:250); rabbit anti-PDGFR- $\alpha$ (Santa Cruz Biotechnology, Santa Cruz, CA at 1:200). After washing in PBS, sections were placed in the appropriate secondary antibodies diluted in blocking solution at 1:500 for two hours at room temperature with agitation (Alexa 555 donkey anti-guinea pig, Alexa 488 goat 
anti-chicken, Alexa 647 goat anti-rabbit, and Alexa 555 donkey anti-mouse from Molecular Probes, Grand Island, NY; Alexa 488 donkey anti-chicken and Alexa 647 donkey anti-rat from Jackson Immunoresearch Laboratories, West Grove, PA). The sections were washed with PBS.

Sections were imaged using a confocal microscope (model LSM-510 Meta, Zeiss, Thornbridge, NY). A small section of a cover slip was placed on top of the brain section, sitting in a cover slipbottomed dish containing PBS, to prevent movement during the scanning process. Three-color detection was performed in two imaging channels. The first channel used simultaneous excitation at 488 (KrAr laser) and $633 \mathrm{~nm}$ (HeNe laser) and 505-525 nm and 650 long pass emission filters, respectively. The second channel used $543 \mathrm{~nm}$ excitation and 545-605 nm emission filter. Scanning parameters were optimized for one time point (usually the age of highest expression) and left unchanged for the other three time points. Brightness and contrast of the resulting images were optimized for maximum clarity. The exceptions to this are parvalbumin and Tnc which were gain-matched across ages, using identical scanning and optimization parameters at each age allowing for direct comparison.

\section{Results}

Microarray Analysis of Gene Expression in MNTB

In order to characterize the transcriptome of the developing MNTB, we performed a detailed microarray analysis spanning the first two weeks of postnatal development (Fig. 1B). During this time frame, MNTB cells pass through several developmental milestones, including (1) rapid growth of the large calyx of Held terminal onto their cell body between postnatal day $(P) 2$ and P4; (2) maturation of biophysical properties of principal neurons also between P2-P4 (Hoffpauir 
et al., 2006; Hoffpauir et al., 2010); (3) topographic refinement of axonal projections of MNTB neurons to the lateral superior olive between P4-P8 (Kim \& Kandler, 2003; Noh et al., 2010); and (4) the onset of sensitivity to airborne sounds between P8-P12 (Mikaelian et al., 1965)(Fig. 1B). To investigate the changing transcript levels associated with these events, we employed dense temporal sampling of gene expression by extracting RNA from micro-dissected MNTB tissue (Fig. 1A') at seven ages: P0, P1, P2, P3, P4, P6 and P14. To obtain greater statistical power, we used five replicates at each age. Our focus for this report is on expression changes associated with calyx of Held formation, which is complete on most MNTB neurons by P6 (Hoffpauir et al., 2006; Hoffpauir et al., 2010). Given the increasingly appreciated role for glia in neural circuit assembly (Kucukdereli et al., 2011; reviewed by Eroglu \& Barres, 2010), we utilized a preparation that contained all cell types present within the developing MNTB. Using a one-way analysis of variance with a false discovery rate of $0.1 \%$, we identified 541 genes found to be changing significantly between P0 and P6. This time period was chosen to focus on the genes that are differentially expressed during calyx growth and rapid maturation of MNTB neurons.

\section{Clustering of Genes by Expression Profiles}

When $k$-means clustering analysis was used to group the genes with similar temporal profiles (Fig. 2A), this analysis yielded four groups containing 299 genes with monotonically increasing expression levels (groups 1-4), two groups containing 54 genes with complex profiles displaying intervals of both increasing and decreasing expression levels (groups 5-6), and two groups containing 188 genes with monotonically decreasing expression levels (groups 7-8). The first major difference among groups that share a common direction of change (i.e. groups 1-4 and 78 ) is the age associated with the inflection point in each profile. The second major difference is the slope of the profile between P6 and P14, which indicates gene expression changes that 
occur after the majority of calyces have formed and through the onset of hearing. A heat map representation of the 541 genes arranged by group shows the average normalized signal intensity covering the range capturing most of the expression changes (Fig. 2B).

After the genes were divided into their $k$-means clustering groups, we examined the cell-specific expression of the 541 genes based upon the transcriptome database for developing neurons and glia provided by Cahoy et al. (2008). Our experiments extracted RNA from the entire MNTB, which includes astrocytes, oligodendrocytes, oligodendrocyte precursor cells, microglia, and endothelial cells in addition to neurons. Note that the neurons in mouse MNTB form a nearly homogeneous population of principal cells (our unpublished observations). When crossreferencing cell-specific expression with the enrichment values from supplemental tables in Cahoy et al. (2008), we used a 5-fold enrichment cutoff to produce lists that included 72 genes enriched in neurons, 51 genes enriched in astrocytes, 69 genes enriched in oligodendrocytes, and 349 genes with no cell-type specific enrichment (Table 2). Interestingly, there is a strong association between expression group and cell type, providing a detailed picture of transcription during this dynamic phase of growth in the early postnatal MNTB. More than $75 \%$ of the astrocyte-enriched genes (40 of 51) and 95\% of the oligodendrocyte-enriched genes (68 of 69) display increasing expression profiles from groups $1-4$. Conversely, more than $70 \%$ of the neuron-enriched genes (53 of 72) display decreasing expression profiles from groups 7 and 8 . These trends likely reflect multiple aspects of the development of each cell type, consistent with different sample ages and maturational states between the MNTB and the forebrain samples used to generate the enrichment tables (Cahoy et al., 2008). 
Validation of Gene Expression Profiles

Confirmation of the expression level changes for a subset of genes was performed using quantitative real-time PCR ( $\mathrm{PPCR}$ ) and included at least two representatives from every group. In order to address the recurring challenge of normalizing our qPCR data to appropriate reference genes (Gutierrez et al., 2008), more difficult across developmental age, we utilized published data and our microarray data to identify potential reference gene candidates (Bahr et al., 2009). Our requirements were that reference gene candidates are stably expressed across the developmental time window of P0 to P14, have "housekeeping" functions consistent with their expression at a constant concentration, and have varied expression levels to better represent the range seen in the list of 541 differentially expressed genes. Four reference genes from this candidate list were validated. Two were chosen from previously-identified reference genes (ATP synthase, $\mathrm{H}+$ transporting mitochondrial F1 complex, beta subunit (ATP5b) and tyrosine 3-monooxygenase/tryptophan 5-monooxygenase activation protein, zeta polypeptide (Ywhaz)) and are listed in the geNorm mouse reference gene kits, http://medgen.ugent.be/ jvdesomp/genorm/), and two were chosen from our microarray data (helicase with zinc finger domain (Helz) and eukaryotic translation termination factor 1 (Etf1)). The expression levels for all of these genes showed minimal variability across the ages that were examined (Fig. 3A). The two genes identified from our own data set exhibited the greatest stability, supporting the validity of this approach to reference gene selection (Bahr et al., 2009).

To begin our validation of microarray expression data, we chose the gene for the well-studied calcium-binding protein, parvalbumin (Pvalb), which has been localized to the principal neurons of the MNTB in previous studies (Hartig et al., 2001; Felmy \& Schneggenburger, 2004). The expression profiles for the microarray and the qPCR demonstrate excellent correlation, especially considering that different animals were used for each technique (Fig. 3B). The qPCR 
data exhibits a larger fold-change than the microarray data, reflecting the larger dynamic range afforded by qPCR (Chang et al., 2000; Mutch et al., 2002). The protein levels for Pvalb were assessed across the P0-14 age range by immunofluorescence. Pvalb was co-localized with MAP2-positive cell bodies and dendrites indicating that it is expressed predominantly, perhaps exclusively, in neurons (P14 column in Fig. 3C). Pvalb became detectable at P6 in MNTB cells and increased in level greatly by P14. Pvalb has previously been localized to calyces at older ages (Lohmann \& Friauf, 1996; Felmy \& Schneggenburger, 2004). We first detected Pvalb in growing calyces via co-localization with VGlut1 and 2 and in axons at P3, with increasing levels through P14 (white arrowheads in P3, P6, and P14 columns in Fig. 3C).

We applied qPCR to systematically validate genes from each of the eight $k$-means clustering groups. Group 1, consisting of 52 genes, began its increase later than any of the other monotonically increasing groups, followed by a sharp increase through P14. We demonstrate two gene candidates, myelin oligodendrocyte glycoprotein (Mog) and semaphorin 4d (Sema4d), from this group for validation. The qPCR temporal profiles correlate very well with the age of initial increase in expression (P6 for Mog; P2 for Sema4d) and capture the large differences in the magnitudes of expression changes between these genes at P14 (Fig. 4). This group of genes, based upon their expression profiles, may play less of a role in perinatal development than at later postnatal ages and possibly adult function of the MNTB.

Group 2, 3, and 4 consist of 70,106 , and 71 genes, respectively, and these groups exhibit profiles that are increasing in a mostly linear fashion from P0 through P6. The largest difference among these group profiles occurs between P6 and P14, when groups 2 and 3 continue to increase but group 4 shows little change in expression. We chose the validation of representative genes aldolase C, fructose-biphosphate (Aldoc) and cadherin 20 (Cdh20) from group 2, calbindin 1 (Calb1) and SRY-box containing gene 10 (Sox10) from group 3, and bone 
morphogenetic protein 5 (Bmp5) and microphthalmia-associated transcription factor (Mitf) from group 4 (Fig. 4). The qPCR results capture the temporal profiles, especially between P6-14, but also portray subtle day-to-day variations in expression prior to P6 that are evident in the microarray data. The genes from these groups cover a wide range of functions as discussed below.

Groups 5 and 6 contain the smallest number of genes, but they display the most dynamic profiles. Group 5 contains 34 genes and has an expression profile that increases early, peaks at P4 or P6, followed by a decrease through P14. Group 6 contains 20 genes and has a mirror image expression profile to group 5, decreasing early with a minimum at P4 or P6 followed by an increase through P14. The genes from these two groups represent some of the most interesting prospects to mediate specific developmental and maturational roles during the time of rapid calyx growth. We demonstrate validation of three members from group 5: endothelin receptor type B (Ednrb), Riken cDNA 2310046A06, and receptor (calcitonin) activity modifying protein 3 (Ramp3) (Fig. 5). As with groups 3 and 4, overall patterns along with many of the subtle daily changes that are apparent in microarray data are captured by qPCR. We show two representatives from group 6 , one of which has its highest expression late, Cd24a antigen (Cd24a), and another which has its highest expression early, dapper homolog 1, antagonist of beta-catenin (Xenopus) (Dact1) (Fig. 5). These differential features of their expression were validated by qPCR.

The monotonically decreasing groups 7 and 8 contain 95 genes and 93 genes, respectively. The profiles for these groups differ slightly in their slopes, with group 7 decreasing sharply between P0 and P4 then leveling out by P14 while group 8 has a less rapid initial decrease. We would expect genes that have primary roles in embryonic stages of development to fall into these groups as they are decreasing in expression after birth. The representative genes shown 
for group 7 are solute carrier family 17 (sodium-dependent inorganic phosphate cotransporter), member 8 (Slc17a8, also known as Vglut3) and tenascin C (Tnc)(Fig. 6). For group 8, we validated the genes cerebellin 1 percursor protein (Cbln1) and doublecortin (Dcx)(Fig. 6). Again, we found excellent correlation between these validation profiles and the microarray data.

\section{Gene Ontology}

We performed Gene Ontology (GO) analysis (see Methods) to identify the most highly enriched and informative GO categories in our 541 gene list. Many GO categories are non-specific and relatively uninformative when considering the potential gene functions (such as developmental process or insoluble fraction), so we highlight the most significant and interesting GO categories in Table 3. The resulting list contains categories spanning a host of different cellular functions and processes. Six different GO categories are involved in regulating biological processes including regulation of neuron projection development, neurogenesis, cell differentiation, axonogenesis, signaling, and transmission of nerve impulse. Cell adhesion, having the second most significant enrichment, and axon guidance are two of the most notable GO categories for our developmental study. Two different cellular component categories are also present, extracellular matrix and synapse. Several of these will be discussed in more detail below.

The GO category for axon guidance contained 17 members, including 3 semaphorins, 1 plexin, 2 ephs, L1cam, Dcc, Unc5a, and Robo2 among others. More than $70 \%$ of these genes (12 of 17) belong to groups 7 and 8 , indicating that they decrease in expression across $P 0-14$. This distribution of expression profiles is not surprising considering that genes from this category have known involvement in the establishment of specific neuronal connectivity. The semaphorins that were changing significantly were Sema3a, Sema3f, and Sema5a. Dcc, Robo2, and Unc5a are membrane-associated extracellular signaling proteins exhibiting 
decreasing expression profiles. Sema5a, Nfasc, and Nr4a3 all belong to profile group 3, implicating their ongoing involvement in MNTB maturation and function.

The GO category for cell adhesion contained 51 members; 22 members belong to the cell-cell adhesion subcategory (the attachment of one cell to another through adhesion molecules) and 13 members belong to the homophilic cell adhesion subcategory (the attachment of one adhesion molecule to an identical molecule on an adjacent cell). Cell adhesion molecules have been shown to have diverse functions within the nervous system, including organization of three-dimensional tissue structure, bidirectional cell signaling, and formation and maturation of synapses. The cell adhesion molecules identified in our study originate from all eight profile groups. Seven members from the cadherin superfamily (Cdh2, Cdh4, Cdh20, Cdh22, Dsg2, Pcdh15, and Celsr3) along with one catenin, the cadherin-associated protein Ctnna2, are represented within the developing MNTB. One of the best-studied members from this diverse group of calcium-dependent adhesion molecules is cadherin 2 (Cdh2), also known as $\mathrm{N}$ cadherin. Cdh2 has been associated with a multitude of synaptogenic events including the accumulation of AMPA (2-amino-3-(5-methyl-3-oxo-1,2- oxazol-4-yl) propanoic acid) receptors and dendritic spine stabilization and growth (Malinverno et al., 2010; reviewed by Brigidi \& Bamji, 2011). Previous studies show that classic cadherins are required for the initial stages of synapse assembly in young neurons but become dispensable at older ages (Togashi et al., 2002; Bozdagi et al., 2004). Three of the four vertebrate members of the L1-CAM family of adhesion proteins (L1cam, Chl1, and Nfasc) are also listed within this gene ontology group. The L1-CAM family members are broadly expressed in the developing nervous system and play important roles in axon outgrowth and fasciculation, axon guidance, and synaptic plasticity (Barry et al., 2010; Demyanenko et al., 2011; reviewed by Maness \& Schachner, 2007). Three different proteoglycans (Acan, Bcan, and Hspg2) are found in this GO category, all belonging to profile group 3. Other GO category members include three integrins (Itga2, Itga6, and Itga8), 
two tenascins (Tnc and Tnr), and a contactin (Cntn4). Taken together, the mixture of both increasing and decreasing expression patterns for genes associated with cell adhesion suggests that some of these protein families undergo member-switching and faster turnover during calyx of Held formation and associated MNTB cell maturation.

The GO category of synapse contained 32 genes split almost equally between increasing (18 genes) profile groups and decreasing (14 genes) profile groups. Because this GO category refers to association with a cellular component, some of the genes also belong to previously described groups such as axon guidance and cell adhesion. Seven genes (Cplx1, Lgi3, Slc17a8, Syt2, Syt5, Unc13b, and Vamp1) in this GO category are associated with synaptic vesicles and their release. An additional 7 genes (Chrm3, Gabra2, Glra1, GIrb, Gria3, Grin2b, and Lin7c) are most commonly found localized to the postsynaptic membrane, 6 of which are receptor subunits (all except Lin7c). Two genes that are commonly associated with the presynaptic membrane (Atp1a2 and Erc2) were also on this list.

Four Different Cells Types Visible Across Ages

Since our tissue dissection included glial cells, we performed a series of immunofluorescence experiments using some well-known markers for specific cell types to assay their prevalence in the developing MNTB (Figs. 7 and 8). Antibodies for the following proteins were used to label specific cell types: microtubule-associated protein 2 (MAP2) for neuronal somata and dendrites; aldehyde dehydrogenase 1 family, member L1 (Aldh1L1) for astrocytes (Cahoy et al., 2008); anti-ionized calcium binding adaptor molecule 1 (Iba1) for microglia (Fig. 7). Substantial numbers of both neurons and astrocytes are visible at all of the ages examined between P0 and P14. The neurons are clumped closer together at P0, but begin spreading apart by P3. An increase in the Aldh1L1-positive astrocytic processes is apparent with increasing age, showing 
few at P0 and a dense network by P14. Microglia can be seen at ages ranging from P0 to P14, although they are not very numerous when compared to the astrocytes or neurons. There appears to be a slight increase in the numbers of microglia present at P6 and P14 than at P0 and P3 (Fig. 7). Another cell type of interest is oligodendrocytes, but we do not expect markers against the mature cells to identify any cells at P0. Therefore, we used an antibody against platelet-derived growth factor receptor alpha (PDGFRa) to identify oligodendrocyte progenitor cells (Fig. 8). There are a few of these strongly-labeled cells present across the entire age range of P0 to P14 that are distinct from the neuron or astrocyte markers, but there is also some moderate neuronal labeling detected. These data confirm the presence of at least four different cell types and give a foundation to examine the cellular specificity for additional proteins identified from our gene list.

\section{Tenascin C Shows Complex Temporal Localization Patterns}

Finally, we examined protein levels for the cell-adhesion gene tenascin $C$ (Tnc), which belongs to group 7 and exhibits a decreasing expression profile (Fig. 6). From Table 2, we would expect that Tnc is expressed by astrocytes and should therefore co-localize with our astrocyte marker. We examined anti-Tnc (blue) immunofluorescence between P0 and P14 (Fig. 9). We found that the highest intensity labeling was at P0, as expected from the profile, but the antibody against Tnc did not co-localized well with either of the other markers. The labeling appeared strongest next to the neurons or astrocytes or in the nuclei of both. There is weak but visible labeling at P3 and P6 in the same areas as P0. By P14, however, localization of the antibody is much different, showing increased signal in the axon tracts and cross-cut fibers passing through the MNTB (Fig. 9, axon tracts marked with white arrows). There is no visible Tnc signal in the axon tracts at P3 or P6. 


\section{Discussion}

In this microarray study, we have provided a detailed look at the transcriptional changes that occur during early postnatal development of the MNTB. This brain region has advantages that can potentially simplify an extremely complex set of processes, such as containing predominantly one neuronal subtype and the rapid growth of its presynaptic terminal. This allows for tying some of the expression profiles to specific events in synapse formation and tissue organization. We found 541 significantly changing genes between P0 and P6, and these genes were assigned to 8 different groups based upon their temporal expression profiles.

Gene Expression Confirmation Extends Beyond Our Validation List

The qPCR confirmation of more than 20 candidate genes showed excellent agreement with the microarray results, and this observation has several important implications for the data set. There was a high degree of similarity between the microarray data, which used individual littermate animals and amplification of the resulting RNA, and the unamplified qPCR data obtained by pooling 4-6 animals from the same litter. Based upon this similarity, the RNA amplification appears to have accurately preserved the relative quantities of the transcripts across a wide range of expression levels. The main difference between the two data sets was the reduction in the magnitude of the expression level changes, probably due to the limited dynamic range of microarray data when compared to qPCR data (Chang et al., 2000; Mutch et al., 2002). We used 4-5 microarray replicates for each time point studied, which added statistical power to the results. The consistent validation of microarray data by qPCR lends confidence to the entire data set, including genes that have not been individually confirmed. Another factor that may have contributed to the reproducibility of the gene expression results was the use of four reference genes that were chosen for their stability in our developing system. Reference 
genes are extremely important in calculating accurate results for qPCR (Vandesompele et al., 2002; Huggett et al., 2005), and reference genes for developmental time points can be quite difficult to identify because of the large changes that occur in the entire transcriptome during these time periods. Our approach permitted rapid identification of viable candidates to use as reference genes in the developing MNTB, and the approach likely generalizes to other experimental systems.

\section{Multiple Sources for the mRNA}

The technique that we used to collect mRNA by microdissection yielded the transcriptome of the entire developing system as opposed to cell type-specific information that could have been obtained by fluorescent cell sorting. We took a holistic approach for several reasons. First, we do not know where the most important factors influencing the development of the system originate. By collecting all of the cells present in the microenvironment, we ensured that the transcripts of glial origin were also identified. Although many researchers in the past have taken the approach that neurons are the most important cells in the brain, more recently it has become apparent that glia play crucial roles in development including the control of synapse formation and modulation of synaptic transmission (reviewed by Eroglu \& Barres, 2010 and Faissner et al., 2010). We have observed at least four types of cells in the developing MNTB (neurons, astrocytes, oligodendrocytes, and microglia), and we expect that there should also be contribution from endothelial cells in the blood vessels. Second, we cannot be sure of the exact contribution of mRNA from the large growth cones and presynaptic terminals of the forming calyces, and the encompassing approach examining all of the local transcripts ensures that they are also considered in the study. Previous work estimating the abundance of mRNA in presynaptic terminals for local translation have been challenging (reviewed by Willis \& Twiss, 2010), but it has been shown that there are thousands of mRNA transcripts present in 
embryonic and mature dorsal root ganglion axons (Gumy et al., 2011). Many axonal transcripts, especially in developing axons, originate from certain ontology categories such as axon guidance, axonal outgrowth, and synaptic proteins (reviewed by Jung et al., 2012). Considering the large distance between the cochlear nucleus and the MNTB, and the larger than average size of the growing calyceal terminals, it is easy to imagine that a significant proportion of the translation occurs presynaptically. However, the majority of the mRNA in our samples is still expected to be collected from the cell bodies.

Gene Expression Varies Across Cell Types, Ages, and Brain Regions

The cell-specific enrichment information presented in Table 2 highlights that many of the changing genes do not necessarily originate within the developing neurons. The glia and neurons interact in complex ways that are just beginning to be understood (reviewed by Eroglu \& Barres, 2010 and Stipursky et al., 2011). Just as neurons have long been known to vary significantly between brain regions and subtypes (reviewed by Nelson et al., 2006), astrocytes have also been shown to exhibit a wide range of physiological properties and morphologies, often depending upon their location within the brain (reviewed by Zhang \& Barres, 2010). We would expect that there would be some differences in gene expression between the cells from developing brainstem and the cortical cells used by Cahoy et al. (2008). We discovered at least one potential difference in the immunofluorescence data for Tnc which did not co-localize with our astrocyte marker Aldh1L1. Since Tnc is a component of the extracellular matrix, the proteins could both be expressed by astrocytes and compartmentalized to different areas, or Tnc may not originate in the astrocytes of the MNTB. Tnc has been shown to plays a role in preventing oligodendrocyte maturation (Czopka et al., 2009; Czopka et al., 2010), and this idea is also supported by the Tnc profile decreasing quickly, prior to myelination and increasing expression of Mog (Fig. 4) and myelin basic protein (Group 3 in Table 2). An additional level of complexity 
is exemplified in the antibody labeling against Tnc at P14 (Fig. 9) showing increased signal in the axon tracts and cross-cut fibers passing through the MNTB. Even though we sampled the transcriptome of cells contained within the MNTB between P0 and P14, it is likely that proteins synthesized in other brain areas can still play a role through their transport into the MNTB.

\section{Morphology Changes During MNTB Development}

During the course of these experiments, we observed some morphological changes in the MNTB (Figs. 7, 8 and 9). At P0, the principal neurons are clustered very close together. By P3, the cells are growing and spreading apart, and this difference becomes quite apparent by P6. The glia are also developing rapidly within this time frame, surrounding the neurons and occupying much more of the interstitial spaces. One of the factors that may contribute to this transition is the dynamic complement of cell-adhesion molecules that we observed in the

microarray data. As some of these molecules decrease, it may allow the early cell-cell attachments to dissipate while the increasing adhesion molecules begin to form the more mature connections to the astrocytes and growing synapses.

\section{Oligodendrocyte Progenitor Cells Remain Beyond Myelination}

Our PDGFRa labeling detected the presence of oligodendrocyte progenitor cells throughout the age range of $\mathrm{P} 0$ to $\mathrm{P} 14$, which is well after myelination has begun as early as $\mathrm{P} 3$ (Foran \& Peterson, 1992). Both PDGFRa and NG2 have been used to label proliferating oligodendrocyte progenitor cells (reviewed by Nishiyama et al., 2009), but there has been much speculation as to potential ongoing roles for these cells aside from their maturation into myelinating oligodendrocytes. $\mathrm{NG}^{+}$cells can differentiate into multiple cell types including astrocytes, oligodendrocytes and neurons (Horner et al., 2002; Belachew et al., 2003). Previous work in the 
MNTB has identified a population of glial cells that are $\mathrm{NG}^{+}$and receive glutamatergic synaptic input (Muller et al., 2009), and activation of glutamate receptors on $\mathrm{NG}^{+}$oligodendrocyte progenitors inhibits proliferation and lineage progression (Yuan et al., 1998). This implies that a population of these undifferentiated cells could be actively maintained in the mature MNTB.

Potential Roles for Axon Guidance Genes in the Developing MNTB

Traditionally, the primary role for axon guidance molecules was thought to be guiding growth cones to their postsynaptic targets. More recently we are learning that axon guidance molecules play many additional roles in the developing brain (reviewed by Vanderhaeghen \& Cheng, 2010). There are six semaphorins and three plexins in our 541 gene list even though only three semaphorins and one plexin are categorized into axon guidance based upon the GO database. We identified three differentially expressed class 3 semaphorins (Sema3a, Sema3d, and Sema3f) in our 541 gene list, which are all secreted proteins that play roles in repulsive axon guidance (Tran et al., 2007) and bind to receptor complexes containing neuropilins and class A plexins (Kruger et al., 2005). Sema3a is one of the most studied semaphorins, and it has been shown to have axon repellant (Tamagnone et al., 1999), dendritic attractant (Schlomann et al., 2009), and growth cone collapse effects (Fournier et al., 2000). Sema3f appears to be involved in stereotyped pruning in the corticospinal tract (Low et al., 2008), and Sema3d promotes axon fasciculation through regulation of the cell adhesion molecule L1cam (Wolman et al., 2007), which is found in group 8 of our list. Sema4d, Sema5a, and Sema6d are all membrane-bound semaphorins that have functions in the immune system (Kumanogoh \& Kikutani, 2010) in addition to their classical axon guidance roles in the nervous system. Sema4d has been shown to regulate both growth cone collapse of hippocampal neurons (Swiercz et al., 2002) and to stimulate axonal outgrowth of embryonic dorsal root ganglia neurons (Masuda et al., 2004). Sema5a has been identified as having a bifunctional role, participating both in axon guidance 
(Hilario et al., 2009) and in stratification of the developing retina (Matsuoka et al., 2011). Sema6d can control synaptic organization of the dorsal horn of the spinal cord by its involvement in migration of the myelinating oligodendrocytes (Leslie et al., 2011).

Additional axon guidance molecules have already been studied in the MNTB. Signaling through the protein Ephb2 plays a role in preventing formation of ipsilateral connections between the ventral cochlear nucleus (VCN) and MNTB (Hsieh et al., 2010). Mice lacking NB-2/contactin 5 show $8 \%$ of MNTB cells lacking calyces and increased apoptosis (Toyoshima et al., 2009). We found Ephb1 (group 6), Ephb2 (group 8), and contactin 4 (group 8) to be changing significantly in our study. Considering the known roles of these gene families in other systems, it is likely that these genes and others play a crucial role in the developing MNTB during rapid growth of the calyces and competition between growing inputs (Hoffpauir et al., 2010). Future studies will build on this work and continue to elucidate the specific mechanisms underlying nerve terminal targeting, growth, and maturation. 


\section{Table 1: $\quad$ Primers for real-time PCR experiments}

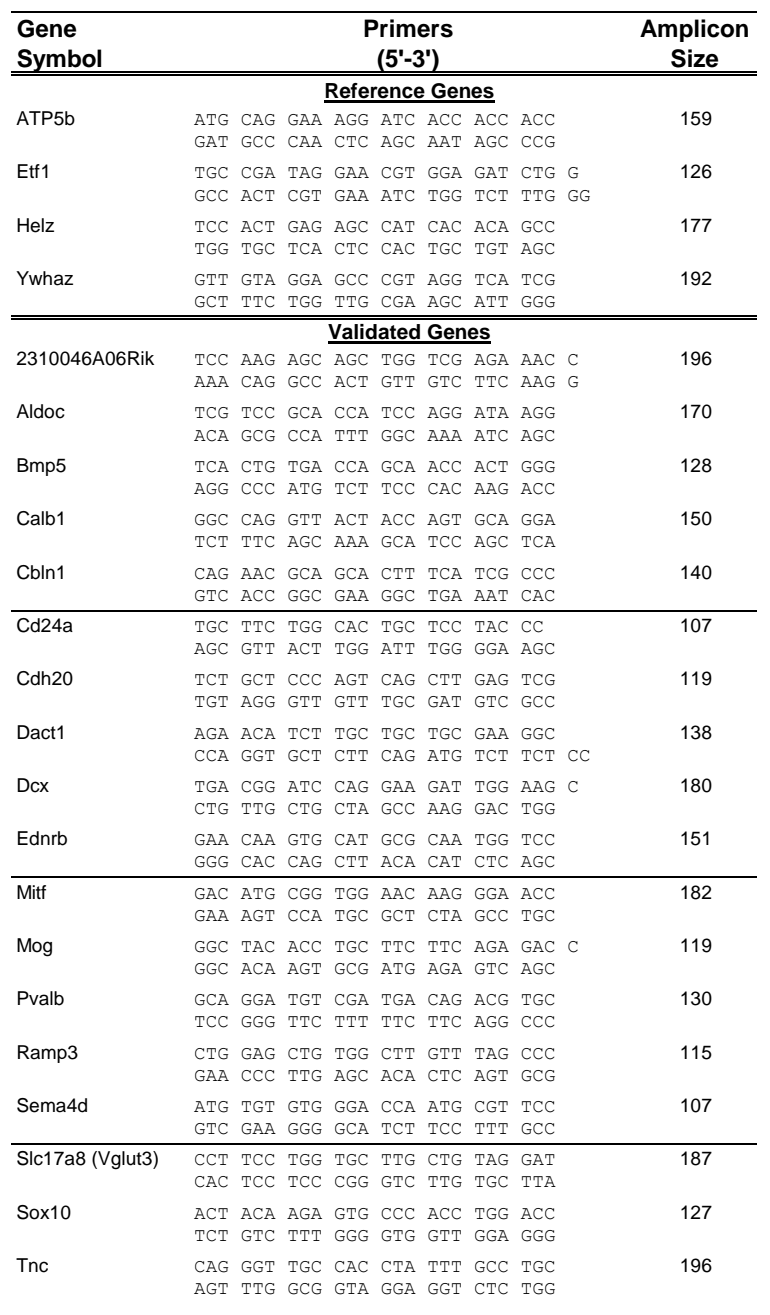


Table 2. Group distribution and cell-specific expression of $0.1 \%$ FDR gene list

\begin{tabular}{|c|c|c|c|c|c|c|c|c|c|c|}
\hline \multirow[t]{6}{*}{ Group 1} & Astrocyte & Neuron & Bace2 & Gsn & Mtap7 & Trf & Cmya5 & Fryl & Nipal4 & Sorbs3 \\
\hline & Chi3l1 & none & Cldn11 & Hhip & Myo1d & Tubb4 & Cox8b & Glra1 & Pla2g16 & Sorl1 \\
\hline & Dio2 & Oligodendrocyte & Cpox & Lgi3 & Pla2g4a & Unspecified & Csrp1 & Hspb8 & Plekhb1 & Spp1 \\
\hline & Hsd11b1 & Adamts4 & Erbb3 & Mal & SIc12a2 & Acsl3 & Efhd1 & Klh12 & Plekhg3 & Tppp \\
\hline & Tpbg & Apod & Fbxo32 & Mcam & St18 & Ankrd33b & Elovl5 & Lpar1 & Sema4d & \\
\hline & & Arhgef10 & Gpr37 & Mog & Tmem63a & Cdk18 & Ermn & Mobkl2b & Slco1a4 & \\
\hline \multirow[t]{8}{*}{ Group 2} & Astrocyte & Gprc5b & Neuron & Gje1 & Tspan2 & Asah2 & Fmn1 & Kcnj10 & Pip4k2a & Trnp1 \\
\hline & Aldh1a1 & Papss2 & none & Gltp & Wipf1 & Auh & Fn3k & KIf9 & Qk & Ttyh1 \\
\hline & Aldoc & Pde4b & Oligodendrocyte & Man1a & Zfp365 & Bbox1 & Gabra2 & Lynx1 & S1pr1 & Tyrobp \\
\hline & Aqp4 & Pygm & Cryab & Sema3d & Unspecified & $\mathrm{Cd} 81$ & Gatm & Mctp2 & $\mathrm{Scd} 2$ & Zeb2 \\
\hline & Atp1a2 & Slc1a2 & Ctss & Slc44a1 & 4732418C07Rik & $\operatorname{Cdh} 20$ & Gramd3 & Myadml2 & Smarca2 & \\
\hline & Atp1b2 & Sparc & Ell2 & Srpk3 & Abcg1 & Elmo1 & Hhatl & Nipal2 & Smyd1 & \\
\hline & $\mathrm{Cd} 38$ & Tlr3 & Enpp2 & Syt12 & Agpat9 & Etl4 & Igsf11 & Omg & Tcf4 & \\
\hline & F3 & & $\mathrm{Fa} 2 \mathrm{~h}$ & Tmeff2 & Arsb & Fam102a & Inpp5j & Ostf1 & Tmbim1 & \\
\hline \multirow{11}{*}{ Group 3} & Agt & $\overline{\text { Calb1 }}$ & Alox5 & Mobp & Ugt8a & Chpt1 & Hapln4 & Nptn & Rnd2 & Tuba4a \\
\hline & Bcar3 & Cds1 & Arpc1b & Nfasc & Unspecified & Cntnap1 & Hipk2 & Nr1d1 & Rora & Ubl3 \\
\hline & $\mathrm{Clu}$ & Nefh & Bmp4 & Pllp & 6530401N04Rik & Cpxm2 & Hlf & $\mathrm{Nr} 4 \mathrm{a} 3$ & s100b & Vamp1 \\
\hline & Gpc5 & Rasgrf1 & Chn2 & Plp1 & 9130019P16Rik & Dynl12 & Hrasls & Odz4 & Sgk1 & Whrn \\
\hline & Htra1 & Rassf5 & Cnksr3 & Prkcq & Acan & $\mathrm{Flt3}$ & Hspg2 & Paqr6 & Sgpp2 & Zfp750 \\
\hline & Igsf1 & Rgs4 & Cnp & Rasgef1b & Adamts1 & Glrb & Inppl1 & Parm1 & Six4 & \\
\hline & Ndrg2 & Zmat4 & Ddc & Rnf122 & Anxa5 & Gm2a & Itga8 & Pcp4l1 & Slc6a5 & \\
\hline & Slc13a3 & & Elov17 & Sema5a & Arhgef6 & Gng12 & Kank1 & Plcg2 & Snx18 & \\
\hline & SIc14a1 & & Enpp6 & Sirt2 & Atp1b1 & Gpr123 & Kcna2 & Pls3 & Sox8 & \\
\hline & Slc39a12 & & Lims2 & Sox10 & Bcan & Gpr37l1 & Mbnl2 & Prune2 & Syt2 & \\
\hline & Slc7a10 & & Mag & Tmem163 & Casr & Gpx6 & Neu4 & Pvalb & $\mathrm{Tnr}$ & \\
\hline \multirow[t]{6}{*}{ Group 4} & Astrocyte & Ppp1r3c & Rit2 & Unspecified & Bmp5 & Dci & Galnt13 & Mreg & Rreb1 & Tcf712 \\
\hline & 1200009022 Rik & $\mathrm{Rftn} 2$ & Scn1a & $1110032 \mathrm{~A} 04 \mathrm{Rik}$ & $\mathrm{Cd} 47$ & Enpep & Hsdl2 & Nceh1 & S100a1 & Timp4 \\
\hline & Apoe & Slc4a4 & Oligodendrocyte & Abhd3 & Cdgap & Epb4.112 & Hspa12a & Nfatc2 & S100a13 & Vwc2l \\
\hline & Atp13a4 & Wnt7a & Bcas1 & Ampd3 & Chrm3 & Epha6 & Itpr2 & Pcdh15 & S100a6 & Zfp488 \\
\hline & Cst3 & Neuron & Gpr17 & Arhgap24 & Cldn10a & Eps8 & Kcnab3 & Ptprm & Sema6d & \\
\hline & Pla2g7 & Kitl & & BC002189 & Dbpht2 & Fyn & Lypd6 & Rap2a & Sod3 & \\
\hline \multirow[t]{6}{*}{ Group 5} & Astrocyte & Neuron & Oligodendrocyte & $\underline{\text { Unspecified }}$ & Dclk3 & $\mathrm{Hrc}$ & Slc12a8 & Sphk1 & & \\
\hline & Ednrb & 2310046 A06Rik & none & $\overline{1700025 \text { G04Rik }}$ & Epcam & Itga2 & Smpx & Tmem215 & & \\
\hline & Gdpd2 & Dgkg & & Adamts16 & Galnt14 & Lrrfip1 & Sntg1 & Trpc3 & & \\
\hline & Hapln1 & Lrrtm3 & & Akap7 & Gipc2 & Mme & Sox6 & & & \\
\hline & 1133 & Ramp3 & & Alox8 & Gucy2f & Parp8 & & & & \\
\hline & Slc6a11 & Slc6a17 & & Angpt1 & Hertr2 & Rrad & & & & \\
\hline \multirow[t]{3}{*}{ Group 6} & Astrocyte & Neuron & Oligodendrocyte & Unspecified & Cnnm4 & Ephb1 & Hopx & Rhpn2 & Tmem200a & \\
\hline & Pla2g3 & $\mathrm{Cd} 24 \mathrm{a}$ & none & Adamts 20 & Dact1 & Gm4951 & Lrrc8d & Rps6ka5 & Txnrd3 & \\
\hline & Psd2 & Uchl1 & & Cdh22 & Dok4 & Hmgcr & Phlda1 & Slco2a1 & & \\
\hline \multirow[t]{10}{*}{ Group 7} & Astrocyte & Celsr3 & St8sia4 & Adamts18 & Clca2 & Fbln2 & Mapk11 & Plxna1 & Sik1 & Vash2 \\
\hline & Itga6 & Cnr1 & Tmtc4 & Adcy5 & Col14a1 & Fbxl7 & Mapt & Plxna3 & Slc17a8 & Vim \\
\hline & Masp1 & Corola & Trhde & Apba2 & Crabp2 & Fmnl1 & Mycn & Plxnb2 & Sncg & Vstm2a \\
\hline & Sdsl & Dpysl5 & Oligodendrocyte & Atp2b4 & Ctnna2 & Fxyd6 & Naip1 & Ppp1r13b & Sn $\times 26$ & Vstm2b \\
\hline & Tnc & Jph4 & none & B4galt2 & Ctxn1 & Gmip & Negr1 & Psd & Tacr1 & Wnk2 \\
\hline & Neuron & Mmp17 & Unspecified & BC068157 & D930015E06Rik & Igsf3 & Nuak1 & Ptpru & Tbc1d16 & Zfp503 \\
\hline & 2410066E13Rik & Pde10a & 2310057J16Rik & Ccdc116 & Dnmt1 & $\mathrm{Kdm} 2 \mathrm{~b}$ & Otof & $\mathrm{Rbm} 9$ & $\operatorname{Tgfb3}$ & Zfp57 \\
\hline & Actl6b & Pde2a & 2310067E19Rik & Cdh4 & Ezr & Kif26b & Ovgp1 & Rufy3 & Ttll1 & Zfp704 \\
\hline & Camkv & Sst & 4931428F04Rik & Cidea & Fads3 & Kirrel3 & Pak7 & Sema3f & Ubxn11 & Zfp811 \\
\hline & Ccdc120 & St8sia2 & 8430427H17Rik & Clca1 & Fam190a & Mad212 & Plcb1 & Sept3 & Unc5a & Zmym3 \\
\hline \multirow[t]{7}{*}{ Group 8} & Astrocyte & Crmp1 & Frmd3 & Prkar2b & Oligodendrocyte & Chl1 & Fbxl19 & Mdga2 & Pnck & Stc1 \\
\hline & none & Cugbp2 & Fst15 & Rab3b & $\mathrm{Hn} 1$ & Dapk1 & Grin2b & Meis1 & Ptpn5 & Stk32b \\
\hline & Neuron & Cxadr & Gap43 & Rasgrp2 & Unspecified & Dcc & Hdac9 & Meis2 & Ptprt & Sub1 \\
\hline & Ablim3 & D11Bwg0517e & Gng2 & Sema3a & 4930506M07Rik & Dclk1 & Khdrbs2 & Msra & Rimklb & Syt5 \\
\hline & Cacna1b & Dcx & Hook1 & Sez6 & Acvr2a & Dock7 & Kif21b & Mylk & Robo2 & Tmem145 \\
\hline & Cacna1e & Dpys13 & L1cam & Spint2 & Adarb2 & Dsg2 & KIhI23 & $\mathrm{Nln}$ & Samd5 & Tnrc4 \\
\hline & Cacna1g & Enc1 & Lmo3 & Stmn2 & B3gnt5 & E130309F12Rik & $\operatorname{Lin} 7 c$ & Nop58 & Satb1 & Tubb5 \\
\hline
\end{tabular}


Table 3. Gene Ontology enrichment analysis

\begin{tabular}{|c|c|c|c|c|c|c|}
\hline GO term & Ontology & Count & Expectation & $\begin{array}{c}\text { Enrichment } \\
\text { score }\end{array}$ & Genes associated with the GO & p-value \\
\hline $\begin{array}{l}\text { regulation of neuron projection } \\
\text { development }\end{array}$ & $\mathrm{BP}$ & 30 & 5.9 & 5.1 & $\begin{array}{l}\text { Cd24a, Cdh2, Cdh4, Cnr1, Dcc, Dpysl3, Ephb2, Inpp5j, Inppl1, Lpar1, Mag, Mapt, } \\
\text { Mbp, Nptn, Omg, Plxna3, Plxnb2, Rap2a, Robo2, Rufy3, Sema3a, Sema3f, } \\
\text { Sema4d, Serpine2, Sgk1, Sphk1, Stmn2, Tnr, Vim, Wnt7a }\end{array}$ & $3.20 \mathrm{E}-08$ \\
\hline cell adhesion & $\mathrm{BP}$ & 51 & 17.4 & 2.9 & $\begin{array}{l}\text { 2310057J16Rik, Acan, Agt, Angpt1, Atp1b2, Bcan, Cd24a, Cd47, Cdh2, Cdh20, } \\
\text { Cdh22, Cdh4, Celsr3, Chl1, Cldn11, Cntn4, Cntnap1, Col14a1, Coro1a, Cpxm2, } \\
\text { Ctnna2, Cxadr, Dsg2, Hapln1, Hapln4, Hspg2, Igsf11, Inppl1, Itga2, Itga6, Itga8, } \\
\text { Kitl, L1cam, Mag, Mcam, Mog, Mycn, Negr1, Nfasc, Nptn, Omg, Pcdh15, Ptprm, } \\
\text { Ptprt, Ptpru, Robo2, Sorbs3, Spp1, Tnc, Tnr, Ttyh1 }\end{array}$ & $6.48 \mathrm{E}-08$ \\
\hline homophilic cell adhesion & $\mathrm{BP}$ & 13 & 1.8 & 7.2 & & $5.88 \mathrm{E}-05$ \\
\hline cell-cell adhesion & $\mathrm{BP}$ & 22 & 6.2 & 3.6 & & 8.46E-04 \\
\hline regulation of neurogenesis & $\mathrm{BP}$ & 37 & 10.5 & 3.5 & $\begin{array}{l}\text { Bmp4, Cd24a, Cdh2, Cdh4, Cnr1, Cntn4, Dcc, Dpysl3, Ednrb, Ephb2, Inpp5j, Inppl1, } \\
\text { Lpar1, Mag, Mapt, Mbp, Meis1, Nptn, Omg, Plxna3, Plxnb2, Rap2a, Robo2, Rufy3, } \\
\text { Sema3a, Sema3f, Sema4d, Serpine2, Sgk1, Sox10, Sphk1, Stmn2, Tcf7l2, Tnr, Vim, } \\
\text { Wnt7a, Zfp488 }\end{array}$ & $1.91 \mathrm{E}-07$ \\
\hline regulation of cell differentiation & $\mathrm{BP}$ & 51 & 22.4 & 2.3 & $\begin{array}{l}\text { Abcg1, Acvr2a, Adamts20, Bmp4, Cd24a, Cdh2, Cdh4, Clu, Cnr1, Cntn4, Ctnna2, } \\
\text { Dcc, Dpysl3, Ednrb, Ephb2, Fbn2, Flt3, Hdac9, Hopx, Inpp5j, Inppl1, Kitl, Lpar1, } \\
\text { Mag, Mapk11, Mapt, Mbp, Meis1, Mitf, Nptn, Omg, Plxna3, Plxnb2, Rap2a, Robo2, } \\
\text { Rufy3, Sema3a, Sema3f, Sema4d, Serpine2, Sgk1, Sox10, Sox8, Sphk1, Stmn2, } \\
\text { Tcf7l2, Tgfb3, Tnr, Vim, Wnt7a, Zfp488 }\end{array}$ & $1.34 \mathrm{E}-04$ \\
\hline axon guidance & $\mathrm{BP}$ & 17 & 3.6 & 4.7 & $\begin{array}{l}\text { Cdh4, Chl1, Dcc, Dpys15, Ephb1, Ephb2, Gap43, L1cam, Nfasc, Nr4a3, Plxna3, } \\
\text { Ptprm, Robo2, Sema3a, Sema3f, Sema5a, Unc5a }\end{array}$ & 3.19E-04 \\
\hline regulation of axonogenesis & $\mathrm{BP}$ & 16 & 3.3 & 4.8 & $\begin{array}{l}\text { Cdh2, Cdh4, Ephb2, Mag, Mapt, Mbp, Omg, Plxna3, Plxnb2, Robo2, Rufy3, } \\
\text { Sema3a, Sema3f, Sema4d, Tnr, Wnt7a }\end{array}$ & $6.74 \mathrm{E}-04$ \\
\hline synapse & $\mathrm{CC}$ & 32 & 11.6 & 2.7 & $\begin{array}{l}\text { Atp1a2, Bcan, Cbln1, Cdh2, Chrm3, Cplx1, Dtna, Ephb2, Erc2, Gabra2, Gap43, } \\
\text { Glra1, Glrb, Gria3, Grin2b, Lgi3, Lin7c, Mme, Otof, Pcdh15, Prkcq, Rasgrp2, Sept3, } \\
\text { Serpine2, Sez6, Slc17a8, Slc1a2, Syt2, Syt5, Unc13b, Vamp1, Whrn }\end{array}$ & 8.69E-04 \\
\hline regulation of signaling & $\mathrm{BP}$ & 73 & 39.7 & 1.8 & $\begin{array}{l}\text { Acvr2a, Adamts20, Agpat9, Agt, Akap7, Angpt1, Apoe, Arhgef10, Arhgef6, Bmp4, } \\
\text { Cacna1b, Cacna1e, Calb1, Cd24a, Cd38, Cd81, Cdh2, Cidea, Cnksr3, Cnr1, Dcc, } \\
\text { Ephb2, Erbb3, F3, Fbn2, Glra1 Gria3, Grin2b, Hhip, Hipk2, Hmgcr, Htra1, Inppl1, } \\
\text { Itga2, Itga8, Kcnj10, Kitl, L1cam, Lmcd1, Lpar1, Mog, Ndrg2, Nptn, Nr1d1, Pde1c, } \\
\text { Phip, Plekhg3, Psd, Psd2, Ramp1, Ramp3, Rap2a, Rasgef1b, Rasgrf1, Rasgrp2, } \\
\text { Rgl1, Rgs4, S100a13, S100b, Serpine2, Sncg, Sorbs3, Sphk1, Tacr1, Tcf712, Tgfb3, } \\
\text { TIr3, Tnr, Trf, Uch11, Unc13b, Wnt7a, Zeb2 }\end{array}$ & 9.97E-04 \\
\hline extracellular matrix & $\mathrm{CC}$ & 26 & 8.4 & 3.1 & $\begin{array}{l}\text { Acan, Adamts1, Adamts16, Adamts18, Adamts20, Adamts4, Bcan, Bmp4, Chl1, } \\
\text { Col14a1, F3, Fbln2, Fbn2, Gpc5, Hapln1, Hapln4, Hspg2, Mmp17, Serpine2, Sod3, } \\
\text { Sparc, Tgfb3, Timp4, Tnc, Tnr, Wnt7a }\end{array}$ & $1.29 \mathrm{E}-03$ \\
\hline $\begin{array}{l}\text { regulation of transmission of } \\
\text { nerve impulse }\end{array}$ & $\mathrm{BP}$ & 22 & 6.4 & 3.5 & $\begin{array}{l}\text { Agt, Cacna1b, Calb1, Cd38, Cdh2, Cnr1, Ephb2, Glra1, Grin2b, Itga2, Kcnj10, Nptn, } \\
\text { Rasgrf1, S100b, Serpine2, Sncg, Sphk1, Tacr1, Tcf7l2, Tnr, Trf, Unc13b }\end{array}$ & $1.50 \mathrm{E}-03$ \\
\hline calcium ion binding & MF & 35 & 14.9 & 2.4 & $\begin{array}{l}\text { Acan, Anxa5, Atp2a2, Calb1, Cdh2, Cdh20, Cdh22, Cdh4, Celsr3, Dgkg, Dsg2, } \\
\text { Dtna, Efhd1, Fbln2, Fbn2, Fstl5, Man1a, Masp1, Mctp2, Mmp17, Otof, Pcdh15, } \\
\text { Pla2g4a, Plcb1, Pls3, Pvalb, Rasgrp2, S100a1, S100a13, S100a6, S100b, Sparc, } \\
\text { Syt2, Tppp, Ttyh1 }\end{array}$ & $9.46 \mathrm{E}-03$ \\
\hline $\begin{array}{l}\text { structural constituent of myelin } \\
\text { sheath }\end{array}$ & MF & 4 & 0.2 & 24.8 & Mal, Mbp, Mobp, Plp1 & 1.07E-02 \\
\hline transporter activity & MF & 56 & 30.0 & 1.9 & $\begin{array}{l}\text { Abcg1, Apod, Apoe, Aqp4, Atp13a4, Atp1a2, Atp1b1, Atp1b2, Atp2a2, Atp2b4, } \\
\text { Cacna1b, Cacna1e, Cacna1g, Cacnb3, Clca1, Clca2, Cox8b, Cplx1, Crabp2, Fxyd6, } \\
\text { Gabra2, Glra1, Glrb, Gltp, Gm2a, Gria3, Grin2b, Itpr2, Kcna2, Kcnj10, Pllp, Ramp1, } \\
\text { Ramp3, S100a6, Scn1a, Slc12a2, Slc12a8, Slc13a3, Slc14a1, Slc17a8, Slc1a2, } \\
\text { Slc39a12, Slc44a1, Slc4a4, Slc6a11, Slc6a17, Slc6a5, Slc7a10, Slco1a4, Slco2a1, } \\
\text { Syt2, Syt5, Trf, Trpc3, Trpm3, Ttyh1 }\end{array}$ & 1.83E-02 \\
\hline metal ion homeostasis & $\mathrm{BP}$ & 21 & 7.1 & 3.0 & $\begin{array}{l}\text { Agt, Apoe, Atp1a2, Atp2a2, Cacna1g, Casr, Cd24a, Cd38, Ednrb, Hrc, Kcnj10, } \\
\text { Lpar1, Nptn, Oprl1, Plcg2, Pygm, S1pr1, Sgk1, Stc1, Tacr1, Trf }\end{array}$ & $3.42 \mathrm{E}-02$ \\
\hline
\end{tabular}




\section{Figure 1}
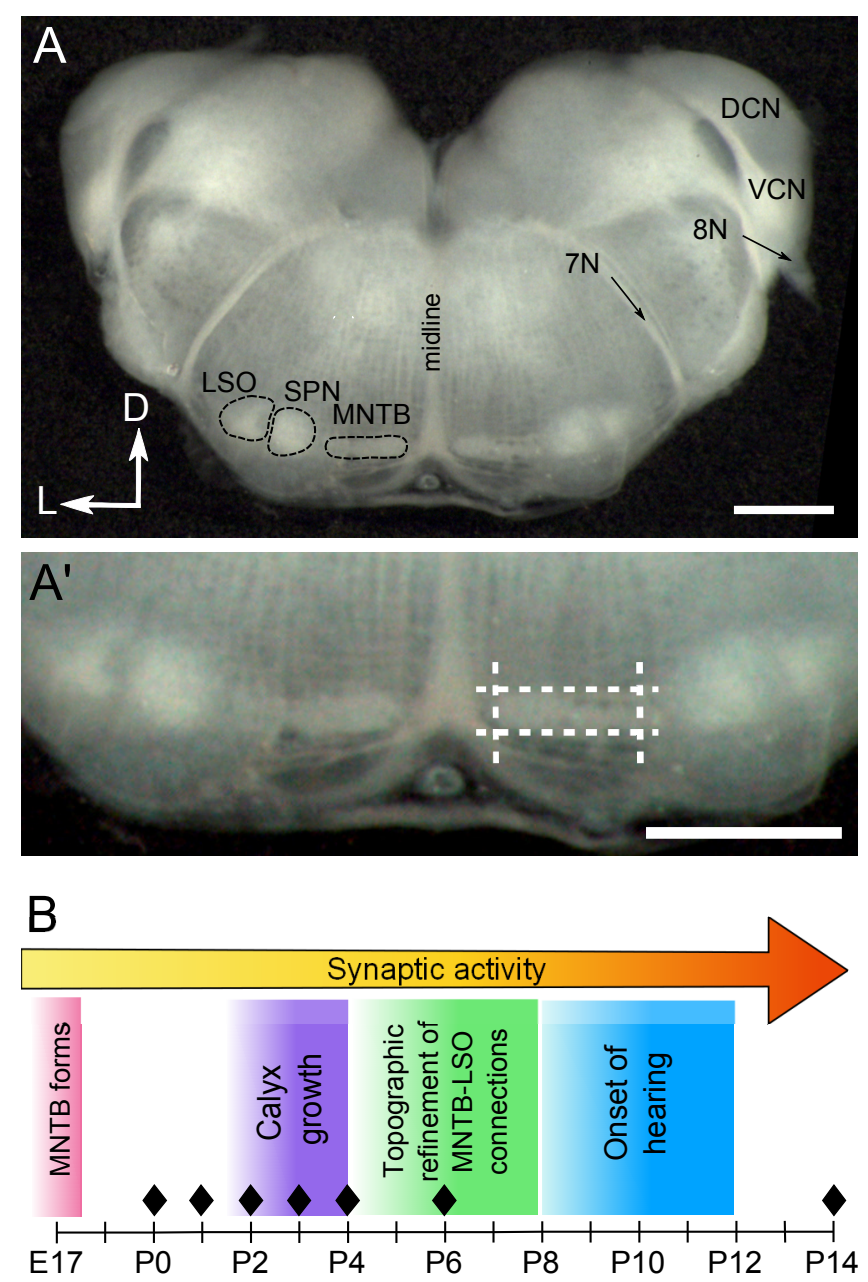

Figure 1. Tissue harvesting and experimental design. A, Example of a freshly prepared brain slice of $\sim 200 \mu \mathrm{m}$ thickness at P3 showing auditory cell groups and landmarks. Scale bar is $500 \mu \mathrm{m}$. MNTB, medial nucleus of the trapezoid body; SPN, superior paraolivary nucleus; LSO, lateral superior olive; DCN, dorsal cochlear nucleus; VCN, ventral cochlear nucleus; $7 \mathrm{~N}$, seventh cranial nerve; $8 \mathrm{~N}$, eighth cranial nerve; D, dorsal; L, lateral. A', Dashed lines show cuts made to extract MNTB tissue (marked with asterisk) for RNA collection. B, Timeline illustrating major events in early MNTB development, designated by colored blocks. Samples were collected at time points marked with black diamonds. 


\section{Figure 2}
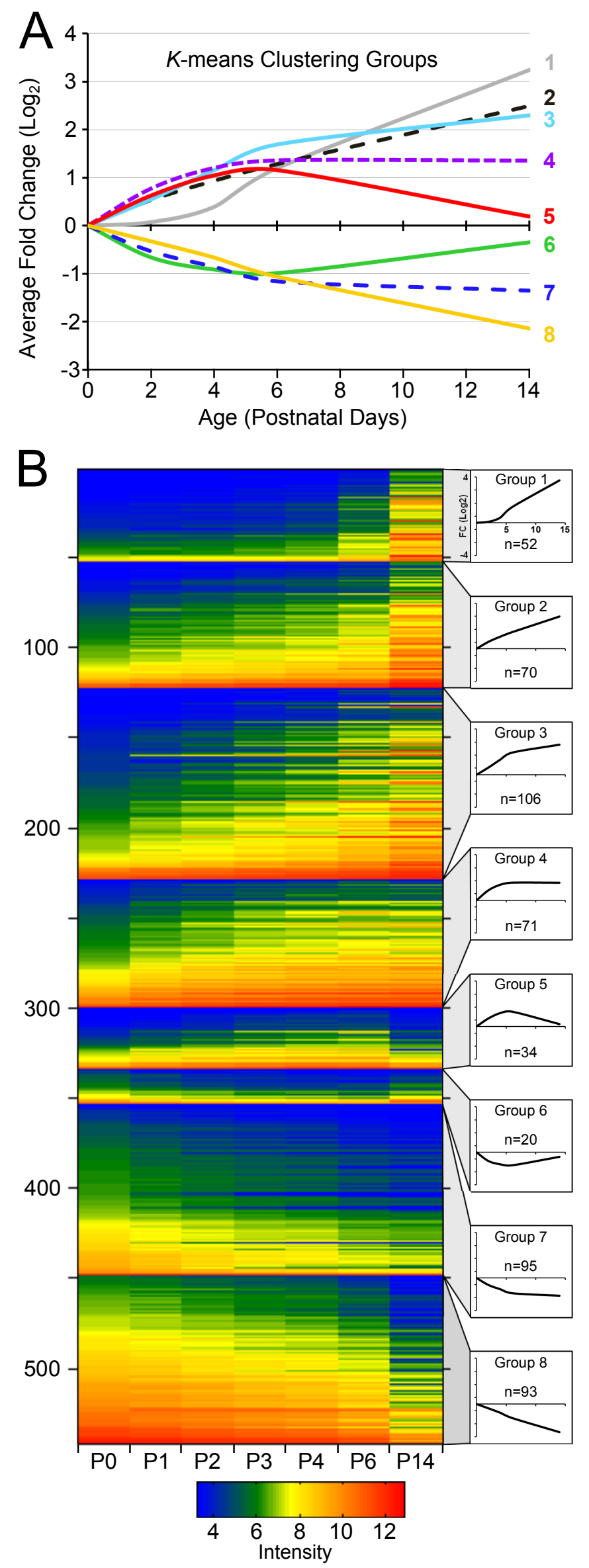

Figure 2. Significantly changing genes grouped into eight temporal expression clusters. A, Group profiles after performing $k$-means clustering analysis $(k=8)$ with correlation metrics. Four groups showed an increase, two groups showed a decrease in expression, while two groups (5 and 6) showed more complex temporal dynamics. B, Heat map of the 541 genes showing the average signal intensity for each gene at a given age as listed across the bottom. The colors correlate to normalized microarray signal intensity values from 4 (blue) through 12 (red). Genes are arranged by clustering group (Group 1 at top) and by increasing microarray signal intensity at P0 within each group. The total number of the 541 genes is designated on the left. The number of genes belonging to each group is shown on the associated graph. 


\section{Figure 3}

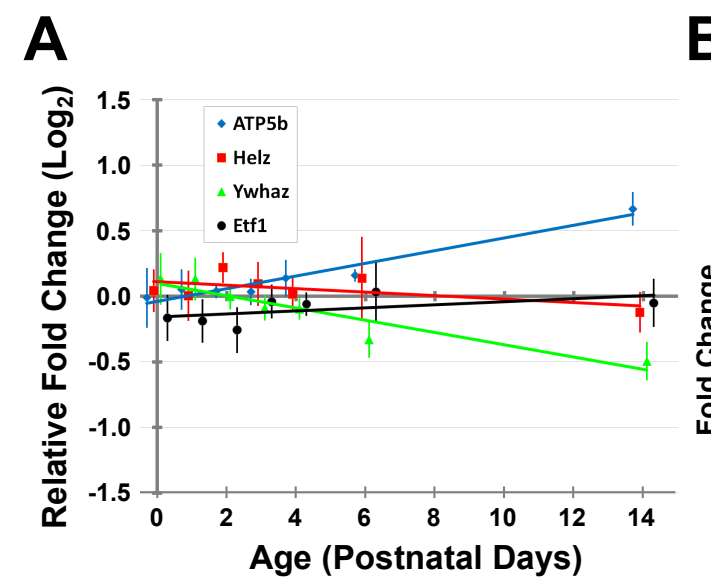

B

C

PO
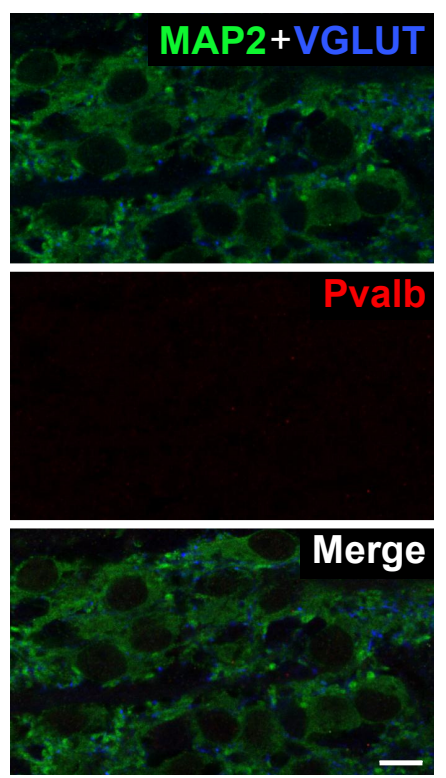

P3
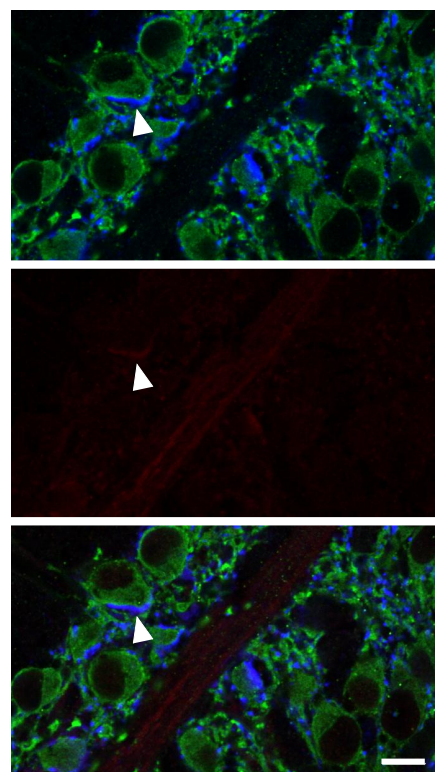

Microarray

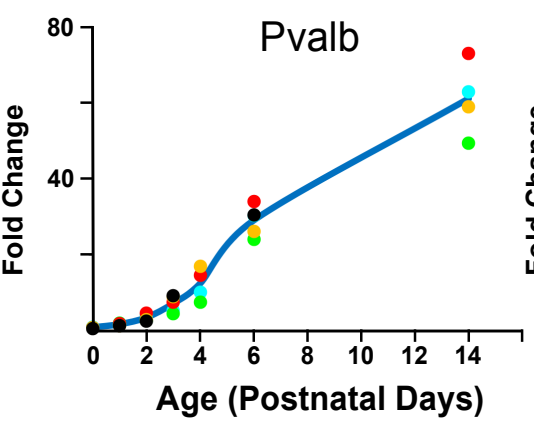

P6
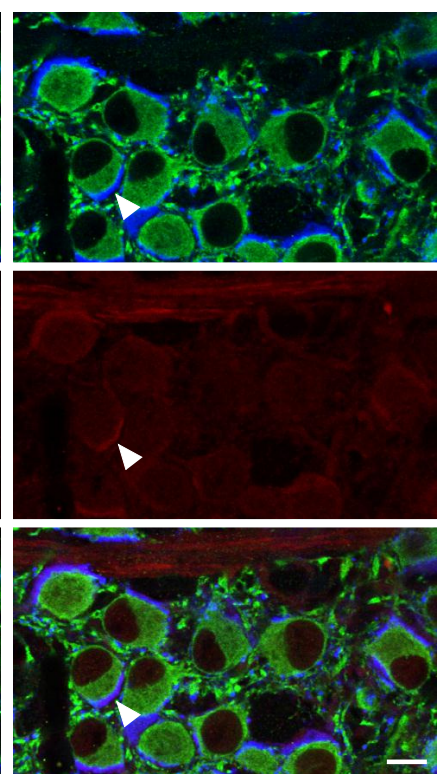

qPCR

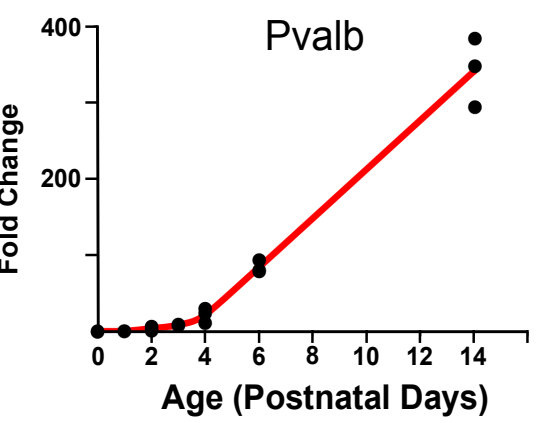

P14
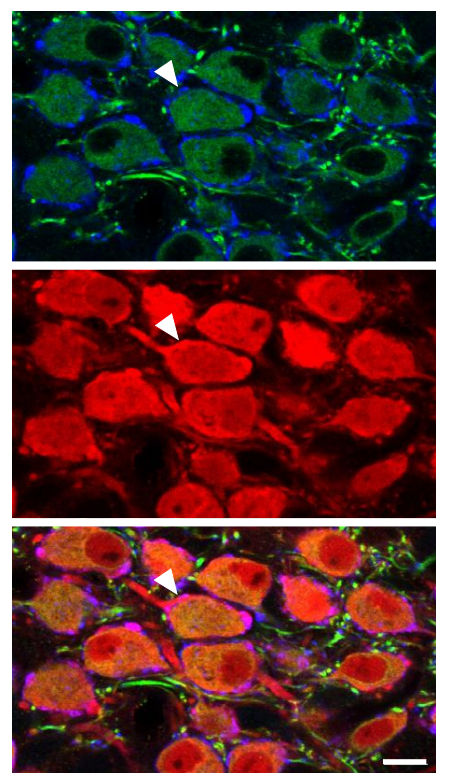

Figure 3. Microarray data were validated by $\mathrm{PPCR}$ and confirmed with protein expression measured by immunofluorescence. A, Reference genes (ATP5b, Ywhaz, Helz, and Etf1) were selected from the least significantly changing transcripts in the microarray data, as they showed the greatest stability across the age range studied (P0, P1, P2, P3, P4, P6, P14). Each gene was normalized to the geometric mean of expression for the group (see methods for details). B, Parvalbumin (Pvalb) microarray and qPCR results exhibit similar temporal profiles and differ only in dynamic range of changing expression levels. Data were normalized to the geometric mean of the four reference genes and shown relative to values at P0. In the microarray plot, similar color symbols represent littermates across ages, while different color symbols distinguish different litters. qPCR data points were generated from pooled animal samples (4-6 littermates); each symbol represents a different litter. C, Anti-Pvalb (red) immunofluorescence increases in MNTB neurons between P0 and P14. Pvalb is not detected at P0. At P3 and P6, Pvalb is mostly located in axons (weakly at P3) and growing calyces of Held (white arrowheads). Calyces are indicated by co-localization with anti-vesicular glutamate transporter (VGlut) 1 and 2 (blue), which label the growing and mature calyx. At P6, low levels of Pvalb are evident in MNTB neurons, which are marked by Anti-microtubule-associated protein 2 (MAP2) (green) expression at all ages. By P14, strong Pvalb expression is observed in the MNTB neurons, calyces, and their axons. Scale bars $=10 \mu \mathrm{m}$. 


\section{Figure 4}

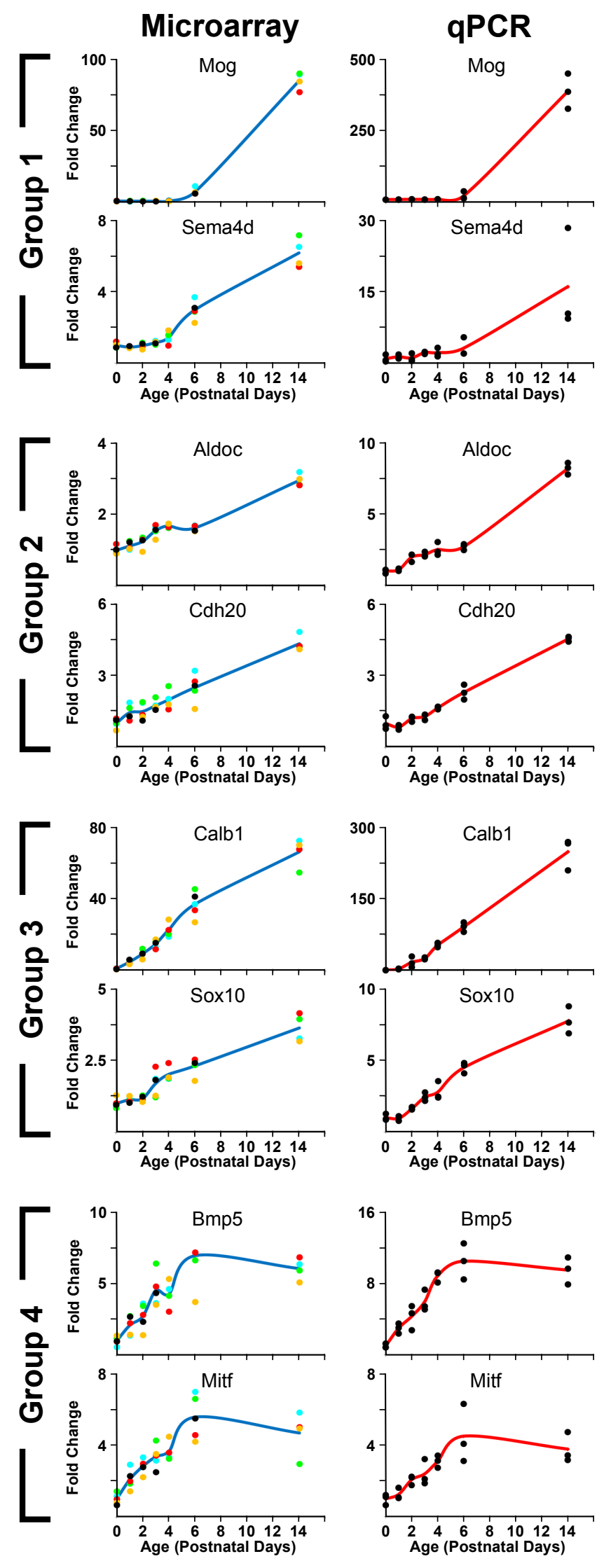

Figure 4. Confirmation of microarray results for selected genes showing increasing MNTB expression.

Gene expression profiles from groups 1-4 were assayed by microarray and validated by qPCR. Two representative genes from each group are shown. Plot format is the same as in Figure 3. Note that the fold-change scale is generally larger for qPCR than for microarray data, especially for large changes. Abbreviations: Mog- myelin oligodendrocyte glycoprotein; Sema4d- semaphorin 4d; Aldoc- aldolase C, fructose-biphosphate; Cdh20- cadherin 20; Calb1- calbindin 1; Sox10- SRY-box containing gene 10; Bmp5- bone morphogenetic protein 5; Mitf- microphthalmia-associated transcription factor. 


\section{Figure 5}

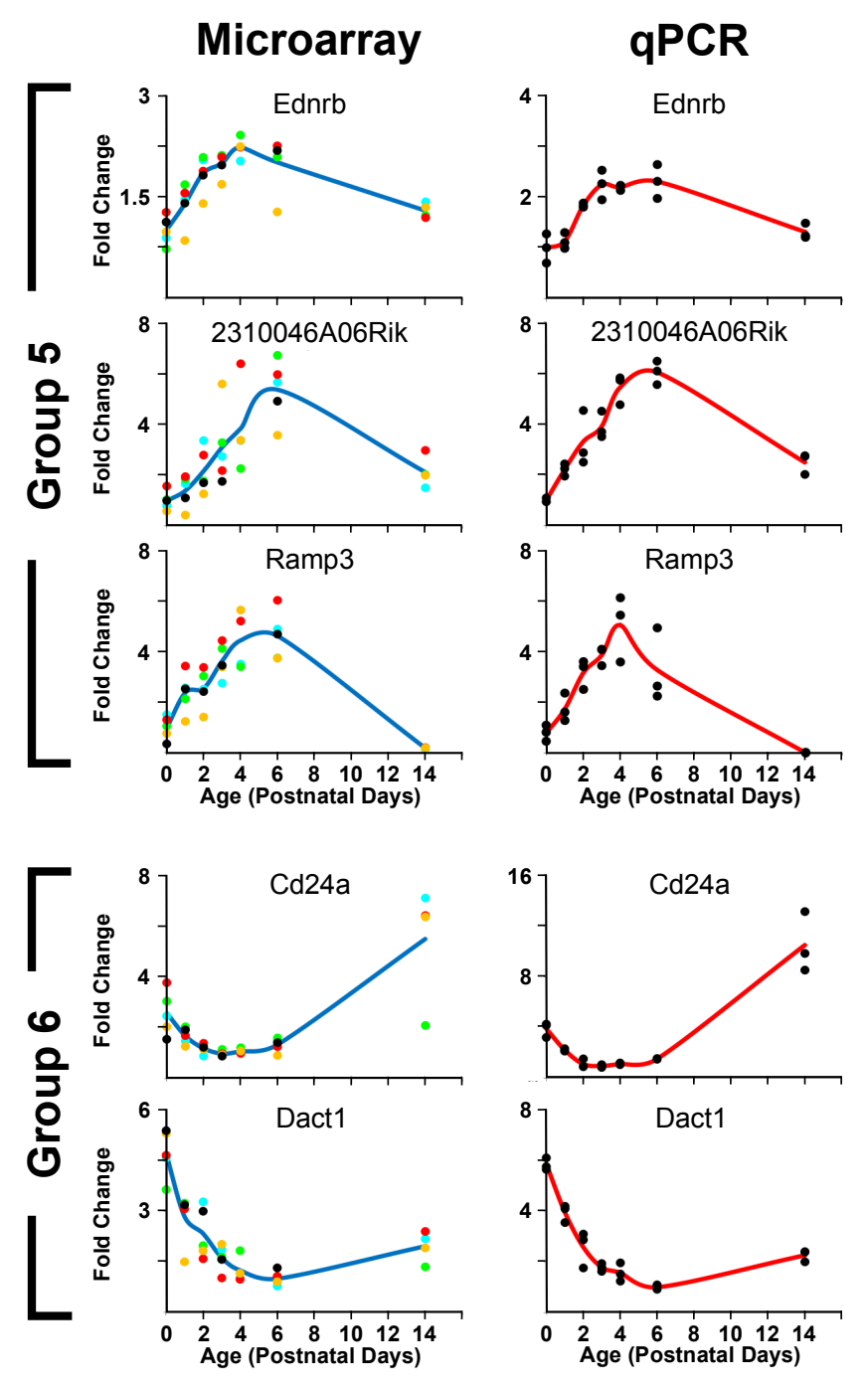

Figure 5. Confirmation of microarray results for selected genes showing complex MNTB expression. Gene expression profiles from groups 5 and 6 were assayed by microarray and validated by qPCR. Representative genes from both groups are shown. Plot format is the same as in Figure 3. Abbreviations: Ednrb- endothelin receptor type B; 2310046A06Rik- Riken cDNA 2310046A06; Ramp3- receptor (calcitonin) activity modifying protein 3; Cd24aCd24a antigen; Dact1- dapper homolog 1, antagonist of beta-catenin (Xenopus). 
Figure 6
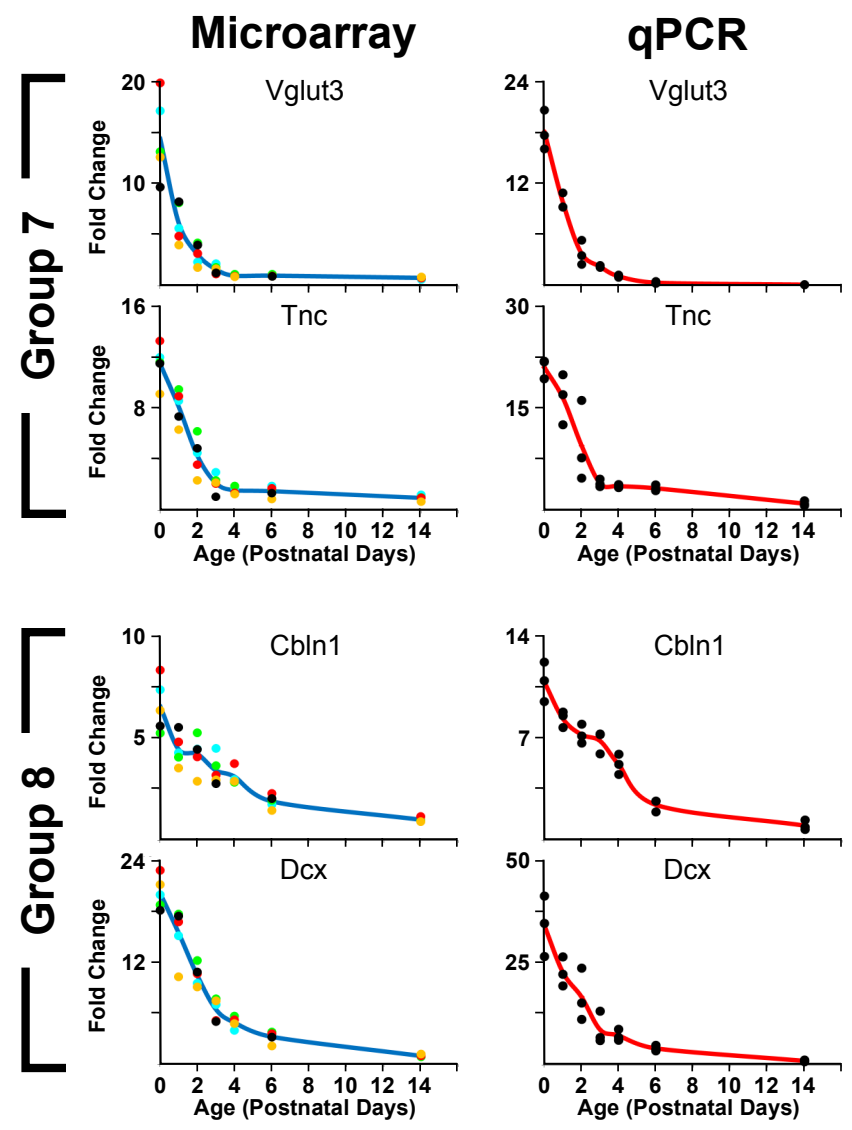

Figure 6. Confirmation of microarray results for selected genes showing decreasing MNTB expression.

Gene expression profiles from groups 7 and 8 were assayed by microarray and validated by qPCR. Two representative genes from each group are shown. Plot format is the same as in Figure 3. Note that different foldchange scale is generally larger for GPCR. Abbreviations: Slc17a8- solute carrier family 17 (sodium-dependent inorganic phosphate cotransporter), member 8 (Vglut3); Tnc- tenascin C; Cbln1- cerebellin 1 percursor protein; Dcxdoublecortin. 


\section{Figure 7}

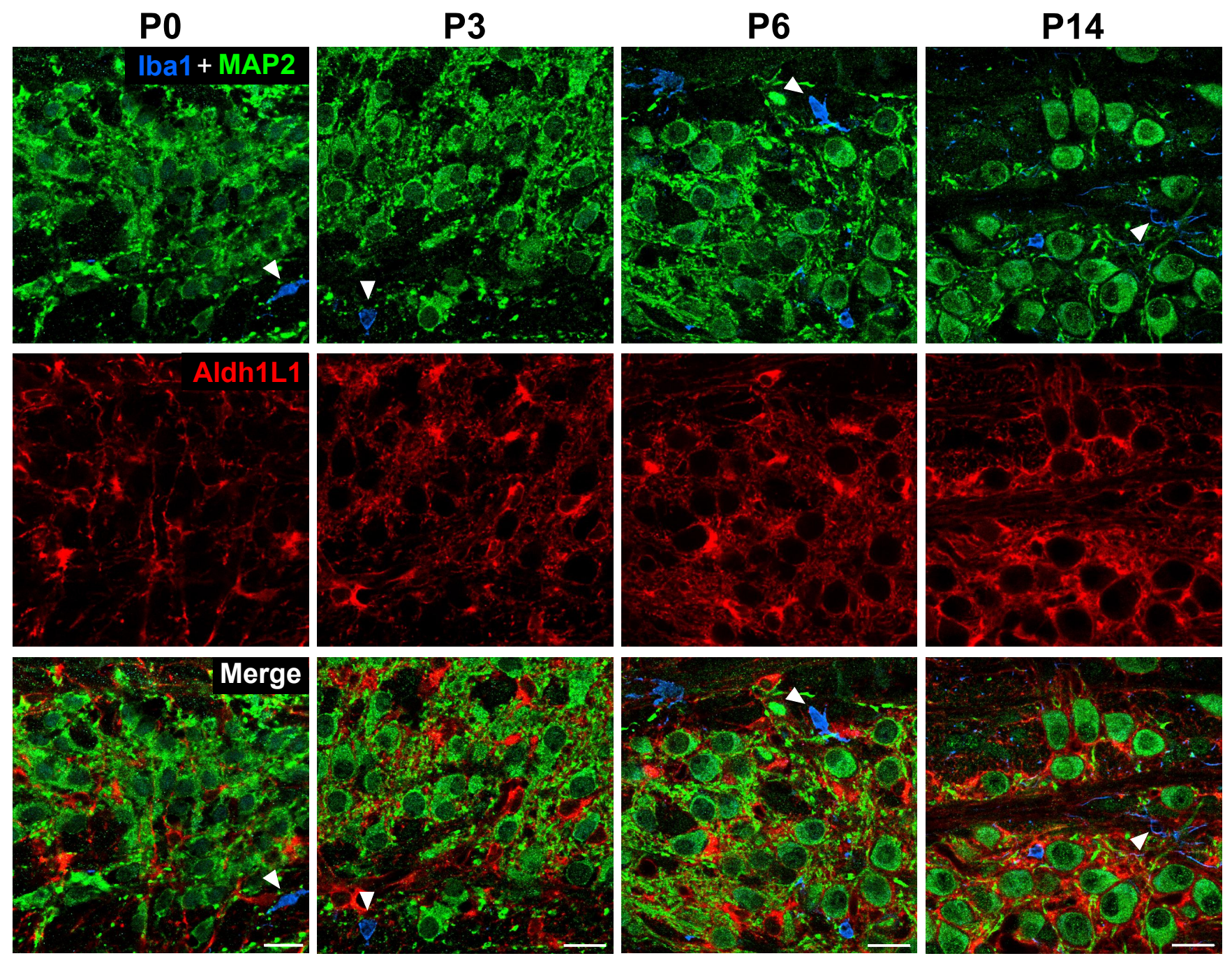

Figure 7. Neurons, astrocytes, and microglia are shown in the MNTB across the ages of P0 to P14. Neurons are labeled with anti-MAP2 (green), astrocytes are labeled with anti-aldehyde dehydrogenase 1 family, member L1 (Aldh1L1)(red), and microglia are labeled with anti-ionized calcium binding adaptor molecule 1 (Iba1)(blue). There are few microglia detected in the area of the MNTB, but they are visible at all ages. Some examples of microglia are marked with white arrowheads at each age. There is no co-localization between any of the markers. Scale bars $=20 \mu \mathrm{m}$. 


\section{Figure 8}
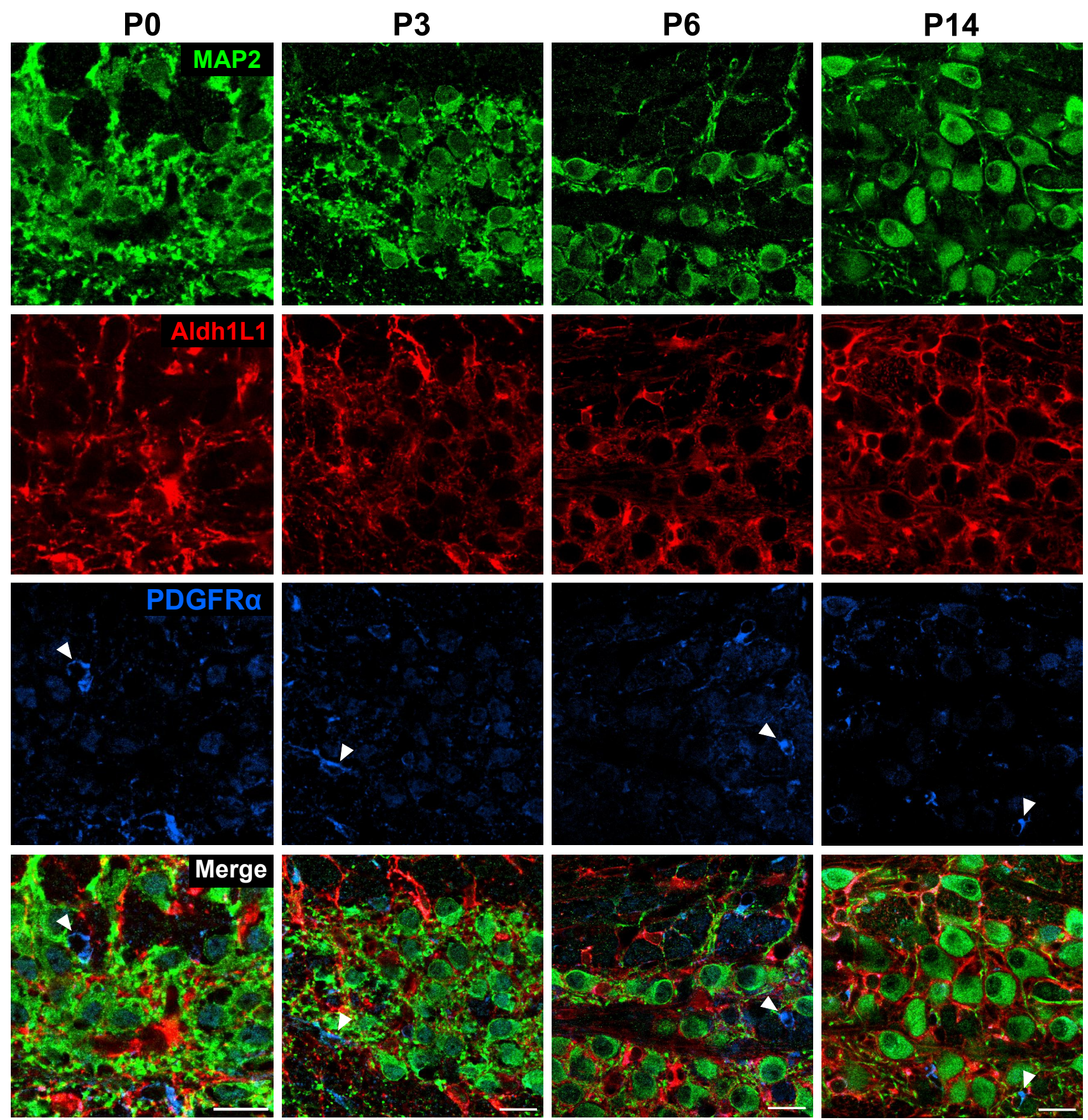

Figure 8. Oligodendrocyte precursors can be found in the MNTB across the ages of P0 to P14. Neurons are labeled with anti-MAP2 (green), astrocytes are labeled with anti-Aldh1L1 (red), and oligodendrocyte progenitor cells are labeled with anti-platelet-derived growth factor receptor alpha (PDGFRa)(blue). There is moderate non-specific labeling in the neurons from the antibody against PDGFRa, but the cells exhibiting the strongest labeling are distinct from the neurons or astrocytes. Examples are marked with white arrowheads at each age. Scale bars $=20 \mu \mathrm{m}$. 


\section{Figure 9}
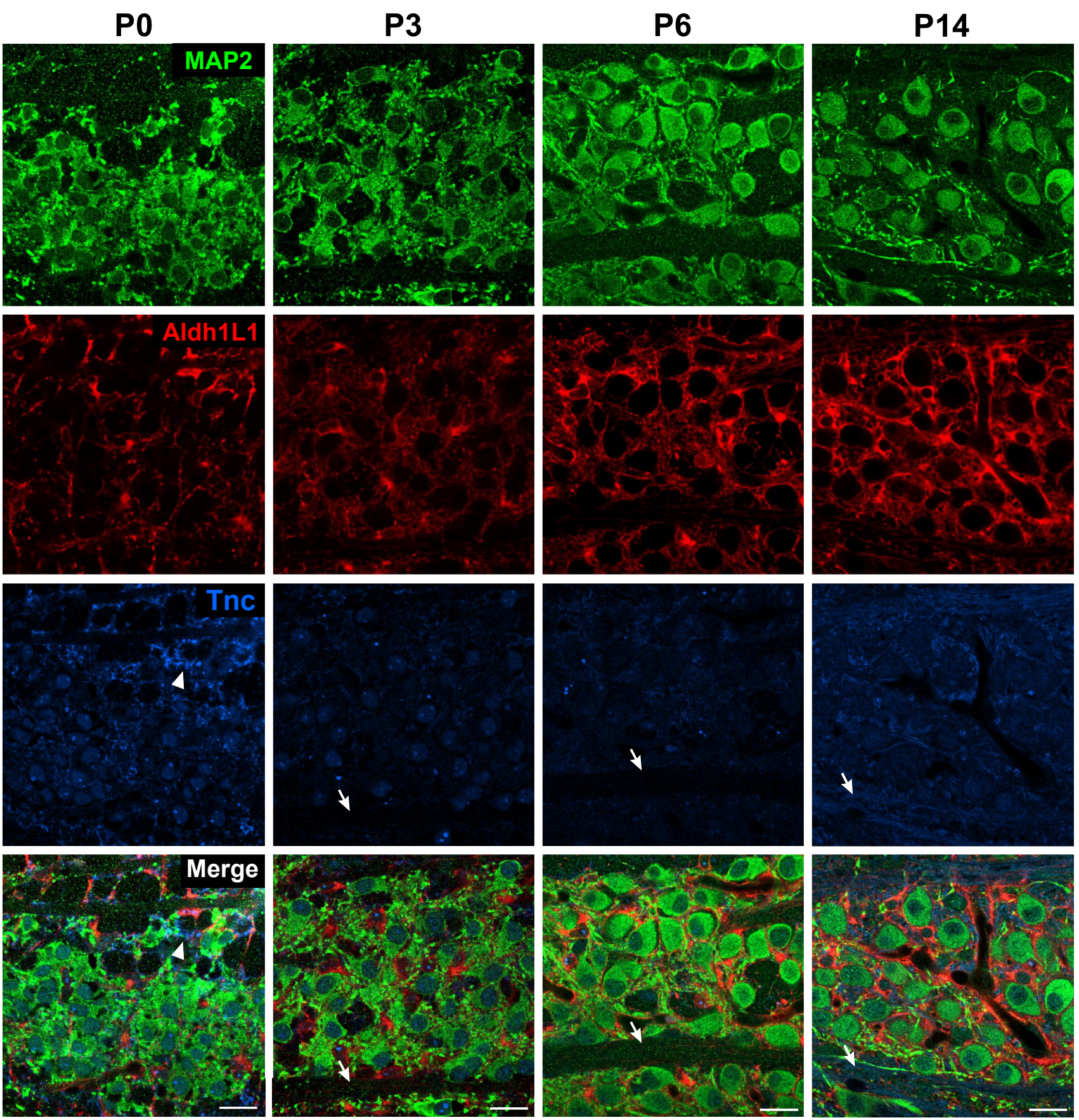

Figure 9. Tenascin $C$ (Tnc) expression patterns show changing localization between P0 and P14. Neurons are labeled with anti-MAP2 (green) and astrocytes are labeled with anti-Aldh1L1 (red). Anti-Tnc (blue) immunofluorescence is the highest at PO (white arrowhead) and does not co-localized well with neuron or astrocyte labeling. Tnc labeling is low but detectable at P3 and P6. At P14, the labeling pattern is much different with the antibody against Tnc showing increased signal in the axon tracts and cross-cut fibers passing through the MNTB (axon tracts marked with white arrows). Nuclei, and even some nucleoli, seem to be labeled strongly with the Tnc antibody at P0. This nuclear labeling decreases through P6 and disappears by P14. Scale bars $=20 \mu \mathrm{m}$. 


\section{Chapter 4: Conclusions}

Genes involved in the formation and growth of synaptic contacts have been sought for many years using many different experimental systems. In these two studies, we have examined transcriptional changes that occur during early postnatal development of the MNTB. This brain region has advantages that may help us interpret data derived from an extremely complex set of processes, such as containing predominantly one neuronal subtype and the rapid growth of its presynaptic terminal. This allows for linking some of the gene expression profiles to characterized events including synapse formation and tissue organization. In the first study, we examined the temporal gene expression profiles for some of the well-studied voltage-gated potassium channels in MNTB neurons during the time frame surrounding growth of the calyx of Held. In the microarray study, we found 541 significantly changing genes using a $0.1 \%$ FDR between P0 and P6, and these genes were assigned to 8 different groups based upon the shapes of their temporal expression profiles.

Although our study utilizes a system that offers some distinct advantages, similar studies in other developing systems have yielded results showing significant overlap with our own results. One recent study by Bruses (2010) focuses entirely on potential synaptogenic factors present during synapse formation in the chick ciliary ganglion, limiting the scope to membrane-bound and secreted factors (Bruses, 2010). The ciliary ganglion is a structure behind the eye that controls constriction of the pupil and focusing of the lens. Ciliary neurons of the chick, unlike those of mammals, develop large calyceal presynaptic terminals that are similar in appearance to calyces of Held in the MNTB of the mouse. At E5, preganglionic afferent fibers from the mesencephalon reach the chick ciliary ganglion, but there is no detectable synaptic transmission at this age (Landmesser \& Pilar, 1976). Between E6 and E8, bouton-like synaptic contacts form between the preganglionic fibers and the ciliary ganglion neurons (Landmesser \& 
Pilar, 1978). The calyx-like presynaptic terminals differentiate between E9 and E12, reaching an anatomically and physiologically mature state by E17 (Landmesser \& Pilar, 1972; 1978). In his study, Bruses collected tissue at E5, E8, E10, and E17, corresponding to the different developmental stages of the ciliary ganglion neurons and their presynaptic terminals. He identified 51 genes encoding cell surface proteins that showed a 2-fold or greater increase in expression between E5 and E8, and these were considered to be the most likely candidates for involvement in synapse formation (Bruses, 2010).

From the list of 51 genes that Bruses identified, 27 of them were associated with the cell membrane, mostly involved in cell adhesion and ligand/receptor interactions. The other 24 genes were secreted factors, including genes associated with the extracellular matrix, neuropeptides, and cytokines/growth factors. Comparing this list of 51 genes to our list of 541 significantly changing genes reveals some interesting similarities even though only 5 of the genes are identical between the two studies (Igsf11, Kirrel3, Cntnap1, Lrrtm3, and Col14a1). Cell adhesion molecules stand out as important components in both studies, and both gene lists have some cadherins, protocadherins, and contactins. Genes encoding proteins associated with the extracellular matrix can be found from each study with collagen type-XIV (Col14a1) appearing on both lists. One of the most interesting genes found on both lists is leucine-rich repeat transmembrane neuronal 3 (Lrrtm3), which is a mostly-uncharacterized member of the Lrrtm family. Even though Lrrtm3 is not well-studied, Lrrtm1 and Lrrtm2 have been strongly implicated in the maintenance of excitatory synapses (Ko et al., 2011) and as synaptic organizers (Linhoff et al., 2009). Most of the relationships between genes in these two sets of experiments are by association between family members, with similar roles often being performed by related genes within a given family. To highlight some examples of these parallels, somatostatin, cerebellin 1 percursor protein, and eph receptor A6 were identified in our MNTB study while somatostatin II, cerebellin 4 precursor protein, and eph receptor A5 were 
identified in Bruses' study. These observations all support the idea that as our understanding of synaptic growth and maturation becomes more complete, governing principals controlling these processes that are applicable to many systems and species will begin to emerge.

Another system that has been used often for genetic studies and has some interesting parallels to our work is the developing cerebellum. Comparisons between studies can be challenging when considering the differences in data analysis and reporting for information, especially regarding the criteria used for gene ontology categorization. One of the best data sets for comparison to ours, as well as one of the earliest global genetic studies in the developing cerebellum, was performed by Kagami and Furuichi (2001). They analyzed samples collected at five ages surrounding developmental events in the cerebellum (E18, P7, P14, P21, and P56) to develop a list of 897 differentially changing genes during this period of time (Kagami \& Furuichi, 2001). Ontology and peak expression ages for the identified genes were the focus of this study. Cell adhesion and cytoskeleton are both represented with many of these genes showing their peak expression at the younger ages of E18 and P7, but some of them also displayed varying expression profiles similar to those we found in the MNTB. Interestingly, several prominent members from our study had been found in these experiments by Kagami and Furuichi, such as $\mathrm{N}$-cadherin and tenascin $\mathrm{C}$. Myelination genes peaked exclusively at $\mathrm{P} 21$, which agrees in part with our data in that we saw drastic increases through P14 but we did not collect the later time points for further comparison. Genes associated with proliferation peaked at P7 in the cerebellum study but did not appear on our GO lists from the MNTB, probably reflecting the continued granule cell proliferation associated with these ages in the developing cerebellum. Since both studies had rather large lists of genes (541 and 897), comparing individual genes becomes less meaningful as it is not surprising to find a good deal of overlap between two areas of the developing brain. As would be expected, several features of the data from Kagami and 
Furuichi (2001) line up well with the results of our study while others appear to reflect differences inherent in the systems and the time points being examined.

A different study of the cerebellum from Takahashi et al. (2005) focused on their "Synaptoarray", which was a custom DNA microarray for detecting 172 genes expected to be involved in synapse formation (Takahashi et al., 2005). As part of this study, they did a screen of genes using Agilent microarrays that varied between P7 and P15 in both control and hypothyroid mice, and the partial list of functionally characterized genes that differed between P7 and P15 control mice was compared to our 541 genes list. There were only 6 genes out of the 59 listed that appeared in both studies (Cd24a, Tubb5, Calb1, Eps8, Plp1, and Aldoc). Comparison of our results directly with the 172 genes on the Synaptoarray would yield little information, as those genes were specifically chosen based upon their presence in the cerebellum. The minimal overlap detected between these data sets is somewhat surprising and most likely reflective of the fact that the study by Takahashi et al. (2005) only used two time points, one of which was much later than the time points used in our MNTB study.

When comparing some of the results from our study to the earlier SAGE study done by Nothwang et al. (2006), there is a good deal of overlap as would be expected since MNTB tissue was included in their SOC dissection (Nothwang et al., 2006). From their list of the 33 genes that were most significantly upregulated in the SOC when compared to both striatum and hippocampus, 10 of the genes appeared on our 541 list (Mbp, Plp, Atp1b1, Mag, Cplx1, Aldoc, Atp1a2, Trf, Ndrg2, and Vamp1). When looking at these how these genes were categorized in our microarray study (Chapter 3 Table 3), all 10 of the genes belong to groups 1-4 displaying increasing expression profiles with 6 of them in group 3. In regards to the cell-type enrichment, 4 of them are associated with oligodendrocytes (Mbp, Plp, Mag, Trf) and 3 with astrocytes (Aldoc, Atp1a2, and Ndrg2). Considering that the SOC tissue was collected from 2-month-old 
rats and the MNTB tissue was collected from mice between P0 and P6, there is a relatively large overlap between these data sets. Since the list of 33 genes shows highly expressed genes in the adult SOC, many of these genes must begin their increase in expression at early postnatal ages.

From our studies in the MNTB, we learned a great deal of information about the temporal profiles of gene expression during periods of rapid change in calyx structure. Although we found interesting dynamics for the Kv channel and Hcn subunits, there are several questions that still need to be answered. Considering the differential regulation of each Kv3.1 isoform (Liu \& Kaczmarek, 1998a), the individual splice variants should be studied with unamplified qPCR. Although some of that information is available in the microarray exon-level data that is already collected, it has not been fully analyzed. Since Hcn1 was not shown previously to be one of the Hen subunits within the MNTB yet was detected by the microarray, the Hon1 channel should be tested with unamplified qPCR to confirm its presence and temporal dynamics. In order to get a more complete picture including the most pertinent ion channels, Kv2.2 could be added to the experiments as it has been shown to play a role in the rapid action potential firing of the MNTB (Johnston et al., 2008b). Since the composition of individual channels cannot be determined, the abundance of mRNA for different channel subunits relative to one another could provide insight into developmental dynamics. This could be accomplished using a more quantitative approach including transcript copy number analyses for many of these channels. Finally, some subunit-specific toxins could be utilized in MNTB slice recordings to determine the contribution of specific proteins encoded by these gene transcripts. Although we now have a good deal of information about channel families, there is much less known about individual subunit function and how it changes over time in parallel with the growth and maturation of the calyx of Held/MNTB. 
Another improvement that could be made to the ion channel study would be with an overhaul of the reference genes as was done in the microarray study. Many of the gene expression profiles generated from the qPCR experiments in the ion channel studies show more variation between consecutive ages than would be expected from a biological perspective. Since all of the qPCR data were normalized to internal reference genes, we think that our chosen reference genes may not have completely stable developmental expression within the MNTB, thus causing some of the variability in the data. The techniques for properly performing qPCR experiments are constantly becoming more refined (Bustin et al., 2009) and recent experiments in our laboratory have adopted the use of four internal reference genes that were validated for their stability across time in the developing MNTB. Although these data would not be expected to change significantly, it is likely that some of the results would improve with more appropriate internal reference genes.

The microarray studies showed strong agreement with the qPCR data. There are numerous additional experiments that can be done to delve into the complex temporal dynamics of the developing MNTB/calyx of Held system. A good starting point would be choosing several of the most interesting genes from groups 5 and 6 as their shapes in comparison to the time course of developmental events would indicate involvement in the growth and stabilization of the calyceal synapses. These groups show highly dynamic regulation within a narrow time window, and that suggests the importance of precise levels of these proteins during the significant events known to occur during these same time periods. Although there is not always a direct correlation between mRNA and protein levels, transcriptional regulation is considered to be the most common mechanism for controlling protein levels. Three genes of high priority for further study are small muscle protein, X-linked (Smpx), Riken cDNA 2310046A06, and Lrrtm3, all from group 5. Smpx has recently been associated with progressive hearing impairment in humans (Schraders et al., 2011), which implicates it as having an important role in the auditory system. 
Riken cDNA 2310046A06 has not been well-studied previously with next to nothing known about its role in the brain, and Lrrtm3 has potential roles in synaptic maintenance and organization as mentioned earlier. Based upon this information along with their enticing profiles and expression levels, they make excellent candidates for further work utilizing in vitro neuronal culture systems to further characterize their functions.

The ways in which activity, and the resulting increases in intracellular calcium, can influence gene expression is a topic of great interest in current neuroscience research. Since the calyx of Held grows and begins to mature before the onset of hearing, there have to be other factors outside of experience-dependent activity influencing its proper development. It has been shown that ATP waves in the developing cochlea generate bursts of activity in spiral ganglion neurons from about P1 until the onset of hearing (Tritsch \& Bergles, 2010), and this spontaneous activity prior to the onset of hearing plays a role in neuronal survival and normal development of the auditory system (Mostafapour et al., 2000; Glueckert et al., 2003). On the other hand, it has also been shown that calyces of Held form in the absence of auditory nerve activity in congenitally deaf mice (Youssoufian et al., 2005), making the functional implications of this patterned activity difficult to assess. Based upon the timing coincidence between the emergence of bursting activity driving MNTB neurons and the major growth phase of the calyces of Held, it is quite feasible that this change in activity is one of the triggers initiating changes in maturation and gene expression. This idea has been set forth in several papers ((Hoffpauir et al., 2010; Rusu \& Borst, 2011) and warrants further investigation in the future.

Aside from the evaluation of activity patterns and their necessity for normal development, the basic premise of activity-based gene expression changes has long been established (reviewed by West \& Greenberg, 2011). From the discovery of the first immediate early genes, such as Jun and Fos, the concept arose that activity can quickly result in increased gene expression in 
many different systems by increasing intracellular calcium levels inside of a neuron (Greenberg et al., 1986; reviewed by Greer \& Greenberg, 2008). More specifically, several studies have already linked changes in intracellular calcium levels to changes in potassium channel gene expression in MNTB neurons (Liu \& Kaczmarek, 1998b; Tong et al., 2010). Changes in calcium levels would be expected to coincide with the significant changes in the biophysical properties of MNTB neurons preceding and during calyx of Held growth (Hoffpauir et al., 2006) and have been directly observed in electrophysiology slices (Hoffpauir et al., 2010). In our microarray experiments, one of the most enriched GO categories in Table 3 was calcium ion binding, and there were 35 genes in that group which highlights the biological significance of precise management of calcium levels in this developing system. The mode of calcium entry as well as its localization within the cell is important, with different signaling cascades arising based upon these factors (Zhang et al., 2009; reviewed by West \& Greenberg, 2011). These are difficult areas of research, and further experiments examining the activity and calcium dependence of the gene expression changes we observed in our study could prove quite useful to the current knowledge base in these areas.

One of the challenges often present in these global studies is the lack of accurate or relevant Gene Ontology information for many of the genes. A surprisingly large number of significantly changing genes identified in our microarray experiment, greater than $30 \%$, have poorlycharacterized functions within the brain. This is especially prominent in groups 5 and 6 , which are potentially some of the most interesting genes based upon their profiles. Since many of the analyses are based upon the number or percentage of genes present with certain functions, this severely hampered our Gene Ontology, functional clustering, and pathway analyses. Since the databases are constantly being updated as more information becomes available, it is likely that reanalyzing these data in the future would provide additional insight into MNTB development. 
Several levels of information still exist in the microarray data and have yet to be explored. Our analysis focused on the periods of time surrounding growth of the calyx of Held, but we also have microarray data at P14, after the onset of hearing, and these data still need to be explored. We also have not examined the exon-level data from the microarray experiments, and alternative splicing now being considered as a major control mechanism during brain development (Grabowski, 2011). Another complexity to these experiments lies in the level of depth to which the mouse genome was examined. All of our data were generated using the core-level genes, which are well-characterized and annotated with the most accuracy. However, there is a myriad of additional information present in the microarrays at both the extended and full level of gene analysis. These analyses will require significant additional effort to organize and consider, but these data have already been collected. As more advancement is made to understanding the mouse transcriptome, these data will prove quite useful in future studies. 


\section{Literature Cited}

Adams, J.C. \& Mugnaini, E. (1990) Immunocytochemical evidence for inhibitory and disinhibitory circuits in the superior olive. Hear Res, 49, 281-298.

Altman, J. (1972) Postnatal development of the cerebellar cortex in the rat. J Comp Neurol, 145, 353514.

Attali, B., Wang, N., Kolot, A., Sobko, A., Cherepanov, V. \& Soliven, B. (1997) Characterization of delayed rectifier Kv channels in oligodendrocytes and progenitor cells. J Neurosci, 17, 8234-8245.

Bahr, S.M., Borgschulte, T., Kayser, K.J. \& Lin, N. (2009) Using microarray technology to select housekeeping genes in Chinese hamster ovary cells. Biotechnol Bioeng, 104, 1041-1046.

Banks, M.I. \& Smith, P.H. (1992) Intracellular recordings from neurobiotin-labeled cells in brain slices of the rat medial nucleus of the trapezoid body. J Neurosci, 12, 2819-2837.

Barry, J., Gu, Y. \& Gu, C. (2010) Polarized targeting of L1-CAM regulates axonal and dendritic bundling in vitro. Eur J Neurosci, 32, 1618-1631.

Bekar, L.K., Loewen, M.E., Cao, K., Sun, X., Leis, J., Wang, R., Forsyth, G.W. \& Walz, W. (2005) Complex expression and localization of inactivating $\mathrm{Kv}$ channels in cultured hippocampal astrocytes. $J$ Neurophysiol, 93, 1699-1709.

Belachew, S., Chittajallu, R., Aguirre, A.A., Yuan, X., Kirby, M., Anderson, S. \& Gallo, V. (2003) Postnatal NG2 proteoglycan-expressing progenitor cells are intrinsically multipotent and generate functional neurons. J Cell Biol, 161, 169-186.

Benoit, C.E., Rowe, W.B., Menard, C., Sarret, P. \& Quirion, R. (2011) Genomic and proteomic strategies to identify novel targets potentially involved in learning and memory. Trends Pharmacol Sci, 32, 43-52.

Bergsman, J.B., De Camilli, P. \& McCormick, D.A. (2004) Multiple large inputs to principal cells in the mouse medial nucleus of the trapezoid body. J Neurophysiol, 92, 545-552.

Berrebi, A.S. \& Spirou, G.A. (1998) PEP-19 immunoreactivity in the cochlear nucleus and superior olive of the cat. Neuroscience, 83, 535-554. 
Bordey, A. \& Sontheimer, H. (2000) lon channel expression by astrocytes in situ: comparison of different CNS regions. Glia, 30, 27-38.

Borst, J.G., Helmchen, F. \& Sakmann, B. (1995) Pre- and postsynaptic whole-cell recordings in the medial nucleus of the trapezoid body of the rat. J Physiol, 489 ( Pt 3), 825-840.

Bozdagi, O., Valcin, M., Poskanzer, K., Tanaka, H. \& Benson, D.L. (2004) Temporally distinct demands for classic cadherins in synapse formation and maturation. Mol Cell Neurosci, 27, 509-521.

Brew, H.M. \& Forsythe, I.D. (1995) Two voltage-dependent K+ conductances with complementary functions in postsynaptic integration at a central auditory synapse. J Neurosci, 15, 8011-8022.

Brew, H.M., Gittelman, J.X., Silverstein, R.S., Hanks, T.D., Demas, V.P., Robinson, L.C., Robbins, C.A., McKee-Johnson, J., Chiu, S.Y., Messing, A. \& Tempel, B.L. (2007) Seizures and reduced life span in mice lacking the potassium channel subunit Kv1.2, but hypoexcitability and enlarged Kv1 currents in auditory neurons. J Neurophysiol, 98, 1501-1525.

Brew, H.M., Hallows, J.L. \& Tempel, B.L. (2003) Hyperexcitability and reduced low threshold potassium currents in auditory neurons of mice lacking the channel subunit Kv1.1. J Physiol, 548, 1-20.

Brigidi, G.S. \& Bamji, S.X. (2011) Cadherin-catenin adhesion complexes at the synapse. Curr Opin Neurobiol, 21, 208-214.

Bruses, J.L. (2010) Identification of gene transcripts expressed by postsynaptic neurons during synapse formation encoding cell surface proteins with presumptive synaptogenic activity. Synapse, 64, 47-60.

Buffelli, M., Busetto, G., Bidoia, C., Favero, M. \& Cangiano, A. (2004) Activity-dependent synaptic competition at mammalian neuromuscular junctions. News Physiol Sci, 19, 85-91.

Bustin, S.A., Benes, V., Garson, J.A., Hellemans, J., Huggett, J., Kubista, M., Mueller, R., Nolan, T., Pfaffl, M.W., Shipley, G.L., Vandesompele, J. \& Wittwer, C.T. (2009) The MIQE guidelines: minimum information for publication of quantitative real-time PCR experiments. Clin Chem, 55, 611-622.

Cahoy, J.D., Emery, B., Kaushal, A., Foo, L.C., Zamanian, J.L., Christopherson, K.S., Xing, Y., Lubischer, J.L., Krieg, P.A., Krupenko, S.A., Thompson, W.J. \& Barres, B.A. (2008) A transcriptome database for astrocytes, neurons, and oligodendrocytes: a new resource for understanding brain development and function. J Neurosci, 28, 264-278. 
Cavallaro, S., Schreurs, B.G., Zhao, W., D'Agata, V. \& Alkon, D.L. (2001) Gene expression profiles during long-term memory consolidation. Eur J Neurosci, 13, 1809-1815.

Chang, B.D., Watanabe, K., Broude, E.V., Fang, J., Poole, J.C., Kalinichenko, T.V. \& Roninson, I.B. (2000) Effects of p21Waf1/Cip1/Sdi1 on cellular gene expression: implications for carcinogenesis, senescence, and age-related diseases. Proc Natl Acad Sci U S A, 97, 4291-4296.

Chen, C. (1997) Hyperpolarization-activated current (Ih) in primary auditory neurons. Hear Res, 110, 179-190.

Cho, J.H., Jung, H.H., Lee, S.H., Im, G.J., Chang, J. \& Kim, S.J. (2009) Gene expression profiles of rat olfactory bulb at developmental stage. J Neurosci Methods, 177, 14-19.

Coetzee, W.A., Amarillo, Y., Chiu, J., Chow, A., Lau, D., McCormack, T., Moreno, H., Nadal, M.S., Ozaita, A., Pountney, D., Saganich, M., Vega-Saenz de Miera, E. \& Rudy, B. (1999) Molecular diversity of K+ channels. Ann N Y Acad Sci, 868, 233-285.

Connors, E.C., Ballif, B.A. \& Morielli, A.D. (2008) Homeostatic regulation of Kv1.2 potassium channel trafficking by cyclic AMP. J Biol Chem, 283, 3445-3453.

Czopka, T., von Holst, A., ffrench-Constant, C. \& Faissner, A. (2010) Regulatory mechanisms that mediate tenascin C-dependent inhibition of oligodendrocyte precursor differentiation. J Neurosci, 30, $12310-12322$.

Czopka, T., Von Holst, A., Schmidt, G., Ffrench-Constant, C. \& Faissner, A. (2009) Tenascin C and tenascin $\mathrm{R}$ similarly prevent the formation of myelin membranes in a RhoA-dependent manner, but antagonistically regulate the expression of myelin basic protein via a separate pathway. Glia, 57, 1790-1801.

Demyanenko, G.P., Siesser, P.F., Wright, A.G., Brennaman, L.H., Bartsch, U., Schachner, M. \& Maness, P.F. (2011) L1 and CHL1 Cooperate in Thalamocortical Axon Targeting. Cereb Cortex, 21, 401412.

Dodson, P.D., Barker, M.C. \& Forsythe, I.D. (2002) Two heteromeric Kv1 potassium channels differentially regulate action potential firing. J Neurosci, 22, 6953-6961.

Dorrell, M.I., Aguilar, E., Weber, C. \& Friedlander, M. (2004) Global gene expression analysis of the developing postnatal mouse retina. Invest Ophthalmol Vis Sci, 45, 1009-1019.

Eroglu, C. \& Barres, B.A. (2010) Regulation of synaptic connectivity by glia. Nature, 468, 223-231. 
Faissner, A., Pyka, M., Geissler, M., Sobik, T., Frischknecht, R., Gundelfinger, E.D. \& Seidenbecher, C. (2010) Contributions of astrocytes to synapse formation and maturation - Potential functions of the perisynaptic extracellular matrix. Brain Res Rev, 63, 26-38.

Felmy, F. \& Schneggenburger, R. (2004) Developmental expression of the Ca2+-binding proteins calretinin and parvalbumin at the calyx of held of rats and mice. Eur J Neurosci, 20, 1473-1482.

Foran, D.R. \& Peterson, A.C. (1992) Myelin acquisition in the central nervous system of the mouse revealed by an MBP-Lac Z transgene. J Neurosci, 12, 4890-4897.

Forsythe, I.D. \& Barnes-Davies, M. (1993) The binaural auditory pathway: membrane currents limiting multiple action potential generation in the rat medial nucleus of the trapezoid body. Proc Biol Sci, 251, 143-150.

Fournier, A.E., Nakamura, F., Kawamoto, S., Goshima, Y., Kalb, R.G. \& Strittmatter, S.M. (2000) Semaphorin3A enhances endocytosis at sites of receptor-F-actin colocalization during growth cone collapse. J Cell Biol, 149, 411-422.

Furuichi, T., Shiraishi-Yamaguchi, Y., Sato, A., Sadakata, T., Huang, J., Shinoda, Y., Hayashi, K., Mishima, Y., Tomomura, M., Nishibe, H. \& Yoshikawa, F. (2011) Systematizing and cloning of genes involved in the cerebellar cortex circuit development. Neurochem Res, 36, 1241-1252.

Ghosh, A. \& Greenberg, M.E. (1995) Calcium signaling in neurons: molecular mechanisms and cellular consequences. Science, 268, 239-247.

Glueckert, R., Wietzorrek, G., Kammen-Jolly, K., Scholtz, A., Stephan, K., Striessnig, J. \& Schrott-Fischer, A. (2003) Role of class D L-type Ca2+ channels for cochlear morphology. Hear Res, 178, 95-105.

Goldowitz, D. \& Hamre, K. (1998) The cells and molecules that make a cerebellum. Trends Neurosci, 21, 375-382.

Grabowski, P. (2011) Alternative splicing takes shape during neuronal development. Curr Opin Genet Dev, 21, 388-394.

Greenberg, M.E., Ziff, E.B. \& Greene, L.A. (1986) Stimulation of neuronal acetylcholine receptors induces rapid gene transcription. Science, 234, 80-83.

Greer, P.L. \& Greenberg, M.E. (2008) From synapse to nucleus: calcium-dependent gene transcription in the control of synapse development and function. Neuron, 59, 846-860. 
Grothe, B. (2003) New roles for synaptic inhibition in sound localization. Nat Rev Neurosci, 4, 540-550.

Gumy, L.F., Yeo, G.S., Tung, Y.C., Zivraj, K.H., Willis, D., Coppola, G., Lam, B.Y., Twiss, J.L., Holt, C.E. \& Fawcett, J.W. (2011) Transcriptome analysis of embryonic and adult sensory axons reveals changes in mRNA repertoire localization. RNA, 17, 85-98.

Gurantz, D., Lautermilch, N.J., Watt, S.D. \& Spitzer, N.C. (2000) Sustained upregulation in embryonic spinal neurons of a Kv3.1 potassium channel gene encoding a delayed rectifier current. $J$ Neurobiol, 42, 347-356.

Gutierrez, L., Mauriat, M., Guenin, S., Pelloux, J., Lefebvre, J.F., Louvet, R., Rusterucci, C., Moritz, T., Guerineau, F., Bellini, C. \& Van Wuytswinkel, O. (2008) The lack of a systematic validation of reference genes: a serious pitfall undervalued in reverse transcription-polymerase chain reaction (RT-PCR) analysis in plants. Plant Biotechnol J, 6, 609-618.

Gutman, G.A., Chandy, K.G., Grissmer, S., Lazdunski, M., McKinnon, D., Pardo, L.A., Robertson, G.A., Rudy, B., Sanguinetti, M.C., Stuhmer, W. \& Wang, X. (2005) International Union of Pharmacology. LIII. Nomenclature and molecular relationships of voltage-gated potassium channels. Pharmacol Rev, 57, 473-508.

Harris, G.L., Henderson, L.P. \& Spitzer, N.C. (1988) Changes in densities and kinetics of delayed rectifier potassium channels during neuronal differentiation. Neuron, 1, 739-750.

Harris, J.A., Hardie, N.A., Bermingham-McDonogh, O. \& Rubel, E.W. (2005) Gene expression differences over a critical period of afferent-dependent neuron survival in the mouse auditory brainstem. $J$ Comp Neurol, 493, 460-474.

Hartig, W., Singer, A., Grosche, J., Brauer, K., Ottersen, O.P. \& Bruckner, G. (2001) Perineuronal nets in the rat medial nucleus of the trapezoid body surround neurons immunoreactive for various amino acids, calcium-binding proteins and the potassium channel subunit Kv3.1b. Brain Res, 899, 123-133.

Harvey, A.L. \& Robertson, B. (2004) Dendrotoxins: structure-activity relationships and effects on potassium ion channels. Curr Med Chem, 11, 3065-3072.

Hassfurth, B., Magnusson, A.K., Grothe, B. \& Koch, U. (2009) Sensory deprivation regulates the development of the hyperpolarization-activated current in auditory brainstem neurons. Eur $J$ Neurosci, 30, 1227-1238. 
He, B. \& Guo, W. (2009) The exocyst complex in polarized exocytosis. Curr Opin Cell Biol, 21, 537-542.

Hilario, J.D., Rodino-Klapac, L.R., Wang, C. \& Beattie, C.E. (2009) Semaphorin 5A is a bifunctional axon guidance cue for axial motoneurons in vivo. Dev Biol, 326, 190-200.

Hodgkin, A.L. \& Huxley, A.F. (1952) A quantitative description of membrane current and its application to conduction and excitation in nerve. J Physiol, 117, 500-544.

Hoffpauir, B.K., Grimes, J.L., Mathers, P.H. \& Spirou, G.A. (2006) Synaptogenesis of the calyx of Held: rapid onset of function and one-to-one morphological innervation. J Neurosci, 26, 5511-5523.

Hoffpauir, B.K., Kolson, D.R., Mathers, P.H. \& Spirou, G.A. (2010) Maturation of synaptic partners: functional phenotype and synaptic organization tuned in synchrony. J Physiol, 588, 4365-4385.

Horner, P.J., Thallmair, M. \& Gage, F.H. (2002) Defining the NG2-expressing cell of the adult CNS. J Neurocytol, 31, 469-480.

Howell, D.M., Morgan, W.J., Jarjour, A.A., Spirou, G.A., Berrebi, A.S., Kennedy, T.E. \& Mathers, P.H. (2007) Molecular guidance cues necessary for axon pathfinding from the ventral cochlear nucleus. J Comp Neurol, 504, 533-549.

Hsieh, C.Y., Hong, C.T. \& Cramer, K.S. (2007) Deletion of EphA4 enhances deafferentation-induced ipsilateral sprouting in auditory brainstem projections. J Comp Neurol, 504, 508-518.

Hsieh, C.Y., Nakamura, P.A., Luk, S.O., Miko, I.J., Henkemeyer, M. \& Cramer, K.S. (2010) Ephrin-B reverse signaling is required for formation of strictly contralateral auditory brainstem pathways. $J$ Neurosci, 30, 9840-9849.

Huang, D.W., Sherman, B.T., Tan, Q., Kir, J., Liu, D., Bryant, D., Guo, Y., Stephens, R., Baseler, M.W., Lane, H.C. \& Lempicki, R.A. (2007) DAVID Bioinformatics Resources: expanded annotation database and novel algorithms to better extract biology from large gene lists. Nucleic Acids Res, 35, W169175.

Huang, X.Y., Morielli, A.D. \& Peralta, E.G. (1994) Molecular basis of cardiac potassium channel stimulation by protein kinase A. Proc Natl Acad Sci U S A, 91, 624-628.

Huggett, J., Dheda, K., Bustin, S. \& Zumla, A. (2005) Real-time RT-PCR normalisation; strategies and considerations. Genes Immun, 6, 279-284. 
Johnston, J., Forsythe, I.D. \& Kopp-Scheinpflug, C. (2010) Going native: voltage-gated potassium channels controlling neuronal excitability. J Physiol, 588, 3187-3200.

Johnston, J., Griffin, S.J., Baker, C. \& Forsythe, I.D. (2008a) Kv4 (A-type) potassium currents in the mouse medial nucleus of the trapezoid body. Eur J Neurosci, 27, 1391-1399.

Johnston, J., Griffin, S.J., Baker, C., Skrzypiec, A., Chernova, T. \& Forsythe, I.D. (2008b) Initial segment Kv2.2 channels mediate a slow delayed rectifier and maintain high frequency action potential firing in medial nucleus of the trapezoid body neurons. J Physiol, 586, 3493-3509.

Jung, H., Yoon, B.C. \& Holt, C.E. (2012) Axonal mRNA localization and local protein synthesis in nervous system assembly, maintenance and repair. Nat Rev Neurosci, 13, 308-324.

Kagami, Y. \& Furuichi, T. (2001) Investigation of differentially expressed genes during the development of mouse cerebellum. Brain Res Gene Expr Patterns, 1, 39-59.

Kandler, K., Clause, A. \& Noh, J. (2009) Tonotopic reorganization of developing auditory brainstem circuits. Nat Neurosci, 12, 711-717.

Kandler, K. \& Friauf, E. (1993) Pre- and postnatal development of efferent connections of the cochlear nucleus in the rat. $J$ Comp Neurol, 328, 161-184.

Khurana, S., Liu, Z., Lewis, A.S., Rosa, K., Chetkovich, D. \& Golding, N.L. (2012) An essential role for modulation of hyperpolarization-activated current in the development of binaural temporal precision. J Neurosci, 32, 2814-2823.

Kim, G. \& Kandler, K. (2003) Elimination and strengthening of glycinergic/GABAergic connections during tonotopic map formation. Nat Neurosci, 6, 282-290.

Ko, J., Soler-Llavina, G.J., Fuccillo, M.V., Malenka, R.C. \& Sudhof, T.C. (2011) Neuroligins/LRRTMs prevent activity- and $\mathrm{Ca} 2+/$ calmodulin-dependent synapse elimination in cultured neurons. J Cell Biol, 194, 323-334.

Koch, U., Braun, M., Kapfer, C. \& Grothe, B. (2004) Distribution of HCN1 and HCN2 in rat auditory brainstem nuclei. Eur J Neurosci, 20, 79-91.

Kochubey, O., Lou, X. \& Schneggenburger, R. (2011) Regulation of transmitter release by $\mathrm{Ca}(2+)$ and synaptotagmin: insights from a large CNS synapse. Trends Neurosci, 34, 237-246. 
Koehl, A., Schmidt, N., Rieger, A., Pilgram, S.M., Letunic, I., Bork, P., Soto, F., Friauf, E. \& Nothwang, H.G. (2004) Gene expression profiling of the rat superior olivary complex using serial analysis of gene expression. Eur J Neurosci, 20, 3244-3258.

Kruger, R.P., Aurandt, J. \& Guan, K.L. (2005) Semaphorins command cells to move. Nat Rev Mol Cell Biol, 6, 789-800.

Kucukdereli, H., Allen, N.J., Lee, A.T., Feng, A., Ozlu, M.I., Conatser, L.M., Chakraborty, C., Workman, G., Weaver, M., Sage, E.H., Barres, B.A. \& Eroglu, C. (2011) Control of excitatory CNS synaptogenesis by astrocyte-secreted proteins Hevin and SPARC. Proc Natl Acad Sci U S A, 108, E440-449.

Kumanogoh, A. \& Kikutani, H. (2010) Semaphorins and their receptors: novel features of neural guidance molecules. Proc Jpn Acad Ser B Phys Biol Sci, 86, 611-620.

Kuwabara, N., DiCaprio, R.A. \& Zook, J.M. (1991) Afferents to the medial nucleus of the trapezoid body and their collateral projections. J Comp Neurol, 314, 684-706.

Landmesser, L. \& Pilar, G. (1972) The onset and development of transmission in the chick ciliary ganglion. J Physiol, 222, 691-713.

Landmesser, L. \& Pilar, G. (1976) Fate of ganglionic synapses and ganglion cell axons during normal and induced cell death. J Cell Biol, 68, 357-374.

Landmesser, L. \& Pilar, G. (1978) Interactions between neurons and their targets during in vivo synaptogenesis. Fed Proc, 37, 2016-2022.

Leao, K.E., Leao, R.N., Sun, H., Fyffe, R.E. \& Walmsley, B. (2006) Hyperpolarization-activated currents are differentially expressed in mice brainstem auditory nuclei. J Physiol, 576, 849-864.

Leil, T.A., Ossadtchi, A., Cortes, J.S., Leahy, R.M. \& Smith, D.J. (2002) Finding new candidate genes for learning and memory. J Neurosci Res, 68, 127-137.

Leil, T.A., Ossadtchi, A., Nichols, T.E., Leahy, R.M. \& Smith, D.J. (2003) Genes regulated by learning in the hippocampus. J Neurosci Res, 71, 763-768.

Leslie, J.R., Imai, F., Fukuhara, K., Takegahara, N., Rizvi, T.A., Friedel, R.H., Wang, F., Kumanogoh, A. \& Yoshida, Y. (2011) Ectopic myelinating oligodendrocytes in the dorsal spinal cord as a consequence of altered semaphorin 6D signaling inhibit synapse formation. Development, 138, 4085-4095. 
Li, W., Kaczmarek, L.K. \& Perney, T.M. (2001) Localization of two high-threshold potassium channel subunits in the rat central auditory system. J Comp Neurol, 437, 196-218.

Lim, C.R., Fukakusa, A. \& Matsubara, K. (2004) Gene expression profiling of mouse postnatal cerebellar development using cDNA microarrays. Gene, 333, 3-13.

Linhoff, M.W., Lauren, J., Cassidy, R.M., Dobie, F.A., Takahashi, H., Nygaard, H.B., Airaksinen, M.S., Strittmatter, S.M. \& Craig, A.M. (2009) An unbiased expression screen for synaptogenic proteins identifies the LRRTM protein family as synaptic organizers. Neuron, 61, 734-749.

Liu, S.J. \& Kaczmarek, L.K. (1998a) The expression of two splice variants of the Kv3.1 potassium channel gene is regulated by different signaling pathways. J Neurosci, 18, 2881-2890.

Liu, S.Q. \& Kaczmarek, L.K. (1998b) Depolarization selectively increases the expression of the Kv3.1 potassium channel in developing inferior colliculus neurons. J Neurosci, 18, 8758-8769.

Lohmann, C. \& Friauf, E. (1996) Distribution of the calcium-binding proteins parvalbumin and calretinin in the auditory brainstem of adult and developing rats. J Comp Neurol, 367, 90-109.

Lohrke, S., Kungel, M. \& Friauf, E. (1998) Electrical membrane properties of trapezoid body neurons in the rat auditory brain stem are preserved in organotypic slice cultures. J Neurobiol, 36, 395-409.

Low, L.K., Liu, X.B., Faulkner, R.L., Coble, J. \& Cheng, H.J. (2008) Plexin signaling selectively regulates the stereotyped pruning of corticospinal axons from visual cortex. Proc Natl Acad Sci U S A, 105, 8136-8141.

Ludwig, A., Zong, X., Jeglitsch, M., Hofmann, F. \& Biel, M. (1998) A family of hyperpolarization-activated mammalian cation channels. Nature, 393, 587-591.

Luo, Y., Long, J.M., Spangler, E.L., Longo, D.L., Ingram, D.K. \& Weng, N.P. (2001) Identification of maze learning-associated genes in rat hippocampus by cDNA microarray. J Mol Neurosci, 17, 397-404.

Maccaferri, G., Toth, K. \& McBain, C.J. (1998) Target-specific expression of presynaptic mossy fiber plasticity. Science, 279, 1368-1370.

Maffie, J. \& Rudy, B. (2008) Weighing the evidence for a ternary protein complex mediating A-type K+ currents in neurons. J Physiol, 586, 5609-5623. 
Malinverno, M., Carta, M., Epis, R., Marcello, E., Verpelli, C., Cattabeni, F., Sala, C., Mulle, C., Di Luca, M. \& Gardoni, F. (2010) Synaptic localization and activity of ADAM10 regulate excitatory synapses through N-cadherin cleavage. J Neurosci, 30, 16343-16355.

Maness, P.F. \& Schachner, M. (2007) Neural recognition molecules of the immunoglobulin superfamily: signaling transducers of axon guidance and neuronal migration. Nat Neurosci, 10, 19-26.

Masuda, K., Furuyama, T., Takahara, M., Fujioka, S., Kurinami, H. \& Inagaki, S. (2004) Sema4D stimulates axonal outgrowth of embryonic DRG sensory neurones. Genes Cells, 9, 821-829.

Matsuoka, R.L., Chivatakarn, O., Badea, T.C., Samuels, I.S., Cahill, H., Katayama, K., Kumar, S.R., Suto, F., Chedotal, A., Peachey, N.S., Nathans, J., Yoshida, Y., Giger, R.J. \& Kolodkin, A.L. (2011) Class 5 transmembrane semaphorins control selective Mammalian retinal lamination and function. Neuron, 71, 460-473.

Mikaelian, D., Alford, B.R. \& Ruben, R.J. (1965) Cochlear Potentials and 8 Nerve Action Potentials in Normal and Genetically Deaf Mice. Ann Otol Rhinol Laryngol, 74, 146-157.

Miyazaki, T. \& Watanabe, M. (2011) Development of an anatomical technique for visualizing the mode of climbing fiber innervation in Purkinje cells and its application to mutant mice lacking GluRdelta2 and $\mathrm{Ca}(\mathrm{v}) 2.1$. Anat Sci Int, 86, 10-18.

Mody, M., Cao, Y., Cui, Z., Tay, K.Y., Shyong, A., Shimizu, E., Pham, K., Schultz, P., Welsh, D. \& Tsien, J.Z. (2001) Genome-wide gene expression profiles of the developing mouse hippocampus. Proc Natl Acad Sci U S A, 98, 8862-8867.

Morest, D.K. (1968) The growth of synaptic endings in the mammalian brain: a study of the calyces of the trapezoid body. Z Anat Entwicklungsgesch, 127, 201-220.

Mostafapour, S.P., Cochran, S.L., Del Puerto, N.M. \& Rubel, E.W. (2000) Patterns of cell death in mouse anteroventral cochlear nucleus neurons after unilateral cochlea removal. J Comp Neurol, 426, 561-571.

Muller, J., Reyes-Haro, D., Pivneva, T., Nolte, C., Schaette, R., Lubke, J. \& Kettenmann, H. (2009) The principal neurons of the medial nucleus of the trapezoid body and NG2(+) glial cells receive coordinated excitatory synaptic input. J Gen Physiol, 134, 115-127.

Mutch, D.M., Berger, A., Mansourian, R., Rytz, A. \& Roberts, M.A. (2002) The limit fold change model: a practical approach for selecting differentially expressed genes from microarray data. $B M C$ Bioinformatics, 3, 17. 
Nakamura, P.A., Hsieh, C.Y. \& Cramer, K.S. (2012) EphB signaling regulates target innervation in the developing and deafferented auditory brainstem. Dev Neurobiol, 72, 1243-1255.

Nelson, S.B., Hempel, C. \& Sugino, K. (2006) Probing the transcriptome of neuronal cell types. Curr Opin Neurobiol, 16, 571-576.

Nishiyama, A., Komitova, M., Suzuki, R. \& Zhu, X. (2009) Polydendrocytes (NG2 cells): multifunctional cells with lineage plasticity. Nat Rev Neurosci, 10, 9-22.

Noh, J., Seal, R.P., Garver, J.A., Edwards, R.H. \& Kandler, K. (2010) Glutamate co-release at GABA/glycinergic synapses is crucial for the refinement of an inhibitory map. Nat Neurosci, 13, 232-238.

Nothwang, H.G., Koehl, A. \& Friauf, E. (2006) Comparative gene expression analysis reveals a characteristic molecular profile of the superior olivary complex. Anat Rec A Discov Mol Cell Evol Biol, 288, 409-423.

O'Sullivan, N.C., McGettigan, P.A., Sheridan, G.K., Pickering, M., Conboy, L., O'Connor, J.J., Moynagh, P.N., Higgins, D.G., Regan, C.M. \& Murphy, K.J. (2007) Temporal change in gene expression in the rat dentate gyrus following passive avoidance learning. J Neurochem, 101, 1085-1098.

Oertel, D., Shatadal, S. \& Cao, X.J. (2008) In the ventral cochlear nucleus Kv1.1 and subunits of HCN1 are colocalized at surfaces of neurons that have low-voltage-activated and hyperpolarizationactivated conductances. Neuroscience, 154, 77-86.

Pfaffl, M.W. (2001) A new mathematical model for relative quantification in real-time RT-PCR. Nucleic Acids Res, 29, e45.

Raab-Graham, K.F., Haddick, P.C., Jan, Y.N. \& Jan, L.Y. (2006) Activity- and mTOR-dependent suppression of Kv1.1 channel mRNA translation in dendrites. Science, 314, 144-148.

Renier, N., Schonewille, M., Giraudet, F., Badura, A., Tessier-Lavigne, M., Avan, P., De Zeeuw, C.I. \& Chedotal, A. (2010) Genetic dissection of the function of hindbrain axonal commissures. PLoS Biol, 8, e1000325.

Ribera, A.B. \& Spitzer, N.C. (1992) Developmental regulation of potassium channels and the impact on neuronal differentiation. Ion Channels, 3, 1-38. 
Robinson, R.B. \& Siegelbaum, S.A. (2003) Hyperpolarization-activated cation currents: from molecules to physiological function. Annu Rev Physiol, 65, 453-480.

Rodriguez-Contreras, A., van Hoeve, J.S., Habets, R.L., Locher, H. \& Borst, J.G. (2008) Dynamic development of the calyx of Held synapse. Proc Natl Acad Sci U S A, 105, 5603-5608.

Rothman, J.S. \& Manis, P.B. (2003) The roles potassium currents play in regulating the electrical activity of ventral cochlear nucleus neurons. J Neurophysiol, 89, 3097-3113.

Rowland, K.C., Irby, N.K. \& Spirou, G.A. (2000) Specialized synapse-associated structures within the calyx of Held. J Neurosci, 20, 9135-9144.

Rozen, S. \& Skaletsky, H. (2000) Primer3 on the WWW for general users and for biologist programmers. Methods Mol Biol, 132, 365-386.

Rubel, E.W. \& Fritzsch, B. (2002) Auditory system development: primary auditory neurons and their targets. Annu Rev Neurosci, 25, 51-101.

Rudy, B. \& McBain, C.J. (2001) Kv3 channels: voltage-gated K+ channels designed for high-frequency repetitive firing. Trends Neurosci, 24, 517-526.

Rusu, S.I. \& Borst, J.G. (2011) Developmental changes in intrinsic excitability of principal neurons in the rat medial nucleus of the trapezoid body. Dev Neurobiol, 71, 284-295.

Sabatier, C., Plump, A.S., Le, M., Brose, K., Tamada, A., Murakami, F., Lee, E.Y. \& Tessier-Lavigne, M. (2004) The divergent Robo family protein rig-1/Robo3 is a negative regulator of slit responsiveness required for midline crossing by commissural axons. Cell, 117, 157-169.

Sato, A., Sekine, Y., Saruta, C., Nishibe, H., Morita, N., Sato, Y., Sadakata, T., Shinoda, Y., Kojima, T. \& Furuichi, T. (2008) Cerebellar development transcriptome database (CDT-DB): profiling of spatiotemporal gene expression during the postnatal development of mouse cerebellum. Neural Netw, 21, 1056-1069.

Satzler, K., Sohl, L.F., Bollmann, J.H., Borst, J.G., Frotscher, M., Sakmann, B. \& Lubke, J.H. (2002) Threedimensional reconstruction of a calyx of Held and its postsynaptic principal neuron in the medial nucleus of the trapezoid body. J Neurosci, 22, 10567-10579.

Schlomann, U., Schwamborn, J.C., Muller, M., Fassler, R. \& Puschel, A.W. (2009) The stimulation of dendrite growth by Sema3A requires integrin engagement and focal adhesion kinase. J Cell Sci, 122, 2034-2042. 
Schneggenburger, R. \& Forsythe, I.D. (2006) The calyx of Held. Cell Tissue Res, 326, 311-337.

Schraders, M., Haas, S.A., Weegerink, N.J., Oostrik, J., Hu, H., Hoefsloot, L.H., Kannan, S., Huygen, P.L., Pennings, R.J., Admiraal, R.J., Kalscheuer, V.M., Kunst, H.P. \& Kremer, H. (2011) Next-generation sequencing identifies mutations of SMPX, which encodes the small muscle protein, X-linked, as a cause of progressive hearing impairment. Am J Hum Genet, 88, 628-634.

Schroeder, A., Mueller, O., Stocker, S., Salowsky, R., Leiber, M., Gassmann, M., Lightfoot, S., Menzel, W., Granzow, M. \& Ragg, T. (2006) The RIN: an RNA integrity number for assigning integrity values to RNA measurements. BMC Mol Biol, 7, 3.

Schuller, U., Kho, A.T., Zhao, Q., Ma, Q. \& Rowitch, D.H. (2006) Cerebellar 'transcriptome' reveals celltype and stage-specific expression during postnatal development and tumorigenesis. Mol Cell Neurosci, 33, 247-259.

Schwenger, D.B. \& Kuner, T. (2010) Acute genetic perturbation of exocyst function in the rat calyx of Held impedes structural maturation, but spares synaptic transmission. Eur J Neurosci, 32, 974984.

Seifert, R., Scholten, A., Gauss, R., Mincheva, A., Lichter, P. \& Kaupp, U.B. (1999) Molecular characterization of a slowly gating human hyperpolarization-activated channel predominantly expressed in thalamus, heart, and testis. Proc Natl Acad Sci U S A, 96, 9391-9396.

Shaikh, A.G. \& Finlayson, P.G. (2003) Hyperpolarization-activated (I(h)) conductances affect brainstem auditory neuron excitability. Hear Res, 183, 126-136.

Shimogori, T., Lee, D.A., Miranda-Angulo, A., Yang, Y., Wang, H., Jiang, L., Yoshida, A.C., Kataoka, A., Mashiko, H., Avetisyan, M., Qi, L., Qian, J. \& Blackshaw, S. (2010) A genomic atlas of mouse hypothalamic development. Nat Neurosci, 13, 767-775.

Smith, A.J., Owens, S. \& Forsythe, I.D. (2000) Characterisation of inhibitory and excitatory postsynaptic currents of the rat medial superior olive. J Physiol, 529 Pt 3, 681-698.

Smith, P.H., Joris, P.X., Carney, L.H. \& Yin, T.C. (1991) Projections of physiologically characterized globular bushy cell axons from the cochlear nucleus of the cat. J Comp Neurol, 304, 387-407.

Smith, P.H., Joris, P.X. \& Yin, T.C. (1998) Anatomy and physiology of principal cells of the medial nucleus of the trapezoid body (MNTB) of the cat. J Neurophysiol, 79, 3127-3142. 
Sommer, I., Lingenhohl, K. \& Friauf, E. (1993) Principal cells of the rat medial nucleus of the trapezoid body: an intracellular in vivo study of their physiology and morphology. Exp Brain Res, 95, 223239.

Song, P., Yang, Y., Barnes-Davies, M., Bhattacharjee, A., Hamann, M., Forsythe, I.D., Oliver, D.L. \& Kaczmarek, L.K. (2005) Acoustic environment determines phosphorylation state of the Kv3.1 potassium channel in auditory neurons. Nat Neurosci, 8, 1335-1342.

Spangler, K.M., Warr, W.B. \& Henkel, C.K. (1985) The projections of principal cells of the medial nucleus of the trapezoid body in the cat. J Comp Neurol, 238, 249-262.

Spirou, G.A., Brownell, W.E. \& Zidanic, M. (1990) Recordings from cat trapezoid body and HRP labeling of globular bushy cell axons. J Neurophysiol, 63, 1169-1190.

Stipursky, J., Romao, L., Tortelli, V., Neto, V.M. \& Gomes, F.C. (2011) Neuron-glia signaling: Implications for astrocyte differentiation and synapse formation. Life Sci, 89, 524-531.

Stover, T. \& Diensthuber, M. (2011) Molecular biology of hearing. GMS Curr Top Otorhinolaryngol Head Neck Surg, 10, Doc06.

Swiercz, J.M., Kuner, R., Behrens, J. \& Offermanns, S. (2002) Plexin-B1 directly interacts with PDZRhoGEF/LARG to regulate RhoA and growth cone morphology. Neuron, 35, 51-63.

Takahashi, M., Kondoh, Y., Tashiro, H., Koibuchi, N., Kuroda, Y. \& Tashiro, T. (2005) Monitoring synaptogenesis in the developing mouse cerebellum with an original oligonucleotide microarray. J Neurosci Res, 80, 777-788.

Tamagnone, L., Artigiani, S., Chen, H., He, Z., Ming, G.I., Song, H., Chedotal, A., Winberg, M.L., Goodman, C.S., Poo, M., Tessier-Lavigne, M. \& Comoglio, P.M. (1999) Plexins are a large family of receptors for transmembrane, secreted, and GPI-anchored semaphorins in vertebrates. Cell, 99, 71-80.

Taschenberger, H., Leao, R.M., Rowland, K.C., Spirou, G.A. \& von Gersdorff, H. (2002) Optimizing synaptic architecture and efficiency for high-frequency transmission. Neuron, 36, 1127-1143.

Togashi, H., Abe, K., Mizoguchi, A., Takaoka, K., Chisaka, O. \& Takeichi, M. (2002) Cadherin regulates dendritic spine morphogenesis. Neuron, 35, 77-89.

Tolbert, L.P., Morest, D.K. \& Yurgelun-Todd, D.A. (1982) The neuronal architecture of the anteroventral cochlear nucleus of the cat in the region of the cochlear nerve root: horseradish peroxidase labelling of identified cell types. Neuroscience, 7, 3031-3052. 
Tollin, D.J. (2003) The lateral superior olive: a functional role in sound source localization. Neuroscientist, 9, 127-143.

Tong, H., Steinert, J.R., Robinson, S.W., Chernova, T., Read, D.J., Oliver, D.L. \& Forsythe, I.D. (2010) Regulation of Kv channel expression and neuronal excitability in rat medial nucleus of the trapezoid body maintained in organotypic culture. J Physiol, 588, 1451-1468.

Toyoshima, M., Sakurai, K., Shimazaki, K., Takeda, Y., Shimoda, Y. \& Watanabe, K. (2009) Deficiency of neural recognition molecule NB-2 affects the development of glutamatergic auditory pathways from the ventral cochlear nucleus to the superior olivary complex in mouse. Dev Biol, 336, 192200.

Tran, T.S., Kolodkin, A.L. \& Bharadwaj, R. (2007) Semaphorin regulation of cellular morphology. Annu Rev Cell Dev Biol, 23, 263-292.

Tritsch, N.X. \& Bergles, D.E. (2010) Developmental regulation of spontaneous activity in the Mammalian cochlea. J Neurosci, 30, 1539-1550.

Trussell, L.O. (1999) Synaptic mechanisms for coding timing in auditory neurons. Annu Rev Physiol, 61, 477-496.

Tusher, V.G., Tibshirani, R. \& Chu, G. (2001) Significance analysis of microarrays applied to the ionizing radiation response. Proc Natl Acad Sci U S A, 98, 5116-5121.

Valles, A., Boender, A.J., Gijsbers, S., Haast, R.A., Martens, G.J. \& de Weerd, P. (2011) Genomewide analysis of rat barrel cortex reveals time- and layer-specific mRNA expression changes related to experience-dependent plasticity. J Neurosci, 31, 6140-6158.

Vanderhaeghen, P. \& Cheng, H.J. (2010) Guidance molecules in axon pruning and cell death. Cold Spring Harb Perspect Biol, 2, a001859.

Vandesompele, J., De Preter, K., Pattyn, F., Poppe, B., Van Roy, N., De Paepe, A. \& Speleman, F. (2002) Accurate normalization of real-time quantitative RT-PCR data by geometric averaging of multiple internal control genes. Genome Biol, 3, RESEARCH0034.

von Gersdorff, H. \& Borst, J.G. (2002) Short-term plasticity at the calyx of held. Nat Rev Neurosci, 3, 5364.

Wang, L.Y., Gan, L., Forsythe, I.D. \& Kaczmarek, L.K. (1998) Contribution of the Kv3.1 potassium channel to high-frequency firing in mouse auditory neurones. J Physiol, 509 ( Pt 1), 183-194. 
Watanabe, M. \& Kano, M. (2011) Climbing fiber synapse elimination in cerebellar Purkinje cells. Eur J Neurosci, 34, 1697-1710.

West, A.E., Chen, W.G., Dalva, M.B., Dolmetsch, R.E., Kornhauser, J.M., Shaywitz, A.J., Takasu, M.A., Tao, X. \& Greenberg, M.E. (2001) Calcium regulation of neuronal gene expression. Proc Natl Acad Sci U S A, 98, 11024-11031.

West, A.E. \& Greenberg, M.E. (2011) Neuronal activity-regulated gene transcription in synapse development and cognitive function. Cold Spring Harb Perspect Biol, 3.

Willis, D.E. \& Twiss, J.L. (2010) Regulation of protein levels in subcellular domains through mRNA transport and localized translation. Mol Cell Proteomics, 9, 952-962.

Wolman, M.A., Regnery, A.M., Becker, T., Becker, C.G. \& Halloran, M.C. (2007) Semaphorin3D regulates axon axon interactions by modulating levels of L1 cell adhesion molecule. J Neurosci, 27, 96539663.

Xu, J., Yu, W., Wright, J.M., Raab, R.W. \& Li, M. (1998) Distinct functional stoichiometry of potassium channel beta subunits. Proc Natl Acad Sci U S A, 95, 1846-1851.

Yellen, G. (2002) The voltage-gated potassium channels and their relatives. Nature, 419, 35-42.

Youssoufian, M., Oleskevich, S. \& Walmsley, B. (2005) Development of a robust central auditory synapse in congenital deafness. J Neurophysiol, 94, 3168-3180.

Yuan, X., Eisen, A.M., McBain, C.J. \& Gallo, V. (1998) A role for glutamate and its receptors in the regulation of oligodendrocyte development in cerebellar tissue slices. Development, 125, 29012914.

Zhang, S.J., Zou, M., Lu, L., Lau, D., Ditzel, D.A., Delucinge-Vivier, C., Aso, Y., Descombes, P. \& Bading, H. (2009) Nuclear calcium signaling controls expression of a large gene pool: identification of a gene program for acquired neuroprotection induced by synaptic activity. PLoS Genet, $\mathbf{5}$, e1000604.

Zhang, Y. \& Barres, B.A. (2010) Astrocyte heterogeneity: an underappreciated topic in neurobiology. Curr Opin Neurobiol, 20, 588-594.

Zook, J.M. \& DiCaprio, R.A. (1988) Intracellular labeling of afferents to the lateral superior olive in the bat, Eptesicus fuscus. Hear Res, 34, 141-147. 


\section{Douglas R. Kolson}

138 Glenhurst Dr.

Verona, PA 15147

E-mail: dkolson@gmail.com

\section{Education:}

2012

West Virginia University School of Medicine

Ph.D., Neuroscience

1994

University of Pittsburgh

B.S., Chemistry

1990

Penn Hills Senior High School

Valedictorian

\section{Publications:}

Kolson, D.R., Wan, J., Wu, J., Dehoff, M., Qian, J., Mathers, P.H. \& Spirou, G.A. (2012) Temporal Patterns of Gene Expression in the MNTB During Calyx of Held Development. (In submission)

Hoffpauir, B.K., Kolson, D.R., Mathers, P.H. \& Spirou, G.A. (2010) Maturation of synaptic partners: functional phenotype and synaptic organization tuned in synchrony. J Physiol, $588,4365-4385$.

Perkins, G.A., Tjong, J., Brown, J.M., Poquiz, P.H., Scott, R.T., Kolson, D.R., Ellisman, M.H. \& Spirou, G.A. (2010) The micro-architecture of mitochondria at active zones: electron tomography reveals novel anchoring scaffolds and cristae structured for high-rate metabolism. J Neurosci, 30, 1015-1026.

\section{Abstracts:}

Kolson DR, Wan J, Wu J, Dehoff M, Qian J, Mathers PH, Spirou GA. Temporal Patterns of Gene Expression in the MNTB During Calyx of Held Development. Society for Neuroscience, 2011

Kolson DR, Hoffpauir BK, Mathers PH, Spirou GA. Gene Expression During Early Maturation of the MNTB. Society for Neuroscience, 2009

Kolson DR, Hoffpauir BK, Mathers PH, Spirou GA. Coordinated Maturation of the Calyx of Held and Principal Neurons of the MNTB. Society for Neuroscience, 2007 
Work Experience:

$4 / 00$ - present

Owner and operator of sole proprietorship jewelry business, Custom Gems by Kolson

$1 / 96-8 / 00$

Quality Control Chemist, Mylan Pharmaceuticals

$9 / 95-12 / 95$

Lab Technician, PPG Industries

$6 / 93-9 / 93$

Veterinary Assistant, Verona Pet Hospital

\section{Lab Techniques:}

Quantitative real-time PCR including reference gene studies and primer design RNA collection and handling

Live tissue slicing and microdissection

Confocal microscopy and immunofluorescence labeling

Fixed tissue slicing using cryostat and freezing microtome

Microarray analysis including Gene Ontology

Mouse colony management for developmental studies with genotyping

Provided extensive training to new lab technicians and interns

HPLC, dissolution testing, and UV-Vis spectroscopy for pharmaceutical industry 